\title{
Cirugía Asistida por Computadora
}

\section{Fusión de Información Anatómica y Funcional}

\section{M. en I. Mauricio Arturo Pohl Alfaro}

Tesis presentada para obtener el grado de

Doctor en Ciencias (Ingeniería Biomédica)

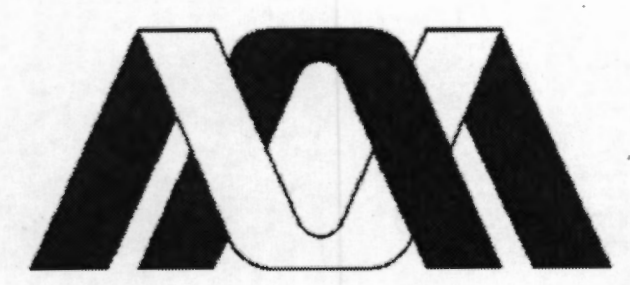

Laboratorio de Investigación en NeuroImagenología

Departamento de Ingeniería Eléctrica

Universidad Autónoma Metropolitana

Iztapalapa

Dirigida bajo la supervisión de:

Dra. Verónica Medina Bañuelos

agosto de 2008 
Agradezco la solidaridad del Pueblo Mexicano al otorgarme una beca para realizar estudios de Doctorado, a través de la Secretaría de Relaciones Exteriores de México. 


\section{Índice general}

$\begin{array}{ll}\text { 1. Introducción } & 1\end{array}$

2. Antecedentes 4

2.1. Esquemas de cirugía asistida por computadora. . . . . . . . . 6

2.1.1. Cirugía asistida por imágenes. . . . . . . . . . 6

2.1.2. Cirugía asistida por computadora. . . . . . . . . 7

2.1.3. Cirugía integrada por computadora (CIS) . . . . . . . 7

2.2. Procesos durante la CIS. . . . . . . . . . . . . . . . 9

2.2.1. Neuro-navegación. . . . . . . . . . . . . 9

2.2.2. Fase pre-operatoria. . . . . . . . . . . . . 10

2.2.3. Fase trans-operatoria. . . . . . . . . . . . . . 11

2.2.4. Fase post-operatoria. . . . . . . . . . . . . . 12

2.3. Tipos de Cirugías Cerebrales. . . . . . . . . . . . . 13

2.3.1. Cirugías estereotáxicas con marco. . . . . . . . . 13

2.3.2. Cirugías estereotáxicas $\sin \operatorname{marco} \ldots \ldots \ldots \ldots \ldots \ldots$

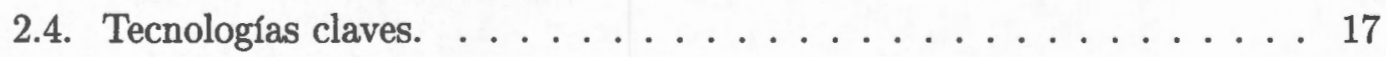

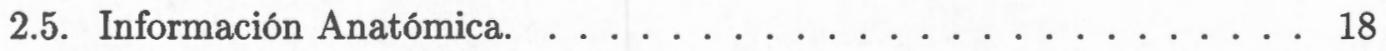

2.5.1. Imágenes médicas y procesamiento de imágenes. . . . . . . 18

2.5.2. Visualización de la información en 2D y 3D. . . . . . 22

2.5.3. Segmentación de imágenes. . . . . . . . . . . . 23 
2.6. Información Funcional. . . . . . . . . . . . . . 27

\section{Generación, Modelado y Estimación de la Actividad Eléctrica del} Cerebro

3.1. Origen Fisiológico de la actividad eléctrica cerebral. . . . . . . . . 34

3.1.1. Modelo Físico. . . . . . . . . . . . . . . . . . 36

3.1.2. Ecuaciones que describen el fenómeno eléctrico dentro de la cabeza. . . . . . . . . . . . . . . 36

3.2. Modelo de fuentes de corriente dentro del cerebro. . . . . . . . . . 39

3.2.1. Modelo de fuentes de dipolo equivalente. . . . . . . . . 39

3.2.2. Modelo de fuentes de corriente distribuida. . . . . . . . . 40

3.3. Problema Directo y Problema Inverso. . . . . . . . . . . . . 41

3.4. Construcción de modelos anatómicos $\ldots \ldots \ldots \ldots \ldots$

3.4.1. Modelos esféricos de volumen conductor de cabeza. . . . . . 47

3.4.2. Modelos realistas de volumen conductor de cabeza. . . . . . 49

3.4.3. Matriz de campo (LFM, Lead Field Matrix) . . . . . . . . 50

3.5. Objetivos de la Tesis. . . . . . . . . . . . . . . 52

4. Metodología propuesta para la solución del problema inverso del EEG $\quad 53$

4.1. Segmentación de imágenes. . . . . . . . . . . . . . 54

4.2. Construcción de la matriz de campo realista $\ldots \ldots \ldots \ldots$

4.2.1. Problema Directo. . . . . . . . . . . . . . . 57

4.2.2. Problema Inverso. . . . . . . . . . . . . . . . 64

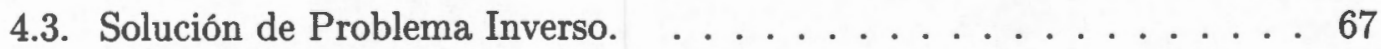

4.3.1. Algoritmo de Tomografía Electromagnética de baja Resolución Estandarizada (sLORETA). . . . . . . . . . . 67 
4.3.2. Algoritmo de Focal Underdetermined System Solver (FOCUSS) estandarizado, combinado con sLORETA. . . . . . . . 68

4.3.3. Algoritmo de Standarized Shrinking LORETA-FOCUSS (SSLOFO) . . . . . . . . . . . . . . . 70

4.4. Simulación de registros de EEG. . . . . . . . . . . . . 71

5. Resultados y Discusión

5.1. Problema inverso . . . . . . . . . . . . . 73

5.1.1. Error de localización. . . . . . . . . . . . . . 73

5.1.2. Modelo esférico de volumen conductor de cabeza. . . . . . . 74

5.1.3. Modelo de volumen conductor realista de cabeza. . . . . . 80

5.2. Visualización de información anatómica y funcional fusionada. . . . . 94

$\begin{array}{ll}\text { 6. Conclusiones } & 96\end{array}$

A. Método de Regularización de Tikhonov 100

B. Herramienta para Construcción del Modelo Anatómico por Interfaz $\begin{array}{ll}\text { Gráfica con usuario. } & 104\end{array}$

B.1. Visualization Toolkit. . . . . . . . . . . . . . . . . 104

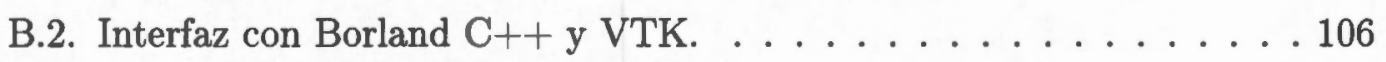

B.3. Interfaz con QT 3.0 y VTK. . . . . . . . . . . . . . . 109

B.3.1. Entrada de datos . . . . . . . . . . . . . . . . 109

B.3.2. Visualización de información anatómica. . . . . . . . 110

C. Metodología de Segmentación por Corrimiento de Media ponderado por Mapas de Confianza y Clasificación por Atlas probabilístico.113

C.1. Corrimiento de Media . . . . . . . . . . . . . 115

C.2. Fusión de Regiones . . . . . . . . . . . . . . . . 120

C.3. Clasificación de regiones con información a priori. . . . . . . . 122 


\section{Índice de figuras}

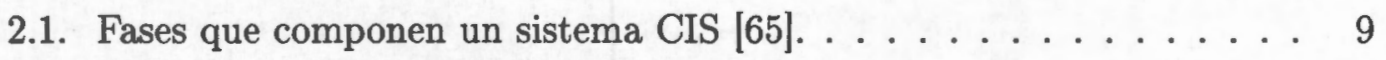

2.2. Montaje de marco estereotáxico. [133] . . . . . . . . . . . 14

2.3. Montaje de marcadores fiduciales sobre el marco estereotáxico, utilizados para la adquisición de imágenes por resonancia magnética. [133] 15

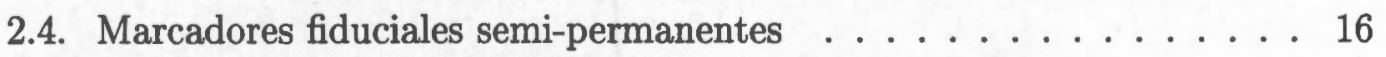

2.5. Mapas de probabilidad correspondientes a una rebanada del volumen simulado de cerebro. La imagen (a) representa la probabilidad de que la clase sea fondo, (b) que sea líquido cefalorraquídeo, (c) que sea materia gris, y (d) que sea materia blanca. [62] . . . . . . . . 27

2.6. Diagrama de bloques de la fusión de imágenes anatómicas con información funcional $\ldots \ldots \ldots \ldots \ldots \ldots \ldots \ldots$

2.7. Mapa de Talairach $[89] \ldots \ldots \ldots \ldots \ldots$. . . . . . . 28

2.8. Determinación de un foco de ataques epilépticos en la corteza frontotemporal izquierda y la simulación en 3D. . . . . . . . 30

3.1. Diversas estructuras cerebrales. 1. Médula, 2. Cerebelo, 3.Cuerpo Calloso, 4. Tálamo, 5. Hipotálamo, 6. Corteza Cerebral, 7. Lóbulo Occipital, 8. Lóbulo Parietal, 9. Lóbulo Temporal, 10. Lóbulo Frontal, 11. Líquido Cefalorraquídeo. . . . . . . . . . . . . 35

3.2. Comparación de métodos de solución de problema inverso. [76] . . . 46

3.3. Diagrama de bloques de Problema Inverso y Problema Directo. . . . . 47 
3.4. Modelo esférico de cabeza inscritos dentro del cráneo humano. . . . . 48

3.5. Modelo realista de volumen conductor a través de BEM. [56] . . . . 50

4.1. Diagrama de bloques del procedimiento utilizado en la implementación del sistema. . . . . . . . . . . . . . . . . . . . 54

4.2. Ejemplos de segmentacion de imagenes reales. Rebanadas de diferentes volumenes mostrando en la columna (a) las imagenes originales, en (b) los resultados de la segmentacion por Corrimiento de media, $\mathbf{y}$ en (c) las clasificaciones manuales por el experto. [62] . . . . . . 56

4.3. Esquema del problema electromagnético. [33] . . . . . . . . . . 57

5.1. Referencias utilizadas en la generación de señales en una esfera unitaria. 74

5.2. Gráfica de comparación de errores de localización $(\varepsilon)$ entre la utilización de Norma Mínima (en azul) y sLORETA (en magenta) en la solución del problema inverso para 18 registros de EEG simulados. Medida en milimetros teniendo en cuenta que el radio de la esfera es $87 \mathrm{~mm} . \ldots \ldots \ldots \ldots \ldots \ldots \ldots \ldots$

5.3. Comparación de errores de localización $(\varepsilon)$ entre lóbulo temporal izquierdo y lóbulo temporal derecho. Esfera unitaria corresponde a

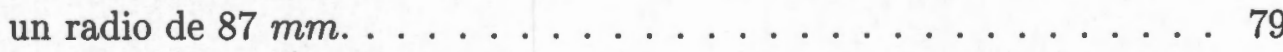

5.4. Comparación de errores de localización $(\varepsilon)$ entre lóbulo temporal izquierdo y lóbulo temporal derecho, para tamaño de voxel de $6 \times 6 \times 6$ $\mathrm{mm}^{3}$. Esfera unitaria que corresponde a un radio de $87 \mathrm{~mm}$. . . . 80

5.5. Volumen esférico conductor (usado en la simulación de EEG, problema directo) registrado con el centro del volumen conductor realista de materia gris (usado en la solución del problema inverso). Esfera unitaria (corresponde a un radio de $87 \mathrm{~mm}$ ) . . . . . . . . 81 
5.6. Error de localización $(\varepsilon)$ calculado para los 10 registros simulados, aplicando las cuatro diferentes combinaciones de parámetros. Las líneas representan la tendencia lineal del error para cada combinación de parámetros (ver Tabla 5.6) y para medio homogéneo infinito (MHI). Esfera unitaria (corresponde a un radio de $87 \mathrm{~mm}$ ). . . . . . . . 83

5.7. Error de localización $(\varepsilon)$ contra profundidad de la fuente para cuatro diferentes combinaciones de parámetros del método sin malla (ver Tabla 5.6) y medio homogéneo infinito (MHI). Esfera unitaria (corresponde a un radio de $87 \mathrm{~mm}$ ) . . . . . . . . . . 85

5.8. Error de localización contra profundidad de fuente: comparación de la combinación MC1 y la solución con medio homogéneo infinito (MHI). 86

5.9. Comparación de los métodos de solución de problema inverso (sLORETA y SLOFO) para la combinación de parámetros MC1 y medio homogéneo infinito (MHI), para detección de fuentes en una profundidad para distancias normalizadas al centro entre 0,63 y 0,88 . Esfera unitaria (corresponde a un radio de $87 \mathrm{~mm}$ ) . . . . . . . 87

5.10. Posición 3D de fuentes radiales localizadas en los lóbulos temporales utilizadas en la generación de 100 registros de EEG simulados. . . . . 90

5.11. Gráfica de valores singulares para las matrices de campo de la combinación de parámetros $\mathrm{MC1}$ (en rojo) y para medio homogéneo infinito

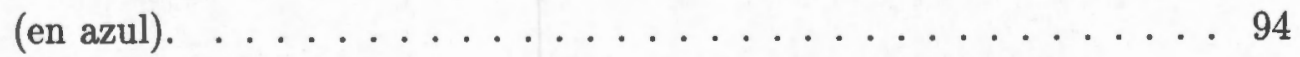

5.12. Información anatómica y funcional fusionada en Matlab . . . . . . . 95

B.1. Reconstrucción 3D de superficie de imágenes por resonancia magnética . Imágenes de 181x217, estudio de 181 imágenes, resolución de voxel de $1 \mathrm{~mm}^{3} \ldots \ldots \ldots . \ldots \ldots$

B.2. Reconstrucción 3D de IRM. a) visualización de los ventrículos a través de opacar la superficie de materia blanca y gris. b) ventrículos . . . 106 
B.3. Imágenes 2D superpuestas al volumen 3D de IRM, cortes axial, coronal y sagital. . . . . . . . . . . . . . . . . . . . 106

B.4. Interfaz gráfica de usuario programada en Borland $\mathrm{C}++$, se pueden apreciar a la izquierda los controles de capa a reconstruir, opacidad de capa, barras de color (RGB). . . . . . . . . . . . . . 107

B.5. Reconstrucción 3D con corte sagital superpuesto. . . . . . . . 108

B.6. Reconstrucción 3D con corte sagital, coronal y axial superpuesto. . . 108

B.7. Ventana de entrada de datos de imágenes 2D, donde solicita el nombre y la localización de la primera imagen de la serie, así como las dimensiones de las imágenes y el número de imágenes de toda la serie, también el número de capa a visualizar, para nuestro caso, 1 pertenece a materia gris, 2, a materia blanca y 3, a líquido cefalorraquídeo. . . . 109

B.8. Interfaz gráfica desarrollada con QT y VTK . . . . . . . . . 110

B.9. Visualización de conFigura ción de electrodos, dentro de la interfaz con el usuario. . . . . . . . . . . . . . . . . . . 111

B.10.Visualización de estudio de Tomografía Computada en interfaz gráfica QT-VTK. . . . . . . . . . . . . . . . 112 


\section{Índice de cuadros}

2.1. Modalidad de Imágenes, disponibilidad en el quirófano, accesibilidad y dimensionalidad. $[138] \ldots \ldots \ldots \ldots$

5.1. Posición de 18 registros de EEG dentro de un modelo esférico de cabeza en unidades normalizadas a esfera unitaria (U.N.), teniendo en cuenta que el radio de la esfera es igual a $87 \mathrm{~mm} . \ldots \ldots \ldots$

5.2. Posiciones de las fuentes generadoras de 17 registros de EEG simulados y error de localización con SLORETA. Las fuentes fueron posicionadas en voxeles de materia gris normalizada pertenecientes también a una esfera unitaria y la actividad fue registrada con 64 electrodos. U.N. es unidad normalizada con respecto al radio de la esfera $(87 \mathrm{~mm})$ donde se localizan los electrodos. . . . . . . . . . 77

5.3. Generación de 8 registros localizados radialmente en el lóbulo temporal derecho (1-4) y lobulo temporal izquierdo (5-8). . . . . . . 78

5.4. Posición de las fuentes utilizadas en la generación de 8 registros de EEG, para una resolución de voxel de $6 \times 6 \times 6 \mathrm{~mm}^{3}$ de materia gris (5426 voxeles en todo el volumen), lóbulo temporal derecho (1-4) y lóbulo temporal izquierdo (5-8). Esfera unitaria (corresponde a un radio de $87 \mathrm{~mm}) \ldots \ldots \ldots \ldots \ldots \ldots . \ldots . \ldots . \ldots 79$ 
5.5. Posiciones de fuentes usadas en la simulación de 10 registros de EEG , las unidades son relativas a una esfera de radio unitario (corresponde a un radio de $87 \mathrm{~mm}$ ). . . . . . . . . . . . . . 82

5.6. Parámetros $\mathrm{R}$ y $\lambda$ de las diferentes combinaciones del método sin malla, usados en las pruebas. . . . . . . . . . . . . . 82

5.7. Posición de las fuentes usadas para la simulación de 15 registros de EEG, unidades relativas a una esfera de radio unitario (corresponde a un radio de $87 \mathrm{~mm}) . \ldots \ldots \ldots$. . . . . . . . . . . 84

5.8. Error promedio de localización en 200 registros de EEG simulados, con fuentes únicas localizadas aleatoriamente en los lóbulos temporales. 90

5.9. Error de localización en 100 registros de EEG simulados, con fuentes únicas localizadas radialmente en los lóbulos temporales. . . . . . . . 90 


\section{Resumen}

El registro de EEG en cuero cabelludo, constituye un sistema de adquisición de actividad eléctrica cerebral con una resolución temporal de milisegundos [27], pero con una resolución espacial muy baja, lo cual dificulta la detección de fuentes eléctricas a través de la solución del problema inverso. Por otro lado, una de las principales características de las imágenes por resonancia magnética (IRM) es su alta resolución espacial; por lo que se vuelve atractivo contar con una buena resolución espacial y temporal, fusionando la información anatómica de IRM y la información funcional de la electroencefalografia, para poder resolver el problema inverso con una mayor precisión. En este trabajo se realizó un sistema de planeación de cirugía de epilepsia, que presenta al médico la información anatómica y funcional fusionada para que éste pueda realizar una planeación de la neurocirugía. El sistema utiliza un modelo de volumen conductor de cabeza innovador por medio del Método sin Malla (Meshless Method) reduciendo la complejidad inherente en la construcción de un mallaje. No se ha sacrificado el error de localización, ya que la metodología propuesta presenta un error promedio de localización de fuentes de $8 \mathrm{~mm}$; cumpliendo el objetivo de integrar herramientas de análisis de información funcional con información anatómica, en un sistema de planeación de neurocirugías. 


\section{Capítulo 1}

\section{Introducción}

La incidencia de la ingeniería en la medicina se ha centrado en otorgar sistemas que permitan al médico tener un panorama más amplio del problema con que se enfrenta. En los últimos años, han aparecido varios sistemas utilizados para una planeación de cirugías cerebrales y una guía para el medico durante la cirugía (REGULUS@ [89], NSPS@, VECTOR VISION@), dichos sistemas proporcionan una dimensión diferente del problema a tratar a través de imágenes y señales del paciente. Particularmente para cirugía estereotáxica, dichos sistemas permiten al cirujano planear la operación con mayor exactitud, presentar dicho plan en el momento de la operación y analizar los resultados, con el objetivo de reducir la invasividad; ésto es necesario cuando se trata de cirugía de epilepsia de lóbulo temporal (ELT), debido a la dificultad de localizar los focos epileptógenos y la cercanía de estos focos con áreas elocuentes del cerebro, que pueden ser dañadas durante el procedimiento. Según la Secretaría de Salud de México, se estima una incidencia de poco más de 100 pacientes con epilepsia por cada 100 mil habitantes, $60 \%$ de los casos inicia en la infancia o antes de los 20 años de edad. Se estima que $85 \%$ de los pacientes con epilepsia pueden ser controlados con medicamentos, siendo el porcentaje restante candidatos a cirugía. El procedimiento quirúrgico de epilepsia puede alcanzar hasta 
un $80 \%$ de éxito, según la localización del daño y la evolución del padecimiento. Actualmente, no existe ningún sistema de planeación de cirugías estereotáxicas de epilepsia de lóbulo temporal (ELT) que permita integrar información anatómica de resonancia magnética e información funcional extraída de la actividad eléctrica cerebral de manera no invasiva, con bajo costo computacional y con una precisión bajo los estándares clínicos. La estimulación cortical es el estándar clínico aceptado para la realización de un mapa funcional [70], esta técnica presenta la desventaja de ser un método muy invasivo y puede llegar a ser demasiado peligroso en procedimientos de extracción de foco epileptógeno [29]. Por lo tanto, se proponen métodos menos invasivos que otorguen la información funcional para cada paciente, fusionando dicha información con imágenes por resonancia magnética, con lo que se busca obtener una buena resolución espacial y temporal.

El sistema de planeación de cirugías realizado, se logra estableciendo una metodología con el afán de conseguir una mejor resolución espacial en la solución del problema inverso de EEG. Dicha metodología abarca el manejo de la información anatómica, específicamente la extracción de estructuras anatómicas relevantes, para la construcción del modelo de volumen conductor de cerebro, es aquí donde tenemos la mayor incidencia de nuestro trabajo, que es utilizar un método innovador (Método sin Malla, conocido en inglés como Meshless Method) para encontrar a partir de la información anatómica del paciente, la matriz de campo para la solución del problema inverso.

A continuación se hace una breve descripción del contenido de esta tesis:

En el Capítulo 2, se presenta el panorama del paradigma de Cirugía Integrada por Computadora (CIS, por sus siglas en inglés), dicho paradigma divide al procedimiento quirúrgico en tres fases importantes, fase pre-operatoria, fase trans-operatoria, fase post-operatoria. Asimismo, se presenta el estado del arte de las cirugías estereotáxicas, las tecnologías claves implicadas en la CIS, imágenes médicas y de la 
información funcional.

En el Capítulo 3, se da un panorama de la generación de la actividad eléctrica cerebral, cómo se modela y cómo se estima dicha actividad. También se presenta la teoría del problema directo e inverso del EEG y el estado del arte del modelado de la cabeza como un volumen conductor esférico o como un volumen realista, terminando el capítulo con el concepto de matriz de campo que caracteriza a dicho modelo de volumen conductor.

En el Capítulo 4, se presenta la metodología propuesta, comenzando por la segmentación de imágenes por resonancia magnética, la generación de los registros simulados de EEG, la solución del problema directo a través de un modelo de volumen conductor por medio del método sin malla, la construcción de la matriz de campo a través de dicho método y se termina el capítulo presentando los algoritmos de solución del problema inverso más novedosos para un modelo de fuentes de corriente distribuidas.

En el Capítulo 5, se presentan los resultados obtenidos en la localización de fuentes con la metodología propuesta, es decir, a partir de un modelo de volumen conductor realista con el método sin malla, comparado contra la suposición de un modelo de medio homogéneo infinito, como referencia. En paralelo se hace una discusión sobre cada resultado obtenido, y cómo esta discusión nos orientó a los conclusiones que se muestran en el Capítulo 6. 


\section{Capítulo 2}

\section{Antecedentes}

Motivados por obtener mejores resultados y con bajos costos, la práctica clínica rápidamente reemplazó los procedimientos de cirugía abierta por técnicas mínimamente invasivas. Esta transición fue desde una retroalimentación visual directa hacia una retroalimentación visual indirecta, es decir, a través de imágenes. La transición de un tipo a otro de procedimiento impone retos a vencer, es decir, en los procedimientos de cirugía abierta los médicos pueden ver y sentir directamente las diferentes estructuras anatómicas; por el contrario, en los procedimientos de cirugías guiadas por imágenes, los médicos necesitan identificar las estructuras anatómicas en las imágenes (segmentación), y establecer las relaciones espaciales entre las imágenes y el paciente (registro); con el objetivo de que la precisión en la ejecución del procedimiento tendiera a ser comparable o mejor que la alcanzada por los procedimientos tradicionales.

Los sistemas de cirugía guiada por imágenes permiten aumentar y complementar las habilidades de los cirujanos para entender la estructura espacial de la anatomía, integrando imágenes y otras fuentes de información. Estos procedimientos pueden transformar la evaluación cualitativa de la intervención quirúrgica en una evaluación cuantitativa, teniendo además una evaluación cuantitativa entre la planeación y la 
ejecución del procedimiento. Además permiten realizar nuevos procedimientos cada vez menos invasivos, considerados anteriormente como peligrosos.

Los procedimientos quirúrgicos son inherentemente procesos integrativos. Los cirujanos integran el conocimiento de las estructuras anatómicas con las imágenes medicas del paciente para planificar y ejecutar la intervención. Los sistemas guiados por imágenes tienen una aproximación similar, donde todas las fuentes de información son integradas y usadas para proveer una guía útil al médico.

Los sistemas de cirugía guiados por imágenes fueron inicialmente aceptados por dos disciplinas médicas, neurocirugía $[48,53,69,113]$ y ortopedia $[26,88]$. La principal razón de esta adopción es que ambas disciplinas asumen un comportamiento rígido de la anatomía. En neurocirugía el movimiento del cerebro está limitado por la estructura ósea, aunque, si bien es cierto, se han suscitado muchas investigaciones sobre el desplazamiento del tejido del cerebro, como cualquier tejido. En ortopedia la suposición es siempre válida. Todos los sistemas comerciales de cirugía guiada por imágenes están basados en la suposición de anatomía rígida. Los sistemas que toman en cuenta el carácter deformable de la anatomía son aún sujetos de investigación.

En cuanto a neurocirugía, se han tenido en los últimos años avances significativos, que permiten al cirujano planear la operación con mayor exactitud, presentar dicho plan en el momento de la operación y analizar los resultados con el objetivo de reducir la invasividad en futuras intervenciones, es cuando aparece el paradigma de Cirugía Integrada por Computadora, como se verá más adelante. Uno de los campos que ha presentado un gran desarrollo ha sido la cirugía estereotáxica de cerebro, en particular cirugía de epilepsia de lóbulo temporal (ELT), permitiendo procedimientos más eficaces. 


\subsection{Esquemas de cirugía asistida por computadora.}

En el desarrollo de una guía para el médico, a través de imágenes y señales, podemos encontrar tres conceptos diferentes pero relacionados entre sí: la Cirugía Asistida por Imágenes (rayos X, tomografía axial computarizada), donde las imágenes sirven de guía al médico para la planeación de la cirugía [72]; la Cirugía Asistida por Computadora (CAS, Computer Assisted Surgery), donde el despliegue y seguimiento de la operación se hace a través de una computadora y el paradigma de Cirugía Integrada por Computadora (CIS, Computer Integrated Surgery) que incluye los dos conceptos anteriores, pero que además se realiza en los momentos pre-operatorio, trans-operatorio y post-operatorio y existe una íntima relación entre los tres.

\subsubsection{Cirugía asistida por imágenes.}

La cirugía asistida por imágenes se remonta al año de 1895 , cuando se utilizaban las imágenes de rayos $\mathrm{X}$ para la extracción de balas en los pacientes, y eran dichas imágenes las que orientaban al médico sobre el camino a seguir en la operación. La radiografía estereoscópica en 1897 y la angiografía en 1963 incrementan las habilidades del cirujano, en esta última se suministra un medio de contraste al paciente que realza, en las imágenes de rayos $\mathrm{X}$, todo el sistema vascular. Con el desarrollo de varias técnicas, se construye la Angiografía de Substracción Digital [98].

Con el descubrimiento de la tomografía axial computarizada inicia una nueva etapa en el desarrollo de la cirugía asistida por imágenes, proporcionando al cirujano información más precisa de la anatomía del paciente, pero estas imágenes tienen el problema del bajo contraste que presentan entre la diferenciación de materia gris y materia blanca, información muy valiosa en procedimientos vasculares intracraneales

Con el surgimiento de imágenes de resonancia magnética, se mejora el contraste 
en las imágenes adquiridas del paciente, además de otorgar discriminación de sutiles diferencias en características de tejido, por medio de procedimientos de procesamiento de imágenes [58]; es por esto que se convierte en la principal modalidad de imágenes que contempla un sistema CAS.

\subsubsection{Cirugía asistida por computadora.}

De la combinación de imágenes por resonancia magnética y un medio de contraste suministrado al paciente, surge la posibilidad de tener imágenes de resonancia magnética que proporcionan información angiográfica, creando así la Angiografía por Resonancia Magnética. Posterior a esto surgen las imágenes de resonancia magnética funcional (fMRI, Functional Magnetic Resonance Image), que proporcionan información funcional superpuesta a la imagen anatómica del paciente, utilizando la concentración de hemoglobina en zonas específicas del cerebro de pacientes realizando maniobras motoras, visuales o sensitivas

Con la resonancia magnética y sus diversas modalidades, las imágenes previas a la intervención quirúrgica sirven para el diagnóstico y planeación de la intervención, pero todavía en este estadio de desarrollo de cirugías asistidas, la mayoría de decisiones se toman en el momento de la operación y no hay una relación entre las diferentes fases del proceso.

\subsubsection{Cirugía integrada por computadora (CIS).}

Los sistemas CIS son capaces de proveer nuevas capacidades que superan las limitaciones humanas en la realización de cirugías. El principal papel de los sistemas CIS es proveer de información precisa y oportuna al cirujano, ya que son capaces de combinar información de imágenes y señales antes, durante y después de la cirugía.

El paradigma de CIS, surge a mediados de los años ochenta, y tiene como objetivo otorgarle al cirujano una retroalimentación visual del procedimiento en tiempo real, 
procesado por la computadora, integrando la información de diferentes fuentes de adquisición de imágenes o señales del paciente durante la operación $[65,135]$. Se trata, entonces, de realzar las habilidades del cirujano, manteniendo éste siempre el control de dicho procedimiento; en ningún momento se busca la sustitución del cirujano en una intervención quirúrgica.

Para que el sistema CIS pueda desarrollar su objetivo, éste se subdivide en dos conceptos interrelacionados $[39,65,135]$ :

1. Sistema CAD/CAM (Computer Assisted Design/ Computer Assisted Machine) quirúrgico: consiste en realizar un modelo del paciente a partir de imágenes adquiridas antes de la operación y otra información pertinente que necesite el cirujano para realizar la operación. Con esto, se logra dar asistencia al médico para que pueda planear la cirugía, también darle asistencia durante la realización de la cirugía, presentando esta información y comparando el procedimiento realizado con respecto al plan elaborado previo a la operación.

2. Sistemas de asistencia quirúrgica: con el propósito de extender las habilidades del cirujano, se crean dispositivos que realcen sus sentidos para permitir la ejecución de la operación de forma precisa y exacta, logrando con esto reducción del tiempo y un procedimiento menos invasivo; hasta llegar a tener la posibilidad de utilizar unos lentes que permiten visualizar un imagen intra-cerebral del paciente superpuesta sobre la piel de éste, lo que se ha dado en llamar "Augmented Reality".

Un sistema CIS está compuesto por tres fases, planeación del procedimiento (o fase pre-operatoria), ejecución del procedimiento (o fase trans-operatoria) y análisis de resultados del procedimiento (o fase post-operatoria) como se observa en la Figura 2.1 y cualquier aplicación debe contemplarlas $[40,131]$. 


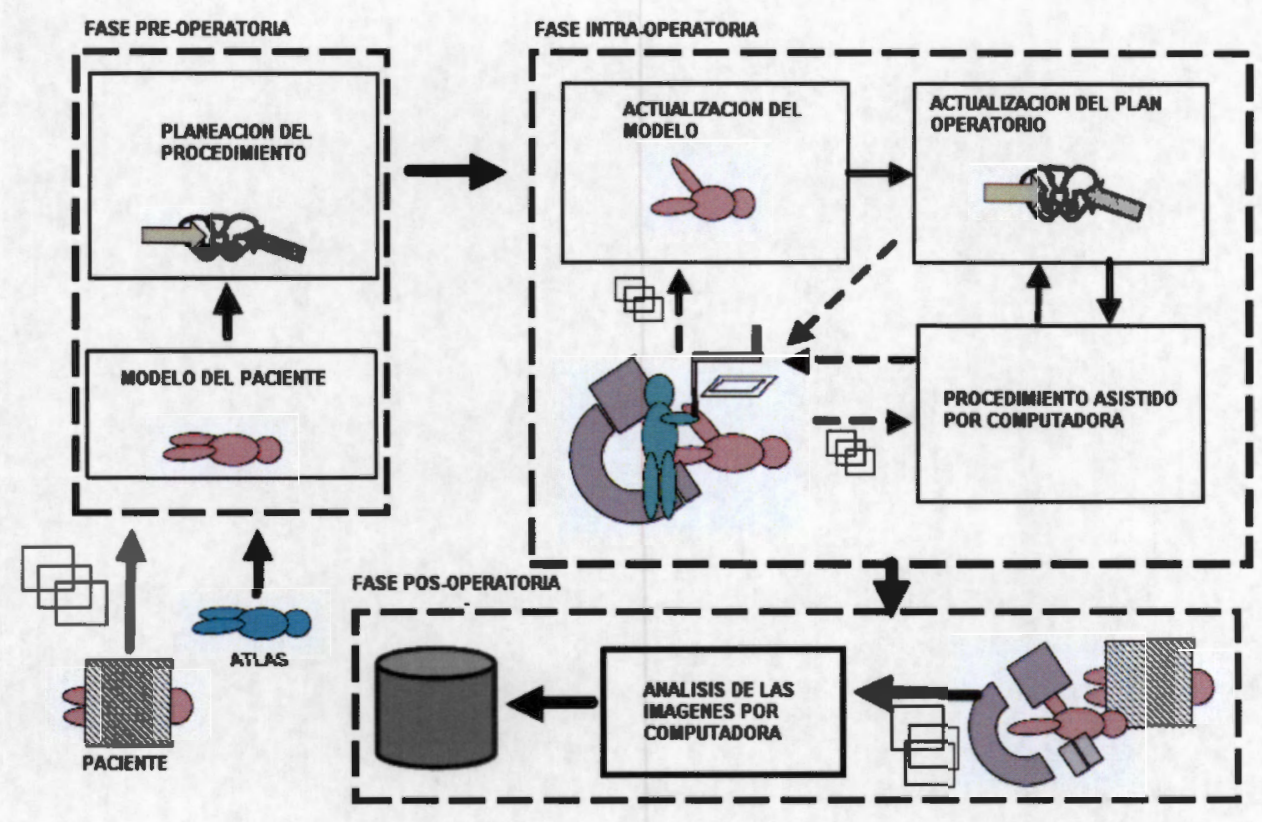

Figura 2.1: Fases que componen un sistema CIS [65].

\subsection{Procesos durante la CIS.}

\subsubsection{Neuro-navegación.}

La neuro-navegación provee una orientación al cirujano durante la operación y ayuda a la planeación de una precisa intervención quirúrgica.

La simulación de una neuro-navegación, ayuda al cirujano para una aproximación precisa de la planeación del procedimiento. Además la incorporación de información funcional provista por Imágenes funcionales por Resonancia Magnética (fMRI), Magnetoencefalografía (MEG) o Electroencefalografía (EEG), incorporan en la planeación la posibilidad de trazar trayectorias que no dañen áreas elocuentes del cerebro [64].

En la neuro-navegación el cerebro es considerado como un volumen geométrico el cual se puede dividir en la intersección de tres planos imaginarios ortogonales (axial, sagital y coronal), basado en un sistema de coordenadas cartesianas, donde 
cada punto del cerebro puede ser descrito por la intersección de estos tres planos.

\subsubsection{Fase pre-operatoria.}

En esta fase, el objetivo es crear un plan quirúrgico basado en imágenes preoperatorias e información adicional tales como la geometría del implante o información funcional. Múltiples modalidades de imágenes pueden ser utilizadas concurrentemente, Imágenes por Resonancia Magnética (IRM) y Tomografía Computada (TC) para tener la visualización del hueso o tejido blando, y Tomografía por Emisión de Positrones (PET) para correlacionar la información anatómica e información funcional. La planeación se realiza en un sistema de coordenadas en el cual todos los datos son mapeados. Esta planeación puede variar en complejidad, desde una simple planeación consistente en la detección del objetivo y trayectoria a seguir [9], a una planeación compleja que incorpora los movimientos de las estructuras y la interacción entre tejido suave y estructuras óseas $[18,126]$. Las tecnologías claves que encierra la fase de planeación pre-operatoria son: (1) Imágenes médicas y procesamiento de estas imágenes, incluyendo la corrección geométrica y distorsión de intensidad; (2) Visualización de los datos, que incluye el despliegue y manipulación de la imagen y datos; (3) Segmentación, la clasificación de los datos de la imagen en estructuras anatómicas significativas; y (4) Registro, la alineación de los datos dentro de un sistema de coordenadas correspondiente a las estructuras anatómicas del paciente.

Se desarrolla un plan de operación a partir de un modelo específico del paciente, dicho modelo está formado por imágenes y señales adquiridas antes de la operación, y fusionando dicha información con el atlas anatómico o una base de datos. El problema es que las imágenes proporcionan sólo información estática, los movimientos de los tejidos y las deformaciones causadas por la cirugía no se visualizan en dichas imágenes. En el plan pre-operatorio se debe seleccionar la posición exacta del objetivo y la mejor trayectoria a seguir, además se puede incorporar la simulación del 
comportamiento dinámico (biomecánico) de los tejidos involucrados en el procedimiento.

\subsubsection{Fase trans-operatoria.}

Tanto las imágenes adquiridas durante la cirugía, el modelo del paciente, realizado en la fase previa, como la información del plan deben ser presentadas al cirujano en el quirófano, para darle el estado exacto del procedimiento utilizando un sistema de localización en 3D, con lo cual se obtiene una retroalimentación de la información y se puede llegar a una corrección en tiempo real del plan.

Una vez que el paciente está dentro de la sala de operaciones, el sistema de coordenadas, en el cual fue realizada la planeación, debe de ser registrado al sistema de coordenadas de la sala de operaciones [4]. El sistema de guía a través de imágenes provee al médico de una asistencia visual, rastreando instrumentos y estructuras anatómicas y desplegando las relaciones espaciales entre éstos, a través de una variedad de interfaces y monitores. Información adicional, tales como imágenes intra-operatorias, pueden ser adquiridas para actualizar la información anatómica y corregir el plan pre-operatorio, si es necesario. Durante el procedimiento el sistema de guía puede registrar las relaciones espaciales entre los instrumentos y la anatomía del paciente. Estos datos pueden ser usados posteriormente para realizar una evaluación cuantitativa de la intervención para procesos futuros. Las tecnologías involucradas en esta fase intra-operatoria incluyen todas las envueltas en la fase preoperatoria más: (1) sistemas de rastreo para la localización de la posición espacial de la anatomía y las herramientas utilizadas; y (2) sistemas de interacción humanocomputadora, incorporando métodos y aparatos para la interacción con el sistema de guía y las formas de transmisión de la información al médico.

La modalidad de imagen adquirida durante la fase intra-operatoria, ha sido por excelencia el ultrasonido, por las características de no invasividad y portabilidad del 
aparato, pero presenta diversas desventajas tales como la naturaleza especular de las imágenes, sombreado, contraste variable y la calidad de la imagen depende en gran medida de la habilidad del operador en la adquisición de éstas [15].

\subsubsection{Fase post-operatoria.}

En esta fase se adquieren imágenes post-operatorias y cuantificando los resultados del procedimiento comparando dichas imágens con el plan pre-operatorio realizado en la primera fase. Las tecnologías claves involucrada en la evaluación post-operatoria son las mismas que las de la fase de planeación.

Con el afán de lograr intervenciones cada vez menos invasivas, se analizan los resultados obtenidos durante la operación, cotejando con el plan realizado en la primera fase [80].

Muchos de los sistemas comerciales de cirugía asistida por computadora en la actualidad utilizan imágenes de TC e IRM combinados, dando cada una ciertas características para construir un modelo del paciente más exacto y preciso, por lo tanto los avances en dichos sistemas, se centran en lo siguiente:

- Combinación de información de múltiples fuentes y sensores.

- Combinación de información geométrica (espacial) e información funcional.

- Análisis sobre la exactitud de los resultados.

- Manejo preciso de la complejidad del sistema o de la información. 


\subsection{Tipos de Cirugías Cerebrales.}

\subsubsection{Cirugías estereotáxicas con marco.}

Las neurocirugías poco invasivas se han logrado por los avances de la tecnología y la introducción de los sistemas computarizados al ambiente hospitalario, mejorando la exactitud y calidad de los procedimientos, lo cual lleva a reducir la morbilidad y el tiempo de ejecución de la cirugía [77].

Estereotaxia, en neurocirugía, se refiere a un sistema de navegación para acceder a un punto determinado dentro del cerebro, con la ayuda de imágenes que muestran marcas anatómicas y estructuras funcionales [57].

Antes del desarrollo de la estereotaxia, alcanzar un punto dentro del cerebro requería la exposición de una gran superficie de la corteza cerebral. El valor de un sistema estereotáxico recae en la habilidad de minimizar el área de la corteza a exposición y la navegación con mínima disrupción cerebral, para alcanzar un tumor, una malformación vascular o un foco epiléptico.

Las técnicas estereotáxicas han podido ser aplicadas a procedimientos de neurocirugía ya que el cerebro es de suave consistencia, por lo tanto fácil de penetrar; el cerebro además se mantiene firme durante el momento en que los instrumentos son introducidos en él, gracias a que se encuentra confinado a un espacio determinado por la estructura ósea craneal; también la forma convexa del cráneo provee una rigidez para el montaje del equipo estereotáxico [46]. En diversos tipos de procedimientos estereotáxicos utilizados para la destrucción, estimulación o monitoreo de focos de ataques epilépticos, la exactitud mecánica proporcionada por el marco de referencia es vital en los resultados satisfactorios y depende de la rigidez de fijación del marco, sin embargo le da a este procedimiento cierto grado de incomodidad extra al paciente (Figura 2.2). 

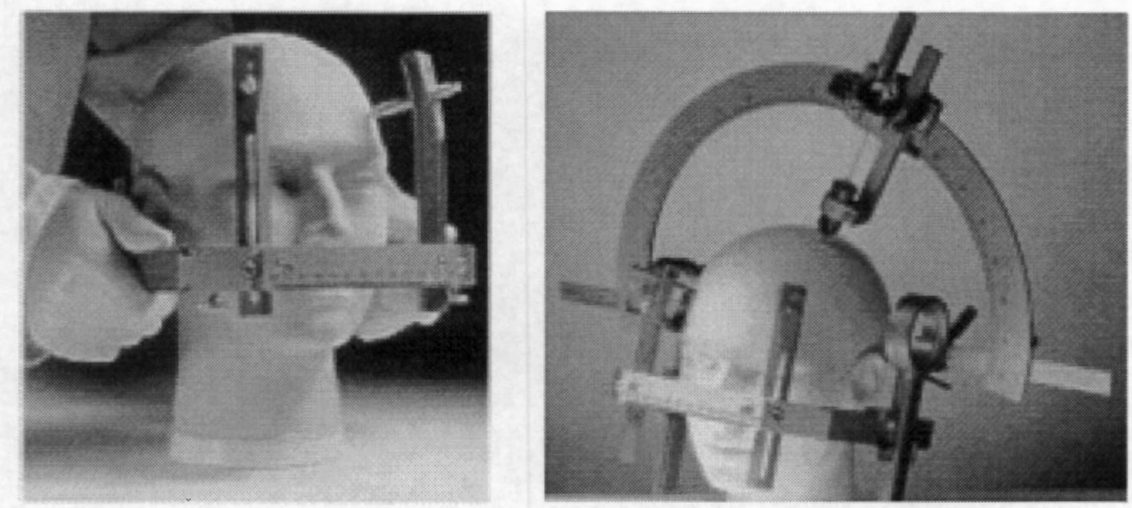

Figura 2.2: Montaje de marco estereotáxico. [133]

En las cirugías estereotáxicas, la precisión es relevante para lograr el éxito, y se pretende una menor invasividad y menor morbilidad [10,132]. Para asegurar que el mapeo anatómico sea correcto se determinan marcas en el paciente para la adquisición de las imágenes, se puede utilizar para este efecto tres métodos: marcas anatómicas, marcas fiduciales semi-permanentes o el marco estereotáxico.

El marco estereotáxico, el cual es un aro metálico montado en la cabeza del paciente y fijado al cráneo a través de cuatro tornillos, ha sido el estándar clínicamente aceptado por sus niveles de exactitud $[64,79,102,118,120,131]$, por lo tanto cualquier otra metodología utilizada debe de ser comparada con ésta.

Tanto la cirugía integrada por computadora como la cirugía asistida por computadora, han encontrado aplicación en diversos tipos de cirugía, como cirugías ortopédicas [16], y de cerebro [40,49,64, 104]. Particularmente han sido utilizados con éxito en neurocirugías estereotáxicas con marco, donde existe una referencia espacial rígida, tanto para la adquisición de imágenes previas a la operación como para los instrumentos utilizados durante el procedimiento [118], este método presenta un error de exactitud espacial entre las imágenes adquiridas y el paciente del orden de $1 \mathrm{~mm}$.

Por las diferentes características entre las modalidades de imágenes que se uti- 
lizan en un sistema de CIS, se necesitan varios tipos de marcos de referencia estereotáxicos, es decir, se pueden encontrar en el mercado diversidad de marcos, de acuerdo al material utilizado en su construcción, así como diferentes tipos de coordenadas espaciales que utilizan para la localización del objetivo (Figura 2.3).
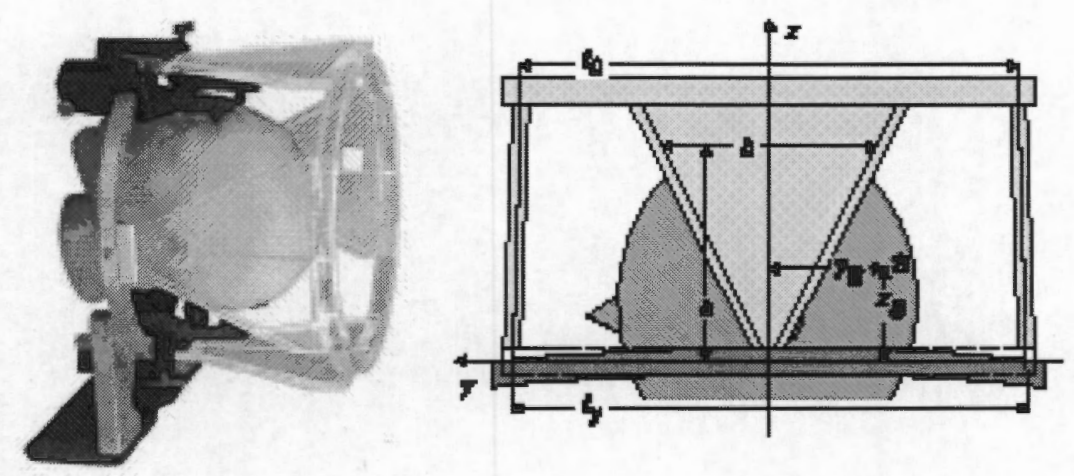

Figura 2.3: Montaje de marcadores fiduciales sobre el marco estereotáxico, utilizados para la adquisición de imágenes por resonancia magnética. [133]

\subsubsection{Cirugías estereotáxicas sin marco.}

Cuando se realizan craneotomías sin marco se puede utilizar marcas anatómicas, tales como el oído izquierdo y derecho, la parte trasera de los ojos, nariz [108] y marcadores fiduciales semi-permanentes (Figura 2.4), menos invasivos, para poder correlacionar las imágenes con el paciente. El problema de este tipo de marcas es que tienen un desplazamiento mayor de $5 \mathrm{~mm}$ en el momento de realizar el procedimiento. Por lo que la utilización del marco estereotáxico, proporciona al médico una mejor precisión en la detección del objetivo y una mayor exactitud en la trayectoria a seguir durante la intervención quirúrgica $[46,64,133]$. En el mercado podemos encontrar un sistema CAS de apoyo en la fase pre-operatoria y fase intra-operatoria denominado LOCALITE que es un sistema muy sencillo que provee al cirujano de una herramienta muy útil en la navegación, a través de IRM, durante una neurocirugía y se ha comprobado que reduce significativamente el tiempo de navegación, 
y es propio para cirugías estereotáxicas sin marco [67].

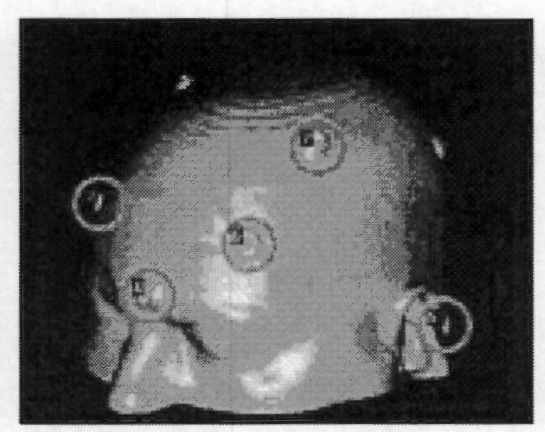

Figura 2.4: Marcadores fiduciales semi-permanentes

Un sistema CIS que se utilice en cirugías estereotáxicas con o sin marco, debe tener una íntima relación en exactitud entre los dos sistemas de referencia espacial, primero el sistema de referencia de la imagen y segundo, el sistema de referencia quirúrgico, el cual puede llegar a tener una variación significativa de tipo mecánica debido a varios factores, dependiendo del tipo de procedimiento neuroquirúrgico que se realice [65].

El uso de marcadores fiduciales para IRM, incrementa el costo del procedimiento y siempre se presenta una distorsión en la imagen, dando un error en la localización. Entonces se ha optado por hacer adquisiciones de imágenes de TC del paciente utilizando marcadores, como referencia espacial y luego fusionarlas con IRM sin la utilización de marcadores, por su alta resolución espacial.

En el afán de provocar menor invasividad en las cirugías estereotáxicas, y en un desarrollo de estas cirugías evitando la utilización del marco, se han creado varios tipos de marcadores fiduciales $[120,132,135]$. El error que se comete con la utilización de los marcadores fiduciales semi-permanentes, al compararlo con medidas absolutas dentro de la imagen y el marco tradicional, puede ser igualado o mejorado y el error está alrededor de $2.95 \mathrm{~mm}$ entre los dos métodos. Comparado con respecto a coordenadas absolutas de la imagen, el error se encuentra para marcadores fiduciales 
cerca de $1.72 \mathrm{~mm}$ y para el marco estereotáxico cerca de $3.35 \mathrm{~mm}$. Además estos marcadores fiduciales presentan la ventaja de que pueden ser colocados varios días antes de la intervención sin provocar molestias adicionales al paciente, y pueden ser retirados varios días después, para procedimientos establecidos en cirugías de epilepsia o en cirugías de ciertos tumores $[79,102]$.

La utilización de marcas anatómicas, en cirugías estereotáxicas sin marco, incrementa las fuentes de error que pueden deberse al proceso de registro que gira alrededor de 0.5-0.6 mm, por distorsión geométrica de la imagen $(0.2-0.3 \mathrm{~mm}), \mathrm{y} / \mathrm{o}$ por movimientos del paciente durante la adquisición de las imágenes $(0.3-0.5 \mathrm{~mm})$. Sin utilizar el marco estereotáxico se introduce otra fuente de error que es el movimiento del paciente con respecto al sistema de referencia quirúrgico durante la cirugía, por lo tanto introduce un error cerca de $0.5 \mathrm{~mm}$ y en algunos casos mayor a 1.5 $m m[79,118]$. Una fuente de error adicional y de difícil predicción es el movimiento del cerebro en el momento de la cirugía, ya sea por pulsaciones periódicas y pequeñas en sincronía con la sístole $(0.5 \mathrm{~mm})$, o por el desplazamiento que se presenta después de la resección de tumores $(>2 \mathrm{~mm})[49]$.

\subsection{Tecnologías claves.}

A partir de la discusión anterior se identifican las tecnologías claves en los procedimientos guiados por computadora:

1. Imágenes Médicas y procesamiento de imágenes.

2. Visualización de la información.

3. Segmentación de imágenes.

4. Registro de imágenes.

5. Sistemas de rastreo.

6. Interfaz humano computadora.

Específicamente, para la realización de una buena planeación, el sistema debe de 
contar con las primeras tres tecnologías mencionadas, más las siguientes dos:

Construcción de un modelo anatómico.

Fusión de información anatómica y funcional.

\subsection{Información Anatómica.}

\subsubsection{Imágenes médicas y procesamiento de imágenes.}

La principal fuente de información para procedimiento guiados por imágenes son las imágenes médicas en sí. El primer procedimiento que usó imágenes fue realizado en 1896, utilizando imágenes de Rayos - X [45,99]. El desarrollo de la imagenología médica ha sido bastante grande, desde imágenes de proyecciones de rayos- $\mathrm{X}$ en películas de plata, hasta llegar a imágenes tomográficas digitales. En la Tabla 2.1 se lista las diferentes modalidades de imágenes médicas en términos de su disponibilidad para uso trans-operatorio, su accesibilidad y la dimensionalidad de los datos. A partir de la Tabla 2.1 se puede ver que en la mayoría de los procedimientos, el médico depende en gran medida de su habilidad para reconstruir mentalmente en tres dimensiones, a partir de las imágenes bidimensionales adquiridas durante el procedimiento quirúrgico.

Todas las imágenes 3D tomográficas, consisten de un conjunto de imágenes de cortes bidimensionales las cuales pueden ser agrupadas para crear un volumen tridimensional. Como los datos son típicamente adquiridos usando un esquema de rebanada, el objeto en estudio debe de estar inmóvil durante la adquisición completa del conjunto de imágenes, o si el movimiento es sistemático (movimiento respiratorio o cardiaco) un sistema de procesamiento de imágenes de corrección de movimiento simple, puede ser utilizado.

La modalidad tomográfica mejor situada para imagenología de estructuras óseas es la Tomografía Computada (TC). Esta modalidad es considerada geométricamente 
Tabla 2.1: Modalidad de Imágenes, disponibilidad en el quirófano, accesibilidad y dimensionalidad. [138]

\begin{tabular}{|l|l|l|l|}
\hline Modalidad & Disponibilidad & Accesibilidad & Dimensionalidad \\
\hline \hline Tomografí Computada (TC) & Disponible & Alta & 3D \\
\hline Resonancia Magnética (IRM) & Disponible & Alta & 3D \\
\hline Rayos- X & Disponible & Alta & proyección \\
\hline Resonancia Magnetica Funcional & & 2D \\
\hline Tomografia por Emisión de Positrones (PET) & No disponible & moderado & 3D \\
\hline Tomografia Computada por Emisión de Foton simple & No disponible & moderado & 3D \\
\hline Fluoroscopia por rayos-X & Disponible & Alta & proyeccion \\
\hline Ultrasonido & 2D \\
\hline Imagenologia Optica & Disponible & Alta & 2D \\
\hline
\end{tabular}

exacta [74], pero presenta artefactos de intensidad cuando algún objeto metálico está presente en el campo de visión del aparato. La TC intra-operatoria está disponible, pero su utilización no es tan fuerte. La necesidad de crear la visualización $3 \mathrm{D}$ a un costo menor, ha generado la introducción de la imagenología por TC-Fluoroscópica $[52,127]$. Esta modalidad utiliza un brazo motorizado isocéntrico (TC-arm) para adquirir pequeñas áreas de visión del conjunto de datos tomográficos, aunque la calidad de estos datos tomográficos es aún más baja que los estándares de TC, se espera mejoras con los avances tecnológicos de los intensificadores de la imagen del TC-arm. La principal desventaja de estas modalidades de imágenes tomográficas es su radiación ionizante $[24,66,105]$. Aunque hace varios años se formuló una hipótesis de que si la radiación ionizante está por debajo de un umbral determinado, es posible que la exposición a tomografía no aumente el riesgo de cáncer; en estudios recientes se sugiere que esta hipótesis no es válida y el riesgo de cáncer no avanza de forma lineal con umbrales más bajos [20].

La mejor modalidad de imágenes tomográficas de tejido blando es la Resonancia 
Magnética, por su resolución espacial; aunque este tipo de imágenes presenta el problema de distorsión geométrica y de intensidad. El primer problema es causado por las inhomogeneidades del campo magnético y la no-linealidad de los gradientes del campo magnético $[74,115]$. Los nuevos resonadores ya incorporan esquemas de corrección de la distorsión geométrica, de tal forma que el resultado final puede ser suficientemente preciso para ciertas aplicaciones [11]. Una reciente evaluación de la distorsión geométrica en sistemas clínicos de IRM, reportó errores de escala de varios milímetros aún cuando la corrección de la distorsión geométrica es aplicada en algunos equipos [124].

Las imágenes de ultrasonido son difíciles de interpretar debido a su baja calidad y la forma en que son adquiridas. Este tipo de imágenes usualmente presentan contraste variable, borrosidad y artefactos de sombreado. Además los datos son adquiridos en un conjunto de imágenes 2D no correlacionados con orientaciones arbitrarias, requiriendo la reconstrucción mental de las diferentes estructuras importantes por parte del médico. La solución a este problema es la adquisición de imágenes 2D por medio de un posicionador mecánico que manipula el transductor, por lo tanto, la posición exacta es conocida a través de un dispositivo de rastreo montado en dicho transductor [47].

Las modalidades de tomografía para imagenología funcional son fMRI, PET y SPECT (Tomografía Computada por emisión de fotón único). Aunque estas son imágenes tomográficas, la correlación entre la información funcional y las estructuras anatómicas fundamentales es difícil de discernir.

Aunque la tomografía axial computada fue la primera modalidad empleada para la planeación de cirugías estereotáxicas, ésta puede ser complementada con otros tipos de imágenes y por excelencia se ha adoptado las imágenes de resonancia magnética que otorga información no disponible en TC. Por el bajo contraste que otorga TC no se puede visualizar detalles sutiles que indican la presencia de anormalidades, 
no así con las IRM.

Un sistema de planeación neuroquirúrgica cuenta con despliegue de imágenes de diversas modalidades. Se hace uso, por tanto, de la información de TC desplegando el hueso y el tejido suave detectado por IRM, se puede llegar a una reconstrucción 3D del cerebro más exacto y con mayor detalle, lo cual posibilita una mejor fusión con la información funcional, y por lo tanto una mejor localización de focos de actividad eléctrica, por ejemplo, focos epileptógenos [98].

Para procedimientos de biopsia, el ancho aceptable de la toma de imágenes de TC es de 3-5 mm, pero para cirugías de epilepsia debe ser de 1-2 mm [14].

Para IRM las modificaciones al marco estereotáxico son obvias, porque éste se debe de habilitar para su uso dentro de un campo magnético alto y evitar que se generen grandes corrientes de Eddy. Una fuente de error adicional a las asociadas con un sistema de referencia fiduciaria, es la causada por la distorsión espacial, particularmente en los planos sagital y coronal de IRM, además cualquier distorsión puede ser incrementada por interferencias del campo magnético producido por el marco estereotáxico.

Los marcadores fiduciales para TC son fabricados de cobre o aluminio, para IRM deben de ser reemplazados por plástico, llenos casi siempre con una solución de sulfato de cobre.

El uso de marcadores fiduciales para IRM, incrementa el costo del procedimiento y siempre se presenta una distorsión en la imagen, dando un error en la exactitud de localización. Entonces se ha optado por hacer adquisiciones de imágenes de TC del paciente, utilizando marcadores como referencia espacial y luego fusionarlas con imágenes de IRM sin la utilización de marcadores. 


\subsubsection{Visualización de la información en 2D y 3D.}

En el Detroit Medical Center, se ha creado un sistema de cirugía asistida por computadora que ha sido usado en más de 300 procedimientos quirúrgicos estereotáxicos [132], tales como cirugía de lesiones, biopsias, resección de lesiones, evacuación de hematomas intracerebrales, radioterapia, entre otras. Cada procedimiento tuvo uno o más estudios de imágenes (TC, IRM, PET, angiografías), además cuenta con una base de datos, donde se guarda esta información para poder correlacionar los datos en las tres fases operatorias antes mencionadas. El problema a solucionar en el despliegue y manipulación de esta información, es la exactitud en el mapeo entre el espacio de la imagen con el espacio quirúrgico [135]. El método más exacto es la utilización del marco estereotáxico, pero tiene varias desventajas en cuanto a que la adquisición de las imágenes del paciente debe realizarse el mismo día de la operación, limitando el tiempo de análisis en la fase pre- operatoria. Además provoca incomodidad tanto en el paciente como en el campo de acción para el cirujano durante la operación (fase intra-operatoria), y limita al cirujano en la elección de trayectorias posibles para el acceso del objetivo en la cirugía estereotáxica [64,134]. En la fase post-operatoria, no se obtiene una correlación con las imágenes tomadas en la primera fase, porque el marco ya ha sido retirado de la cabeza del paciente.

Una vez que se ha obtenido la mayor correlación posible en las imágenes $2 \mathrm{D}$ se puede reconstruir un volumen (3D), de esta forma se tiene una mejor visualización del objetivo de la cirugía, permitiendo una planeación más exacta de ésta. Después de determinar el volumen de interés, se puede realizar una medición de área, volumen y distancias a través de un análisis geométrico de la reconstrucción. Con la obtención de dos puntos del volumen (el centro de la región de interés y la superficie de la corteza) se puede trazar una trayectoria para realizar el procedimiento quirúrgico.

La reconstrucción 3D a partir de imágenes de resonancia magnética, ha sido utilizada para facilitar la detección y extracción del foco epiléptico en población infantil 
que sufre de epilepsia intratable con medicamentos [19], lo reportado es que todos los pacientes tratados (8 niñas y dos niños, en edades entre 3 y 17 años), toleraron el procedimiento y no presentaron problemas neurológicos post-operatorios, por lo que se garantiza que una buena planeación de la cirugía está orientada a un beneficio post-operatorio y mejora la calidad de vida de los pacientes.

\subsubsection{Segmentación de imágenes.}

La segmentación o separación de estructuras de interés en una imagen es un campo esencial en el área de procesamiento de imágenes. Específicamente en procesamiento de imágenes médicas, la segmentación es importante para la extracción de características, mediciones y despliegue de imágenes. En ciertas aplicaciones se busca clasificar los pixeles de la imagen en regiones, por ejemplo en huesos, músculos o vasos sanguíneos, mientras que, en otras, se buscan regiones patológicas, como cáncer, deformaciones de tejido y esclerosis múltiple. En imágenes por resonancia magnética de cerebro uno de los objetivos es separar las regiones de materia gris (MG), materia blanca (MB) y líquido cefalorraquídeo (LCR), esto es debido a que para el estudio, diagnóstico, planeación de cirugía o tratamiento de muchas enfermedades cerebrales, es necesario conocer con la mejor precisión posible el tipo de tejido o en algunos otros casos, la estructura anatómica afectada.

La segmentación de un objeto se logra ya sea identificando todos los pixeles o voxeles que pertenecen al objeto o localizando aquellos que forman su frontera. Algunos métodos están basados principalmente en la intensidad de los pixeles, pero otros atributos, como la localización espacial, pueden ser asociados con el pixel para realizar la segmentación, cuyo objetivo principal es dividir una imagen en regiones, también llamadas clases, que son homogéneas con respecto a una o más características.

La delineación manual de MG, MB y LCR en imágenes por RM por un experto 
humano es difícil porque requiere un conocimiento anatómico detallado y un examen cuidadoso de grandes cantidades de datos, su realización manual es tediosa, consume mucho tiempo, y por lo tanto es propensa a errores debido a la complejidad de las estructuras cerebrales; mostrando probablemente una gran variabilidad intra e interobservador. Sin embargo, la ventaja de la técnica manual es que refleja la interpretación del radiólogo, que es la única verdad válida disponible. Los resultados serán más reproducibles con los métodos automatizados porque producirán los mismos resultados para los mismos datos. La confiabilidad aumenta porque los errores debidos a la fatiga se eliminan. La variabilidad puede disminuirse con las técnicas automáticas mientras se conserva alta la confiabilidad. Por lo anterior, el diseño de métodos de segmentación automáticos y confiables es altamente deseable por lo que ha sido uno de los intereses del Laboratorio de Investigación en Neuroimagenología (UAM- Iztapalapa) que ha desarrollado metodologías para la segmentación automática. Entre los métodos de segmentación desarrollados, existe uno de particular interés por el hecho de que no asume ninguna distribución de los datos, es decir no asume ningún modelo de función de distribución de probabilidad ( $f d p$ ) sino que permite que los datos formen grupos en base a sus propias características. Este procedimiento está basado en la segmentación por corrimiento de media, por las características que presenta, ha dado buenos resultados sobre imágenes médicas, particularmente en IRM.

La segmentación por regiones de la imagen es una operación que divide una imagen en regiones bien delimitadas, evitando que exista superposición en ellas. Una región es un conjunto de pixeles que son adyacentes, que siguen ciertas reglas de conectividad y que en general se definen entre los cuatro o los ocho vecinos más cercanos. Comúnmente se emplea la conectividad con los ocho vecinos más cercanos, ya que ésta se aproxima bien a la clasificación intuitiva que los seres humanos efectúan cotidianamente. La forma de un objeto se puede describir por medio de sus 
límites (bordes) o en términos de la región que éste ocupa. Los dos enfoques son complementarios. En el caso de regiones se desea definir características que distingan una sección de la imagen de otras y que todas ellas sean homogéneas dentro de la región de interés. Algunos elementos de este tipo son la textura y la intensidad de la imagen.

La segmentación de las imágenes se puede hacer normalmente por varios métodos, entre los cuales la segmentación por umbral es probablemente la más sencilla y la que funciona para objetos que se encuentran sobre un fondo bien contrastado. Normalmente una persona asigna los valores superiores a un umbral al objeto y los valores abajo del umbral como fuera del objeto. Este manejo del umbral se puede hacer de manera global si el fondo está bien contrastado y todos los objetos tienen valores semejantes. Otros métodos posibles son la segmentación adaptiva, cuando se emplea un umbral que pueda variar lentamente con la posición de la imagen o el empleo del histograma para determinar un umbral, notablemente en el caso de imágenes con histogramas bimodales. Este tipo de segmentación se define así: para una imagen $f(x, y)$ y un umbral $T$, se calcula que si $f(x, y)<T$ entonces $f(x, y)=a$ si no, entonces $f(x, y)=b$, donde $a$ y $b$ son niveles de gris diferentes, denotando clases.

La segmentacion por corrimiento de media ponderado con mapas de confianza, es una metodología que ha probado ser muy robusta ante la presencia de diferentes tipos y niveles de ruido y ha sido desarrollada por $[81,82]$ y aplicada a IRM en el Laboratorio de Investigación en Neuroimagenología (UAM- Iztapalapa) [63]. Esta metodología se basa en el cálculo del corrimiento de media, el cual estima las modas locales de la función de densidad de probabilidad para definir los centros de clase en el espacio característico. Se hace una mejora en la calidad de las fronteras entre las regiones o clases utilizando un mapa de confianza de bordes, esto es, la medida de la confianza de que el pixel analizado es un borde. El corrimiento de media se 
pondera con la información del mapa de confianza de cada pixel, de esta manera, las técnicas de segmentación por región y la detección de bordes se combinan para generar resultados más precisos. Primero se hace el cálculo del mapa de confianza de bordes de la imagen, con esta información se calcula el corrimiento de media, se hace un filtrado de la imagen, pero como se ha añadido la información del mapa de confianza, se preservan los bordes. Cuando se han obtenido las clases o regiones y sus centros, se hace una fusión de dichas regiones utilizando criterios de adyacencia y fuerza de bordes. Después, se hace un podado las regiones demasiado pequeñas (segun un parámetro). Finalmente se hace la clasificación de las estructuras para lo que es necesario hacer el registro al espacio de Talairach de las imágenes y luego la correlación de éstas con un atlas probabilístico, de fondo, de materia gris, de materia blanca y de líquido cefalorraquídeo (ver Figura 2.5) para garantizar que la clasificación sea lo más precisa posible. La correlación con un atlas probabilístico es lo que hace de esta metodología de segmentación adecuada para su uso en la construcción de un modelo de volumen conductor de cabeza, ya que asegura que el espacio de solución sean los voxeles que pertenecen a materia gris. 


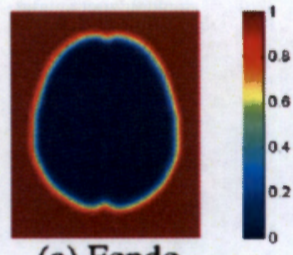

(a) Fondo

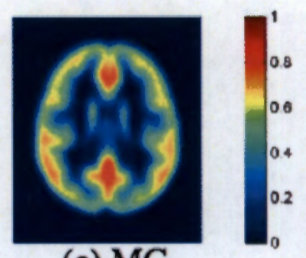

(c) MG

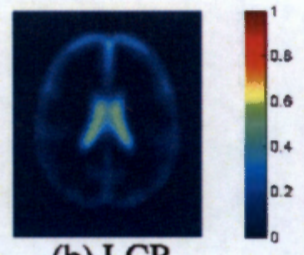

(b) LCR

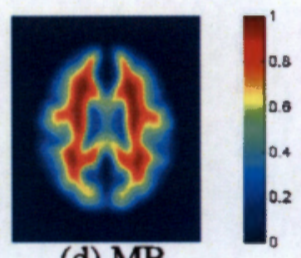

(d) MB

Figura 2.5: Mapas de probabilidad correspondientes a una rebanada del volumen simulado de cerebro. La imagen (a) representa la probabilidad de que la clase sea fondo, (b) que sea líquido cefalorraquídeo, (c) que sea materia gris, y (d) que sea materia blanca. [62]

\subsection{Información Funcional.}

En la Figura 2.6 se puede ver el proceso a seguir para la fusión de imágenes anatómicas con información funcional:

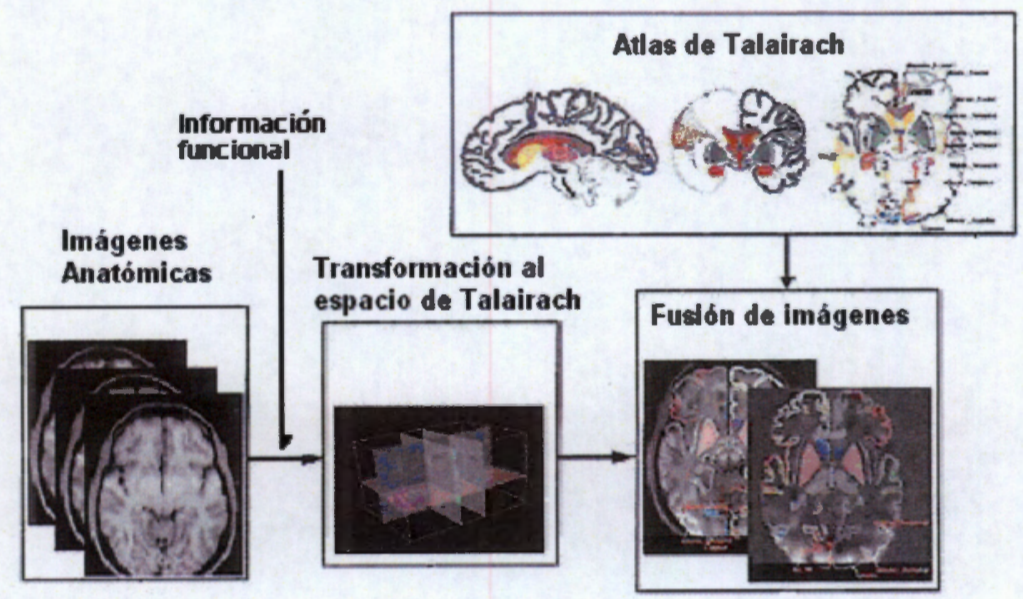

Figura 2.6: Diagrama de bloques de la fusión de imágenes anatómicas con información funcional 
El cerebro humano tiene variaciones significativas de una persona con respecto a otra, por lo tanto, para poder comparar cerebros o fusionar información funcional y anatómica, es necesario hacer lo siguiente: 1) Establecer referencias dentro de las cuales los resultados sean normalizados, 2) Definir una transformación que escale un cerebro dado dentro de un marco de referencia, 3) Establecer un sistema de coordenadas del cerebro. Para lo anterior se puede utilizar el atlas de Talairach del cerebro (Figura 2.7), la transformación normalizada del cerebro y el sistema de coordenadas estereotáxico $[90,91,117]$.
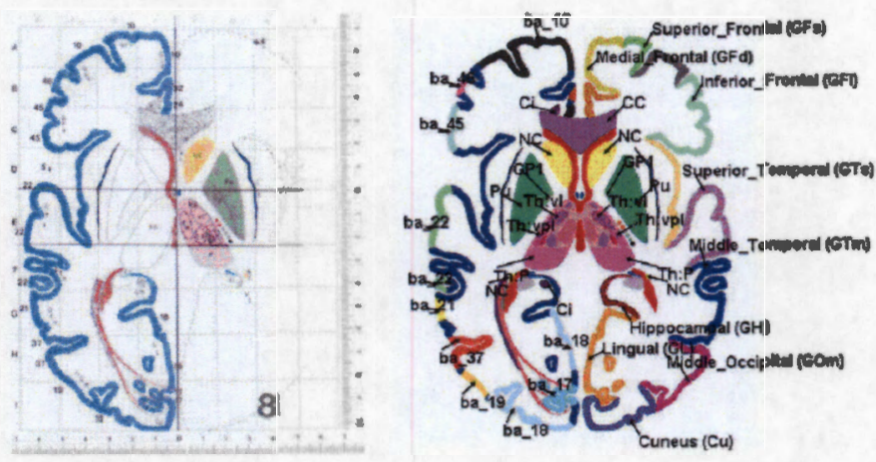

Figura 2.7: Mapa de Talairach [89]

Por lo tanto, cada una de la imágenes anatómicas debe de estar referenciada y escalada a la cuadrícula de Talairach antes de poder realizar una fusión entre estas imágenes y la información funcional.

La protección de funciones potencialmente en riesgo durante la realización de una cirugía, se realiza a través de la construcción de un mapa funcional de áreas elocuentes críticas $[13,60,70,87,107]$.

La estimulación cortical es aceptada como estándar clínico para la realización del mapa funcional [70], pero presenta la desventaja de ser un método muy invasivo y puede llegar a ser demasiado peligroso en operaciones de extracción de foco epiléptico [29]. Por esto, se plantean métodos menos invasivos que otorguen la información funcional para cada paciente, fusionando dicha información con imágenes 
de resonancia magnética, con lo que se busca obtener una buena resolución espacial y temporal.

Para realizar el mapa funcional de un paciente en específico, se puede utilizar diversas técnicas, las cuales pueden ser divididas en dos grandes áreas: 1) Aquellas que involucran técnicas basadas en la interrupción de un proceso, entre las que encontramos la estimulación magnética transcraneal, y la estimulación Electrocorticográfica, 2) Técnicas basadas en la activación de un proceso, tales como potenciales evocados, EEG, MEG (Magnetoencefalografía), PET, fMRI.

El mapeo funcional a través de estudios de MEG, ha resultado ser un método menos invasivo para la localización de ciertas funciones cerebrales, localizando la corteza somatosensorial y la hendidura central; además presenta la ventaja que se realiza rápidamente antes de la operación de pacientes con lesiones corticales cercanas o dentro del área de la corteza elocuente [59].

La actividad eléctrica cerebral tiene características temporales y espaciales. Los registros de EEG en cuero cabelludo, constituyen un método de adquisición de la actividad cortical con una resolución temporal de milisegundos $[27,130,136]$, pero la resolución espacial en la localización de fuentes generadoras de actividad eléctrica, a través de la solución del problema inverso del EEG, es muy baja [60]. La característica principal de las imágenes por resonancia magnética es su alta resolución espacial, por lo tanto, el tener a la mano una resolución espacial y temporal aceptable sería de mucha utilidad para la localización de los focos epilépticos en la fase de planeación de la cirugía. Para este efecto se han desarrollado varias metodologías que presentan al médico la localización precisa del foco epiléptico en base a información anatómica y funcional.

Con el surgimiento de la digitalización de las señales de EEG, se abrió un nuevo campo a los usuarios de esta técnica en cuanto al procesamiento de los datos [90], en donde un mapa topográfico se convirtió en una nueva forma de presentar los 
datos resultantes de EEG, y los potenciales en un cierto momento o periodo de tiempo son codificados en colores en la correspondiente localización espacial, los puntos en el espacio entre electrodos son calculados por aproximaciones utilizando diversos métodos, siempre en la superficie de la corteza cerebral. Para extrapolar la información eléctrica dentro del espacio intracerebral, se utilizan métodos de solución de problema inverso $[23,29,37]$ a pesar de su baja resolución espacial, en comparación a fMRI. Se siguen buscando métodos para mejorar dicha resolución ya que se cuenta con la ventaja de tener alta resolución temporal, la cual es necesaria para estudiar ciertos padecimientos, tal es el caso de epilepsia. Se prefiere utilizar EEG y no MEG, por el costo y disponibilidad del equipo necesario.

En [19] se presenta un modelo anatómico 3D a partir de imágenes por resonancia magnética, segmentadas a través de intensidad de señales y conectividad de voxeles, además fusionado con información funcional, específicamente con EEG (Figura 2.8), para la implantación de electrodos subdurales durante la operación y con este procedimiento poder localizar el foco de ataques epilépticos. Es decir, se mejora significativamente el alcance de visión del cirujano al tener un esquema de todo el cerebro (visualización 3D), tanto la distribución espacial, como las zonas funcionales etiquetadas (motoras, visuales y sensoriales) que no deben de ser dañadas durante la intervención [68].

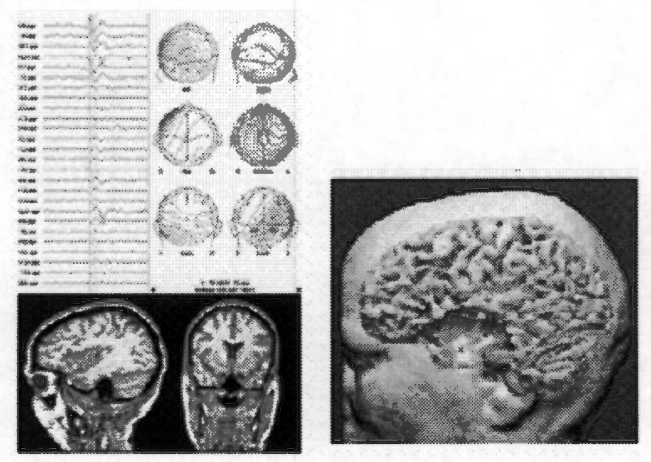

Figura 2.8: Determinación de un foco de ataques epilépticos en la corteza frontotemporal izquierda y la simulación en 3D. 
Según Rutten, y colaboradores [108], aunque se encuentre en proceso de investigación la utilidad clínica de fMRI, ésta presenta un futuro prometedor, con un menor grado de invasividad y mejor resolución espacial, con respecto a EEG y MEG; siendo en algunos casos más apropiada su utilización [108,123].

La factibilidad de usar imágenes por resonancia magnética para el mapeo de actividad neuronal con la técnica de BOLD (blood oxygen level-dependent) fue demostrada por Kwong [73]. Esta técnica presenta una mejor resolución espacial; sin embargo por su baja resolución temporal, se tienen problemas en la detección del origen de la actividad de ataques epilépticos [107].

Las fMRI presentan una resolución espacial de $2-3 \mathrm{~mm}$ y una resolución temporal de 1 - 2 segundos [78]. La relación entre la señal de BOLD con la actividad neuronal sigue en discusión, sobre si la primera es un reflejo de la segunda. Asimismo, si para una actividad determinada entran en juego varias partes del cerebro en coordinación, es muy difícil desarrollar un procedimiento en que sólo actúe una parte en específico.

En la detección de señales negativas y positivas de BOLD, se puede reconstruir toda la información pertinente a las áreas del cerebro involucradas en una actividad. La presencia de señales de BOLD negativo han sido encontradas en zonas adyacentes a regiones que presentan señales de BOLD positivos, estas respuestas negativas han sido atribuidas a la reducción de flujo de sangre en zonas circundantes a las regiones activadas, por lo tanto, la detección de zonas activadas por la tarea es incierta. Otro problema que se encuentra en las fMRI es que la señal BOLD positiva puede extenderse a lo largo de las venas que drenan sangre al tejido del cerebro activado y dichas venas se pueden extender a lo largo de varios milímetros o hasta centímetros, por lo tanto la identificación del sitio de activación y su comportamiento temporal, está limitada no sólo por la característica de la respuesta hemodinámica, que también por la arquitectura vascular del cerebro [78]. 
En un afán de mejorar la resolución temporal de las imágenes por resonancia magnética funcional (fMRI), en la detección de focos epilépticos, se tiene que la adquisición de dichas imágenes se realiza en coordinación con las señales de EEG (adquisición simultánea), es decir, se utiliza el EEG para el disparo de adquisición de la imagen $[6,8,37,60]$.

Según [123] el problema que tiene la adquisición simultánea de EEG-fMRI, es que en el momento en que el EEG dispara la toma de la imagen, se deja de tener información del registro. Además, por el hecho que las imágenes por resonancia magnética utilizan pulsos de RF, para excitar los tejidos del cerebro, esto introduce picos de interferencia en el registro del EEG. También los electrodos metálicos y especialmente los cables afectan los campos magnéticos haciendo borrosa la imagen en ciertas partes. Tampoco se tiene claro el número de picos de actividad crítica epiléptica que se requieren para obtener una respuesta BOLD significativa y las investigaciones varían en este número desde 4 descargas a $3 \mathrm{~T}$ hasta 20 a $1.5 \mathrm{~T}$, además se presentan cambios significativos de BOLD en solo $40 \%$ a $80 \%$ de los sujetos en estudio.

Como se ha visto anteriormente la localización de fuentes epileptógenas puede ser determinada por tres métodos: EEG, MEG y EEG-fMRI. La detección de la señal en MEG, depende de la descarga de una población suficientemente grande de neuronas corticales que deben de estar sincronizadas en tiempo y alineadas en espacio. Para la localización de fuentes con MEG, el problema directo y el problema inverso necesitan ser resueltos con modelos adecuados para poder obtener soluciones aceptables. Aunque la tecnología del MEG es más atractiva que la tecnología del EEG, presenta la desventaja del costo. A parte de la ventaja del EEG sobre el MEG en su portabilidad y comfortabilidad, también presenta la ventaja de que puede servir para el monitoreo en infante, monitoreo de largos períodos de tiempo y algo muy importante es que no es significativo los artefactos por movimientos de 
la cabeza [101].

En [78] se reportan los siguientes problemas en la combinación de EEG-fMRI; en primer lugar es incierto pensar que las señales de EEG y fMRI están estrechamente correlacionadas, ya que el EEG busca la actividad eléctrica neuronal determinada, y la fMRI detecta efectos hemodinámicos con énfasis en la macrovasculatura. En segundo lugar, las señales de EEG no sólo pierden sensibilidad con la profundidad de la fuente en el cerebro, sino que también están influenciadas por la orientación de las neuronas en los diferentes tejidos, entonces las regiones detectadas por las fMRI pueden generar señales no detectadas por el EEG. La más importante desventaja de la fMRI o la combinación de esta técnica con EEG, es su baja resolución temporal, si se quiere utilizar para detectar fuentes epileptógenas, además esta combinación de técnicas tiene un desajuste espacio-temporal debido a que la señal BOLD es una respuesta fisiológica de la estructura cerebral y no es dependiente de la sincronización y alineamiento de la actividad neuronal en lo cual está basado el EEG [101].

Podemos concluir que la precisión de localización de fuentes por medio de EEG depende del modelo de volumen conductor de cabeza, el modelo de fuentes de corriente utilizado y el método empleado en la solución del problema inverso, por lo que, nuestro trabajo está centrado en mejorar la precisión de localización de fuentes a través de una nueva metodología, que utilice un método de solución de problema inverso preciso, un modelo de fuentes de corriente distribuida $\mathrm{y}$, sobretodo, el planteamiento de un modelo realista de volumen conductor, para seguir contribuyendo en el mejoramiento de la resolución espacial del EEG, por su principal característica de no invasiva, y es la prueba diagnóstica fundamental y la más clásica para la epilepsia. 


\section{Capítulo 3}

\section{Generación, Modelado y Estimación de la Actividad Eléctrica del Cerebro}

\subsection{Origen Fisiológico de la actividad eléctrica cere- bral.}

El cerebro es una estructura altamente compleja, organizada en materia gris y materia blanca, ésta última generalmente considerada como soporte. La materia gris está formada por neuronas (su número está estimado en el rango de $10^{11}-10^{12}$ ) y es la parte activa del cerebro, donde se procesa toda la información y se toman las decisiones, en un nivel consciente o inconsciente. Desde un punto de vista anatómico, el cerebro esta dividido en lóbulos, y la capa exterior del cerebro es llamada corteza cerebral, la cual es una red altamente densa de neuronas interconectadas. El fenómeno de transmisión de información de una neurona a otra, se llama sinapsis [38]. 

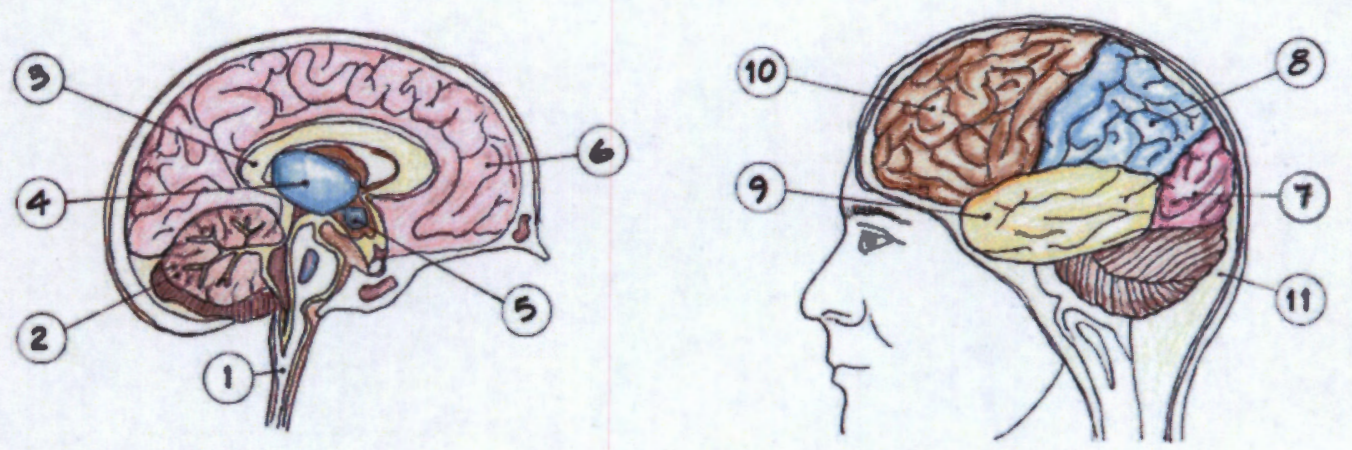

Figura 3.1: Diversas estructuras cerebrales. 1. Médula, 2. Cerebelo, 3.Cuerpo Calloso, 4. Tálamo, 5. Hipotálamo, 6. Corteza Cerebral, 7. Lóbulo Occipital, 8. Lóbulo Parietal, 9. Lóbulo Temporal, 10. Lóbulo Frontal, 11. Líquido Cefalorraquídeo.

La neurona se compone de tres partes importantes, cuerpo de la célula, usualmente llamado soma, las dendritas y el axón. Las dendritas sirven como receptores de la información generada en la sinápsis por otras neuronas a través de neurotransmisores químicos. El contacto de los neuro-transmisores con las membranas de la célula actúan en los canales de Sodio y Potasio, liberando un flujo de iones y produciendo los potenciales post-sinápticos (PPS). Los PPS pueden ser excitatorios o inhibitorios, y su contribución espacial y/o temporal incrementa el potencial de la membrana arriba del umbral de disparo que es cuando en la neurona se genera un potencial de acción (PA), el cual se propaga a lo largo del axón hacia otras neuronas, liberando a los neuro-transmisores en el área de la sinápsis, para que puedan reaccionar después de un tiempo.

Desde el punto de vista de la física, los PPS pueden ser modelados como dipolos de corriente, los cuales presentan un potencial de campo eléctrico dipolar, dicho potencial decrece con el cuadrado de la distancia a la fuente. Por otro lado, el potencial de acción se propaga en el axón, debido a la simetría circular de éste, presentando un campo eléctrico cuadripolar que se decrementa con el cubo de la distancia. Considerando también la duración de los PPS ( $\sim 10 \mathrm{~ms})$ y de los PA ( $1 \mathrm{~ms})$, 
es fácil concluir que el EEG en el cuero cabelludo no es producido por la propagación de información (PA), sino que es debido a la contribución temporal y espacial de los PPS en la membrana celular. De hecho, se requiere la sincronización de los PPS de un gran número de neuronas $\left(10^{5}\right.$, lo cual cubre $1 \mathrm{~mm}^{2}$ de la superficie cortical) para producir un campo que se pueda medir en la superficie del cráneo.

Consecuentemente, el modelo de la actividad eléctrica del cerebro más utilizado es el modelo de dipolos de corriente. Sin embargo, es posible modelar a través de una organización estructurada de un número más grande de dipolos, simplificando la descripción del modelo a través de fuentes de corriente distribuidas.

\subsubsection{Modelo Físico.}

En la sección previa la actividad eléctrica del cerebro fue descrita por fuentes de corriente; por lo tanto, el potencial eléctrico producido por una fuente de corriente $\boldsymbol{J}$ en un medio homogéneo isotrópico infinito, está dado por:

$$
\Phi(\boldsymbol{r})=\frac{\langle\boldsymbol{J}, \boldsymbol{r}\rangle}{4 \pi \sigma\|\boldsymbol{r}\|^{3}}
$$

donde $\boldsymbol{r}$ denota la posición de el punto donde se mide con respecto a la posición de la fuente de corriente, $\sigma$ es la conductividad eléctrica del medio, y \langle\rangle representa el producto escalar entre los dos vectores. El potencial eléctrico en un medio conductor no homogéneo y anisotrópico, tal como la cabeza humana, es menos sencillo y podría ser modelado para cada cabeza humana específica.

\subsubsection{Ecuaciones que describen el fenómeno eléctrico dentro de la cabeza.}

El campo electromagnético $(\boldsymbol{E}, \boldsymbol{B})$ en un medio isotrópico lineal con permitividad eléctrica $\varepsilon$ y permitividad magnética $\mu$, está determinado por las ecuaciones de 
Maxwell:

$$
\begin{gathered}
\nabla \cdot \boldsymbol{E}=\frac{\rho}{\varepsilon} ; \quad \nabla \times \boldsymbol{E}=-\frac{\partial \boldsymbol{B}}{\partial t} \\
\nabla \cdot \boldsymbol{B}=0 ; \quad \nabla \times \boldsymbol{B}=\mu\left(\boldsymbol{j}+\varepsilon \frac{\partial \boldsymbol{E}}{\partial t}\right)
\end{gathered}
$$

donde $\boldsymbol{j}$ es la densidad de corriente eléctrica, y $\nabla \cdot$ y $\nabla \times$ son los operadores de divergencia y rotor, respectivamente.

Se considera la cabeza humana como un medio conductor no-polarizado $\left(\varepsilon \simeq \varepsilon_{0}\right.$, permitividad eléctrica del vacío), no-magnético ( $\mu \simeq \mu_{0}$, permitividad magnética de vacío), y libre de cargas $(\rho=0)$. En este caso la densidad de corriente $\boldsymbol{J}$ puede ser descrita como la combinación lineal de una fuente de corriente primaria $\boldsymbol{J}_{P}$ y una fuente de corriente secundaria (corriente óhmica) [38]:

$$
\boldsymbol{J}=\boldsymbol{J}_{P}+\sigma \boldsymbol{E}
$$

Ya que la densidad de carga eléctrica es nula, la divergencia de $J$, la cual mide la variación de la densidad de carga, es también nula:

$$
\nabla \cdot \boldsymbol{J}=0
$$

Es necesario también tomar en cuenta que las mediciones se realizan en condiciones electrostáticas, es decir, que todas las derivadas con respecto al tiempo en las ecuaciones de Maxwell se desprecian. Entonces el rotor de $\boldsymbol{E}$ es nulo, lo que significa que el campo eléctrico $\boldsymbol{E}$ puede ser escrito como el gradiente de un potencial eléctrico escalar $\Phi$ :

$$
\boldsymbol{E}=-\nabla \Phi
$$

Por lo tanto, el potencial eléctrico expresado en función de la densidad de corri- 
ente, queda determinado por:

$$
\nabla \cdot(\sigma \nabla \Phi)=\nabla \cdot J_{P}
$$

Para un medio conductor homogéneo infinito, se particulariza la ecuación de Poisson, donde la divergencia de la fuente de corriente primaria produce una densidad de carga virtual:

$$
\nabla^{2} \Phi=\nabla \cdot J_{P}
$$

donde $\nabla^{2}$ es el operador laplaciano.

El problema de encontrar $\Phi$, en un modelo de volumen conductor de cabeza humana, a partir de la Ec. 3.6 dada una distribución de fuentes de corriente primaria $\boldsymbol{J}_{P}$ determinada, se conoce como problema directo del EEG, mientras que encontrar $\boldsymbol{J}_{P}$ a partir de un potencial eléctrico medido en el cuero cabelludo, se conoce como problema inverso del EEG.

Principio de Superposición El campo eléctrico producido por una conFigura ción de fuentes es igual a la suma de los campos eléctricos producidos por cada fuente independientemente.

El principio de superposición es una consecuencia de la naturaleza lineal de las ecuaciones de Maxwell (Ec. 3.2). En el caso del EEG esto puede ser observado directamente en la Ec. 3.6. Si $\boldsymbol{J}_{P}$ se denota como la suma de fuentes de corriente independientes $J_{P}^{k}$, entonces $\Phi^{k}$ está dado por la solución de la Ec. 3.6 para cada fuente de corriente, es decir:

$$
\nabla \cdot\left(\sigma \nabla \Phi^{k}\right)=\nabla \cdot J_{P}^{k}
$$

Entonces la suma de los potenciales $\Phi^{k}$ es la solución de la Ec. 3.6 para una 
conFigura ción de fuentes $\boldsymbol{J}_{P}$ :

$$
\nabla \cdot\left(\sigma \nabla \sum \Phi^{k}\right)=\sum \nabla \cdot\left(\sigma \nabla \Phi^{k}\right)=\sum \nabla \cdot J_{P}^{k}=\nabla \cdot \sum J_{P}^{k}=\nabla \cdot J_{P}
$$

Consecuentemente, para resolver el problema directo no es necesario resolver la Ec. 3.6 para una conFigura ción compleja de fuentes, sino que se puede encontrar la solución para cada fuente específica y entonces simplemente sumar la contribución de cada una.

En los últimos años se han realizado muchas investigaciones en el área de localización de fuentes epileptógenas a través del EEG, como se mencionó en el Capítulo 2. Existen algunas técnicas de inferencia que involucran la inspección visual de las series de tiempo del EEG o topografía del voltaje en el cuero cabelludo; estos métodos son ampliamente utilizados en la clínica, pero solo proveen una vaga indicación de la naturaleza de la actividad epiléptica que presenta el paciente. Es incuestionable la necesidad de una mejor aproximación para recuperar la información inmersa en los datos de EEG. Cualquier procedimiento para localización de fuentes necesariamente requiere del uso de modelos de las fuentes de potenciales eléctricos cerebrales y del medio conductor (la cabeza), en el cual, la señal biológica se propaga.

\subsection{Modelo de fuentes de corriente dentro del cere- bro.}

\subsubsection{Modelo de fuentes de dipolo equivalente.}

Existe un sólido argumento fisiológico que soporta la suposición que dipolos de corriente pueden aproximar adecuadamente el campo eléctrico producido por una región de células de actividad cortical. Ya que se conoce que los electrodos en el 
cuero cabelludo detectan la magnitud y la orientación neta del campo eléctrico de un grupo de neuronas excitadas dentro del cerebro. De hecho existen señales significativas de algunas células que se cancelan con las señales de otras células con orientación opuesta (por ejemplo, células que pertenecen a diferentes capas de la superficie cortical). Por lo tanto, el modelar las fuentes con dipolo equivalente es apropiado, porque los potenciales del EEG que podrían ser simulados por el dipolo son bastante similares a los que se producen por una agregación de neuronas extendidas sobre varios centímetros cuadrados $[30,106]$. La localización tridimensional y la orientación de un dipolo equivalente es indicativo del centro geométrico y la orientación neta de la región de actividad cortical, respectivamente. A partir de que diferentes combinaciones complejas de generadores corticales pueden emitir señales traslapadas en el tiempo, se vuelve necesario desarrollar modelos de fuentes más complejos que tomen en cuenta tal actividad cerebral, entonces han surgido diversas modalidades del modelo de fuentes por dipolo equivalente, donde dipolos equivalentes espacio-temporales, son analizados. En cualquier caso, es importante notar la habilidad que el modelo de dipolo equivalente tiene de sumar cualquier distribución de dipolos simples para representar cualquier distribución de complejidad arbitraria sobre un determinado período de tiempo y por lo tanto, de representar cualquier tipo de distribución espacial de fuentes bioeléctricas [5].

\subsubsection{Modelo de fuentes de corriente distribuida.}

Alternativamente al modelo de dipolo de corriente, la activación neuronal en un modelo de volumen finito de cabeza puede ser descrita por corrientes volumétricas, las cuales varían en magnitud a través de todos los voxeles dentro del espacio solución. Tal representación de actividad distribuida es encontrada a través de la solución por norma mínima, donde el perfil de la densidad de corriente estimada a través del espacio solución tiene mejor comportamiento para datos de EEG instan- 
táneos o espacio temporales. El método está necesariamente sujeto a limitaciones, tales como suavizado máximo de la solución, asumiendo que el cerebro gasta la mínima energía para producir la señal de EEG medida; tal es el caso de la Tomografía de Baja Resolución (LORETA, Low Resolution Tomography) [95, 96].

Según [27] las fuentes generadoras de ataques epilépticos no están confinadas a un pequeño espacio, sino que están distribuidas en una zona determinada, por lo que, el modelo de fuentes de corriente distribuida es adecuado para estos casos.

\subsection{Problema Directo y Problema Inverso.}

Las neuroimágenes funcionales se dividen en aquellas que utilizan el método de detección de hemodinámica (PET, SPECT, fMRI) y las que utilizan registros de actividad eléctrica (EEG) o magnética (MEG). Para los dos tipos, encontramos numerosas publicaciones que buscan la incorporación de estas técnicas al quehacer clínico, buscando una adecuada técnica de coregistro, entre la información funcional y la información anatómica. Las técnicas que utilizan la detección hemodinámica presentan muy buena resolución espacial, pero una pobre resolución temporal; buscando mejorar esta situación, se han realizado por ejemplo pruebas que buscan registrar fMRI simultáneamente con EEG. Las técnicas de imagenologia funcional se basan en el coregistro de la información anatómica, por ejemplo IRM, con la información funcional proveniente de la adquisición multicanal de EEG y/o MEG, estimando la localización de fuentes electromagnéticas dentro del cerebro, a través de la solución del problema inverso [97].

La localización de fuentes a partir del EEG es el proceso de identificar el origen espacial de una actividad eléctrica en particular dentro del cerebro, basándose en la medición de los potenciales eléctricos registrados en el cuero cabelludo de un paciente. Esto es también conocido como problema inverso en EEG, donde el problema directo constituye el procedimiento opuesto, es decir, el cálculo de los potenciales 
eléctricos inducidos en el cuero cabelludo del paciente por una fuente de corriente.

Las fuentes de corriente neuronales en el cerebro producen campos magnéticos externos y potenciales en la superficie del cuero cabelludo, éstos pueden ser medidos a través de MEG y EEG respectivamente [84]. Los campos de corriente dentro de la cabeza que generan estas señales de EEG y MEG pueden ser separados en dos componentes, el término de la corriente primaria, que representa la corriente celular pasiva microscópica y la corriente volumétrica o secundaria, que es el resultado de los campos eléctricos macroscópicos [86]. Las corrientes primarias constituyen las fuentes de interés en E/MEG, ya que éstas representan las áreas de actividad neuronal asociada con los procesos cognitivos, motores o sensoriales del cerebro. La localización de las áreas corticales generadoras de ciertos procesos es de interés para el correcto diagnóstico en diversas patologías, por ejemplo, en el tratamiento quirúrgico de epilepsia, es importante la localización exacta de los generadores de actividad crítica, antes de un procedimiento quirúrgico, para no dañar áreas elocuentes; en el afán de lograr una mejor precisión en la localización de fuentes se ha utilizado y se ha tomado como estándar clínico la electrocorticografía, pero este procedimiento presenta la desventaja de ser demasiado invasivo, además de tener un alto costo y presenta cierto riesgo de morbilidad, lo cual limita su uso rutinario [136].

Los potenciales eléctricos registrados en el cuero cabelludo asociados con la corriente intracelular proveen una forma no invasiva de monitorear la evolución espaciotemporal de la actividad neuronal del cerebro humano [27]. En este sentido, la solución del problema inverso del EEG intenta estimar las fuentes de actividad eléctrica neuronales a partir de los registros de potenciales del EEG en cuero cabelludo. El problema es que la medición extracraneal del EEG, no contiene suficiente información acerca de la distribución tridimensional de la actividad eléctrica neuronal, y no existe, por lo tanto, solución única al problema inverso [96]. Son muchos los factores que afectan la solución del problema inverso, uno de ellos es el modelo de volumen 
conductor de la cabeza utilizado para describir el cerebro.

Para EEG se habla de la inversión de la ecuación de Poisson la cual también tiene mucha importancia en diversas aplicaciones de la ingeniería [85]. Es aquí, donde se pueden encontrar diversos métodos para resolver el problema inverso, entre ellos, métodos iterativos que buscan minimizar el error entre los datos de la frontera y la solución del problema directo, o aquellos algoritmos directos que obtienen parámetros de la fuente desde los datos de frontera; pero estos últimos requieren encontrar una relación algebraica entre los parámetros de la fuente y los datos observables. Tanto los métodos directos como los iterativos se derivan de las identidades de Green y la elección de las integrales de frontera.

Entre los algoritmos de solución de problema inverso tenemos aquellos que presentan las características de ser lineales, 3D y discretos; se puede mencionar Norma Mínima (MN, Minimun Norm), Norma Mínima Ponderada (WMN, Weighted Minimun Norm), Backus and Gilbert, Optimización de Resolución Ponderada (WROP, Weighted Resolution Optimization), y LORETA. En [93] se presenta una evaluación de estos cinco algoritmos para la localización de fuentes profundas en 3D, concluyendo que LORETA presenta un buen comportamiento en la localización de fuentes profundas y es el único que se puede considerar como tomografía electromagnética, precisamente, por el grado de profundidad que otorga, no así los demás, que proporcionan soluciones proyectivas. En otro estudio [130] se sometieron a evaluación dos modelos de dipolos móviles (1 y 2 dipolos) y dos métodos de regulación de fuentes distribuidas, el método de Norma Mínima y LORETA [93], cada uno de estos últimos dos con diferentes parámetros de regularización de Tikhonov (ver apéndice A) del algoritmo de mínimos cuadrados $(1.0,1.5$ y 2.0), con datos de EEG simulados y reales, y un modelo de cabeza realista, encontrando que tanto en resolución espacial, exactitud de localización, porcentaje de fuentes no detectadas y porcentaje de fuentes falsamente detectadas, LORETA tiene el mejor comportamiento en es- 
tos campos. Al mejorar el modelo de cabeza, LORETA mejora significativamente la resolución espacial, lo que nos plantea utilizar un modelo de cabeza más exacto que se acople a las diferentes curvaturas del cerebro y que mejore la resolución espacial.

En 2002, Pascual-Marqui [94] presenta un nuevo método de construcción de tomografía eléctrica de actividad neuronal, donde la inferencia de localización se basa en imágenes de densidad de corriente estandarizada. El método se denomina Tomografía Electromagnética de baja resolución estandarizada (sLORETA, Standarized Low Resolution Tomography), y se presenta como un método de error cero de localización para diferentes tipos de orientación y localización de fuentes en profundidad, en ausencia de ruido, tanto para EEG como para MEG. sLORETA utiliza la estimación de la densidad de corriente dada por la solución de norma mínima, y la inferencia de localización está basada en la estandarización de los valores de la densidad de corriente estimada. Algunos autores presentan dudas con respecto al error cero de localización de fuentes inmersas en ruido [122], aunque su desempeño en profundidad es mucho mejor que cualquier otro método lineal presentado antes.

Un método de alta resolución muy prometedor es FOCUSS (Focal Underdetermined System Solver) [50,51]; este algoritmo es un método de WMN que realiza ajustes a la matriz de peso de manera recursiva hasta obtener que más elementos de la solución se acerquen a cero. FOCUSS ha sido aplicado a la solución de problema inverso de EEG y de MEG, tal que debe de converger a una solución rala con un número de fuentes no cero menor que el número de sensores. FOCUSS es un algoritmo apropiado para encontrar pocas fuentes, pero necesita de una inicialización robusta. En [83], se utiliza la solución de norma mínima sin sesgo como inicialización del algoritmo de FOCUSS. Se ha propuesto Shrinking LORETA-FOCUSS (SLOFO) [75], el cual utiliza la solución entregada por LORETA como inicialización para el algoritmo recursivo similar a FOCUSS. Aunque Shrinking LORETA-FOCUSS tiene un mejor desempeño comparado a FOCUSS, ninguno de estos métodos es 
capaz de recuperar las fuentes de actividad eléctrica en una serie de tiempo con exactitud. FOCUSS es básicamente un método de WMN, pero la construcción de la matriz de peso se basa en la estimación de la fuente, entonces se aplican diferentes matrices de peso a diferentes tiempos. Shrinking LORETA-FOCUSS reduce recursivamente el espacio solución tal que para diferentes tiempos se tiene diferente espacio solución. Estos factores no lineales dificultan la aplicación de estos dos algoritmos en una serie de tiempo. Shrinking LORETA-FOCUSS pretende, al igual que SCEA (Self-Coherence enhancement algorithm) [129], mejorar la resolución espacial de las soluciones de los sistemas mal condicionados (en nuestro caso, el problema inverso del EEG), o como algoritmos que utilizan el Laplaciano de los potenciales de superficie [114].

El método Standardized Shrinking LORETA-FOCUSS (SSLOFO) [76] mejora la resolución espacial a través de la estrategia recursiva que utiliza FOCUSS de la estimación demasiado suavizada entregada por sLORETA, la cual es utilizada como la inicialización de dicho algoritmo recursivo. Un proceso muy importante es la estandarización que se aplica para guardar la estimación localizada en regiones con actividad significativa, aunque pueden surgir múltiples regiones, por lo tanto, SSLOFO combina las características de alta resolución espacial que presenta FOCUSS y de baja resolución espacial que nos entrega sLORETA. El algoritmo mejora su desempeño por el ajuste automático del espacio solución. Puede extraer regiones de actividad dominante mientras simultáneamente localiza múltiples fuentes en dichas regiones. El algoritmo mejora sustancialmente el comportamiento de los métodos de baja resolución en la reconstrucción de conFigura ciones de fuentes con diferentes formas en un mismo procedimiento como se observa en la Figura 3.2, donde se aprecia que la cantidad de fuentes falsas que encuentra el método de Norma Mínima Ponderada es bastante alta y la dispersión de las fuentes está sobre todo el espacio solución. Luego, si se utiliza el método de sLORETA, el número de fuentes falsas se 
reduce así como la dispersión de las fuentes y el método encuentra la conFigura ción simulada de fuentes, tanto para el lóbulo occipital como para el lóbulo frontal. La desventaja que presenta el método de FOCUSS es la sub-estimación de fuentes, es decir, sólo encuentra la configura ción de fuentes del lóbulo frontal, para este caso. Ahora bien, la utilización de SSLOFO, encuentra las posición de las dos conFigura ciones de fuentes simuladas sin demasiadas fuentes falsas y sin mucha dispersión, pero no encuentra la forma exacta de las conFigura ciones (círculo, para el lóbulo frontal y triángulo, para el lóbulo occipital).

La definición adaptiva del espacio solución en SSLOFO posibilita una vía conveniente para la integración de la información temporal del comportamiento de las fuentes de actividad eléctrica del cerebro.

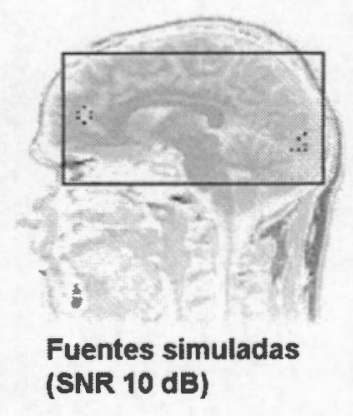

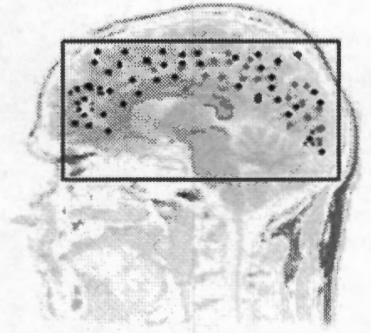

Norma Mínima Ponderada

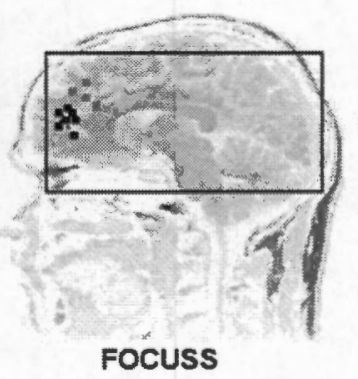

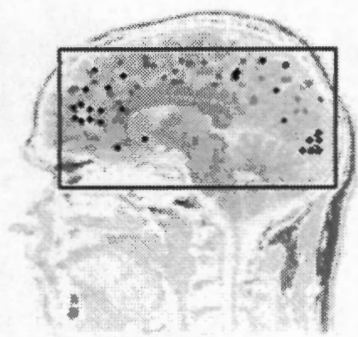

SLORETA

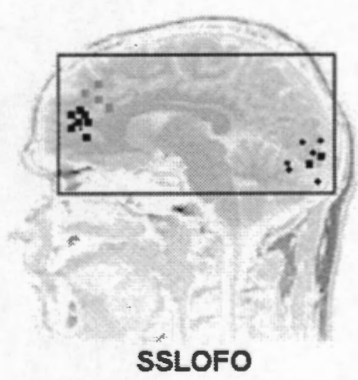

Figura 3.2: Comparación de métodos de solución de problema inverso. [76]

La diferencia entre neuroimágenes funcionales provenientes de la hemodinámica, y aquellas basadas en la localización de fuentes electromagnéticas, es que éstas últimas necesitan de un modelo de volumen conductor del cerebro, en el cual la solu- 
ción del problema inverso se resuelve, sobre un número finito de puntos solución del modelo de cabeza, donde las fuentes de corriente son estimadas. Estos modelos de volumen conductor de cerebro van desde esferas concéntricas [119] o excéntricas [21] con conductividad homogénea, hasta modelos realistas individuales $[7,22,43,71,111]$, que toman en cuenta la geometría de la cabeza con puntos solución restringidos ya sea en la corteza, o en todo el volumen del cerebro, a partir de imágenes por RM o TC.

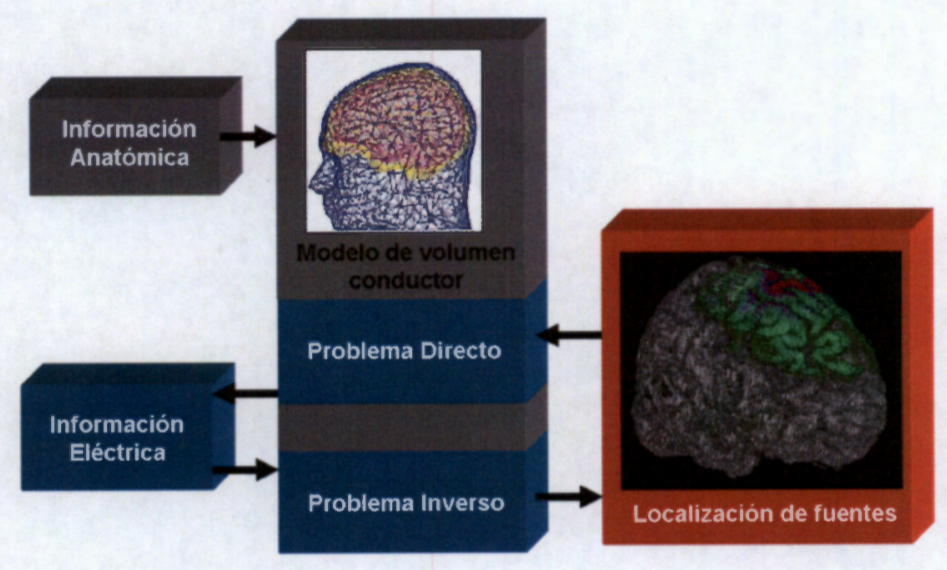

Figura 3.3: Diagrama de bloques de Problema Inverso y Problema Directo.

\subsection{Construcción de modelos anatómicos}

El modelado de las propiedades eléctricas y geométricas del volumen de la cabeza provee una respuesta al problema directo, el cual es prerequisito para la solución del problema inverso.

\subsubsection{Modelos esféricos de volumen conductor de cabeza.}

El primer y mas sencillo modelo de cabeza desarrollado para la localización de fuentes en EEG, fue el modelo de volumen conductor esférico derivado analíticamente. Algunos modelos de este tipo son homogéneos, pero la verdadera aprox- 
imación de un volumen de cabeza demanda que algunas estructuras anatómicas deben ser tomadas en cuenta a través del uso de una esfera no homogénea consistente en tres o cuatro capas concéntricas o excéntricas de diferentes resistividades (para representar el cuero cabelludo, el cráneo, el cerebro, y algunas veces el líquido cefalorraquídeo). Desde hace unos años, es ampliamente conocido que cualquier modelo esférico es demasiado simplificado para la localización exacta de fuentes epileptógenas [2,30,31], por lo que, algunos trabajos presentan el ajuste de potenciales de superficies esféricas a una forma realista de cabeza [110]. Estas técnicas de localización de fuentes pueden ser aceptadas para actividad eléctrica originada en la superficie pero no es exacta cuando se trata de fuentes generadoras profundas dentro del cerebro, donde la forma del cráneo se desvía más de una esfera ideal. Afortunadamente, el modelo esférico analítico sirve como el estándar de oro contra el cual debe de ser evaluado el comportamiento de cualquier modelo de volumen conductor numérico realista.

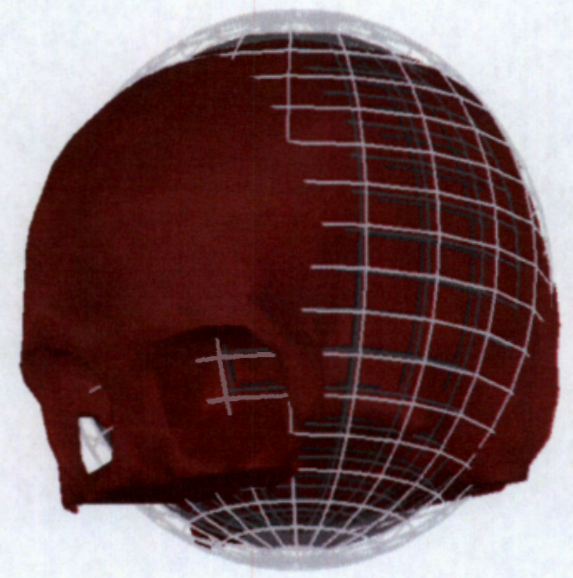

Figura 3.4: Modelo esférico de cabeza inscritos dentro del cráneo humano. 


\subsubsection{Modelos realistas de volumen conductor de cabeza.}

Desde hace varios años se han evaluado muchos modelos de volumen conductor realista de cabeza para localización de fuentes [37]. En contraste al modelo esférico, son necesarios muchos pasos cuando utilizamos un modelo realista. Primero, tener información anatómica del paciente (IRM o TC). Segundo, segmentar dichas imágenes con el objetivo de poder extraer la superficie y/o las diferentes estructuras que componen el cerebro. Es aquí donde nos encontramos con el problema de requerir un algoritmo de segmentación robusta, para determinar con precisión la materia gris (espacio de solución). Tercero, la superficie del cerebro debe de ser geométricamente descrita, ya sea a través de un mallaje, o a través de una descripción paramétrica. Cuarto, se debe utilizar un digitalizador para determinar la localización de los electrodos y registrar estas posiciones a través de marcas fiduciales especiales etiquetadas en las imágenes por resonancia magnética. Por último, cuando se cuenta con toda la información anatómica, se utilizan diversos métodos numéricos para resolver el problema directo en el modelo realista. Para la solución del problema directo encontramos básicamente cuatro métodos: a) Método de diferencias finitas, que remplaza las derivadas por diferencias finitas. b) Método de elemento frontera (BEM, Boundary Element Method), basado en la reformulación del problema como una ecuación de integral de superficie. c) Método de elemento finito (FEM, Finite Element Method), el cual divide el volumen en tetraedros, permitiendo considerar anisotropía del medio y d) Métodos proyectivos, donde encontramos el método sin malla (Meshless Method, o Free-Galerkin Method), que describe a los potenciales o campos magnéticos como combinación de funciones base ponderadas [12]. Para BEM y FEM la conexión entre los nodos se convierte en un procedimiento de alto costo computacional y por ende, de tiempo, además de que la elección de nodos debe de guardar una regularidad [25]. El método sin mallas, que es el propuesto en nuestro trabajo, alivia dichas complicaciones, ya que no requiere ninguna conexión 
entre los nodos.

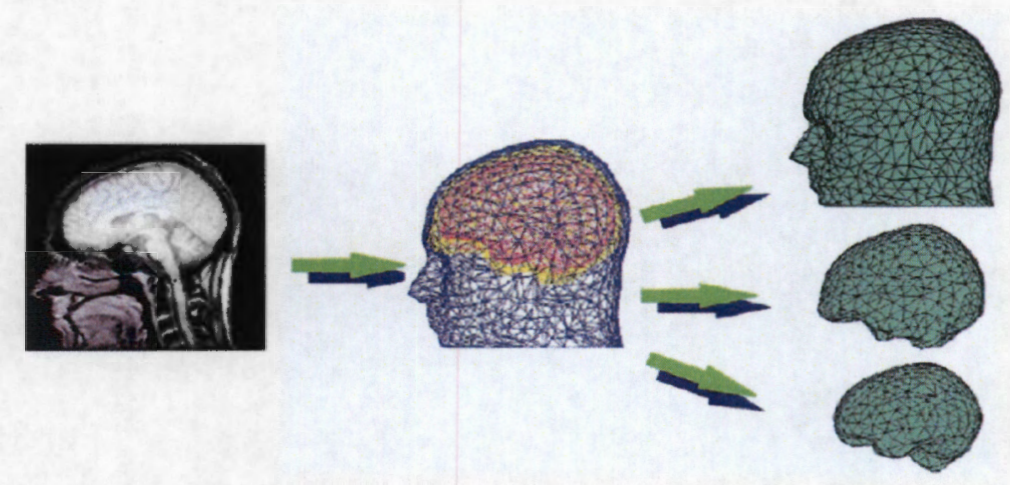

Figura 3.5: Modelo realista de volumen conductor a través de BEM. [56]

\subsubsection{Matriz de campo (LFM, Lead Field Matrix)}

El problema directo relaciona el momento de la corriente dipolar $q$ en la posición $\boldsymbol{r}_{q}$ con el potencial de superficie $\Phi(\boldsymbol{r})$ en la posición $\boldsymbol{r}$. Bajo la suposición de que la cabeza es representada como una superficie de múltiples capas homogéneas no intersectadas de conductividad isotrópica constante, el potencial de superficie en todas las fronteras puede ser encontrado utilizando el teorema de Green.

$$
\begin{aligned}
& \sigma_{0} \Phi_{\infty}(\boldsymbol{r})=\frac{\sigma_{\perp}^{-}+\sigma_{l}^{+}}{2} \Phi(\boldsymbol{r})+ \\
& \frac{1}{4 \pi} \sum_{i=1}^{m}\left(\sigma_{l}^{-}+\sigma_{l}^{+}\right) \int_{S_{i}} \Phi\left(\boldsymbol{r}^{\prime}\right) n_{i}\left(\boldsymbol{r}^{\prime}\right) \cdot \frac{\boldsymbol{r}-\boldsymbol{r}^{\prime}}{\left\|\boldsymbol{r}-\boldsymbol{r}^{\prime}\right\|^{3}} d \boldsymbol{r}^{\prime} \quad \boldsymbol{r} \in S_{i}
\end{aligned}
$$

donde $r^{\prime}$ representa la localización de la fuente, $\sigma_{l}^{-}$y $\sigma_{l}^{+}$representan la conductividad dentro y fuera de la $l$-esima superficie respectivamente, $n_{i}\left(r^{\prime}\right) d r^{\prime}$ es el elemento vector de la superficie $S_{i}$ orientado hacia afuera a lo largo del vector normal unitario de $S_{i}$, y $\Phi_{\infty}(r)$ el potencial debido a las cargas primarias, por lo tanto, para un medio homogéneo infinito de conductividad $\sigma_{0}$ debido a una corriente primaria $j_{p}\left(r^{\prime}\right)$, el potencial queda definido como: 


$$
\Phi_{\infty}(\boldsymbol{r})=\frac{1}{4 \pi \sigma_{0}} \int_{G} \boldsymbol{j}_{p} \cdot \frac{\boldsymbol{r}-\boldsymbol{r}^{\prime}}{\left\|\boldsymbol{r}-\boldsymbol{r}^{\prime}\right\|^{3}} d \boldsymbol{r}^{\prime}
$$

donde la integral está evaluada sobre un volumen cerrado $G$. La Ec. 3.11 es la integral de segundo orden de Fredholm para el potencial de supericie $\Phi(\boldsymbol{r})$. Para el caso especial donde la geometría de la superficie es esférica, existen soluciones analíticas conocidas [54].

La matriz de campo para medio homogéneo infinito queda determinada por:

$$
k_{\infty}\left(\boldsymbol{r}, \boldsymbol{r}^{\prime}\right)=\frac{1}{4 \pi \sigma_{0}} \frac{\left(\boldsymbol{r}-\boldsymbol{r}^{\prime}\right)}{\left\|\boldsymbol{r}-\boldsymbol{r}^{\prime}\right\|^{3}}
$$

Por lo tanto el vector de potenciales en la superficie $\boldsymbol{\Phi}$ debido a un vector de densidades de corriente $\boldsymbol{J}$, localizados en todos los nodos del volumen, que irradian en un medio homogéneo infinito, queda determinado por:

$$
\Phi_{\infty}=K_{\infty} \boldsymbol{J}
$$

En varias investigaciones realizadas en los últimos años, se han determinado con precisión la matriz de campo para una geometría de superficie esférica [36, 84] y matrices de campo a través de la descripción de un volumen realista por medio de BEM [84,103], y por medio de FEM [3,116]; pero hasta el momento nadie ha establecido una matriz de campo que permita la solución del problema inverso cuando el volumen se modela a través del Método sin Malla o también conocido como Free Galerkin Method [137].

Para la solución del problema inverso del EEG debemos construir la matriz de campo, que relaciona la posición de los electrodos con respecto a la posición de los voxeles del espacio solución; por lo tanto, se vuelve necesario contar con un método de segmentación robusto que garantice que dicho espacio solución comprenda a toda la materia gris del cerebro. Además debemos de evaluar diversos métodos de solución 
del problema inverso para encontrar el que mejores resultados nos otorgue.

La motivación de este trabajo parte de un convenio interinstitucional con el sector Salud de México, cuyo objetivo es proporcionar herramientas de planeación quirúrgica útiles en el ambiente clínico.

\subsection{Objetivos de la Tesis.}

La motivación de este trabajo parte de un convenio interinstitucional con el sector Salud de México, cuyo objetivo es proporcionar herramientas de planeación quirúrgica útiles en el ambiente clínico.

La metodología propuesta en esta tesis, para la solución del problema inverso en EEG, busca cubrir los objetivos establecidos para nuestra investigación, dichos objetivos fueron:

- Desarrollar un modelo estructural cerebral para apoyo en la planeación de neurocirugías.

- Integrar herramientas de análisis de información funcional, extraídas de la actividad eléctrica cerebral, en la planeación de neurocirugías.

- Desarrollar un sistema de planeación de neurocirugías que combine información anatómica y funcional, en el cual se muestre las fuentes generadoras de potencial eléctrico localizadas con una buena precisión. 


\section{Capítulo 4}

\section{Metodología propuesta para la}

\section{solución del problema inverso del}

\section{EEG}

La metodología empleada en el presente trabajo puede ser resumida como:

1. Segmentación de imágenes por resonancia magnética para la clasificación de los voxeles que pertenecen a la materia gris, y que serán utilizados como el volumen solución del problema inverso.

2. Construcción de la matriz de campo realista a través del método sin malla para diferentes parámetros y construcción de la matriz de campo para medio homogéneo infinito.

3. Estimación de la Solución del problema inverso a través de sLORETA, SLOFO y SSLOFO.

4. Simulación de registros de EEG, siendo la variable manipulada la localización de la fuente de corriente generadora, para una conFigura ción estándar 10-20 de 64 electrodos. 


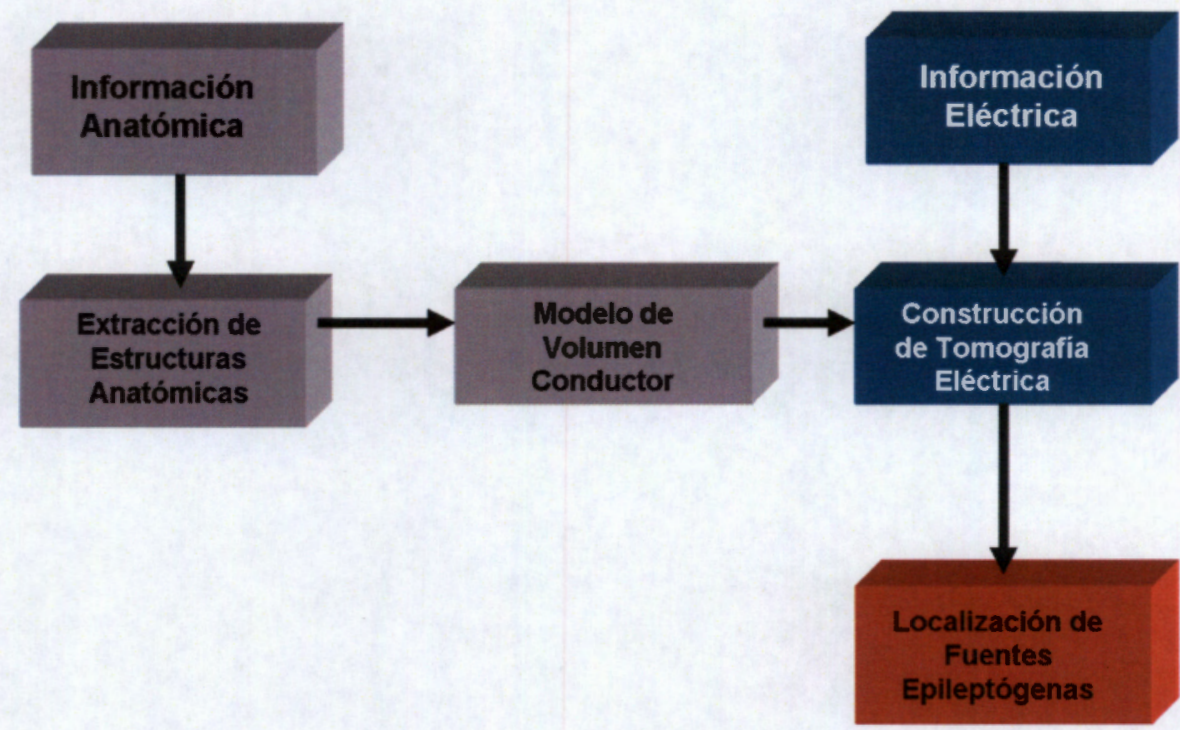

Figura 4.1: Diagrama de bloques del procedimiento utilizado en la implementación del sistema.

En la Figura 4.1 se puede visualizar el diagrama de bloques de la metodología utilizada en nuestro trabajo.

\subsection{Segmentación de imágenes.}

La información anatómica necesaria para la construcción del modelo de volumen conductor, se obtuvo a partir de imágenes por resonancia magnética del sitio IBSR (Internet Brain Segmentation Repository) [41] de Internet, para luego ser segmentadas a través del método de Corrimiento de Media ponderado con mapas de confianza, reportado en [61]. Este procedimiento de segmentación de estructuras cerebrales de imágenes por resonancia magnética utiliza una técnica de estimación no-paramétrica, basada en el algoritmo de corrimiento de media, que usa las modas locales de la función de densidad en el espacio conjunto espacial-intensidad para definir los centros de las agrupaciones. El corrimiento de media ha probado ser robusto en presencia de diferentes niveles y tipos de ruido y no supone la forma de la 
función de densidad de probabilidad de los datos. La calidad de las fronteras entre regiones segmentadas se mejora incluyendo un mapa que representa la confianza de estar verdaderamente en presencia de una frontera entre regiones adyacentes. La medida de confianza también se usa para fusionar regiones con fronteras débiles, a través de la aplicación iterativa de operaciones de cerradura transitiva en un grafo de adyacencias de región. La fusión se termina con un proceso de podado para eliminar las regiones muy pequeñas. La clasificación automática de las regiones, encontradas por corrimiento de media, en materia blanca, materia gris y líquido cefalorraquídeo se realiza aplicando conocimiento a priori contenido en un atlas digital probabilístico de cerebro. La metodología utilizada en este procedimiento de segmentación se encuentra descrita en el Anexo C.

En la Figura 4.2 se muestra un ejemplo de varias rebanadas de un estudio de IRM segmentado por el procedimiento descrito anteriormente. Las estructuras segmentadas presentan un índice de similitud (Tanimoto) de 0.737 para Materia Gris, 0.805 para Materia Blanca y 0.622 para Líquido Cefalorraquídeo, con respecto a la segmentación manual realizada por el experto. El espacio solución que fué utilizado para la construcción del modelo de volumen conductor de cabeza, fueron los voxeles que pertenecen a materia gris. 
Capítulo 4. Metodología propuesta para la solución del problema inverso del EEG
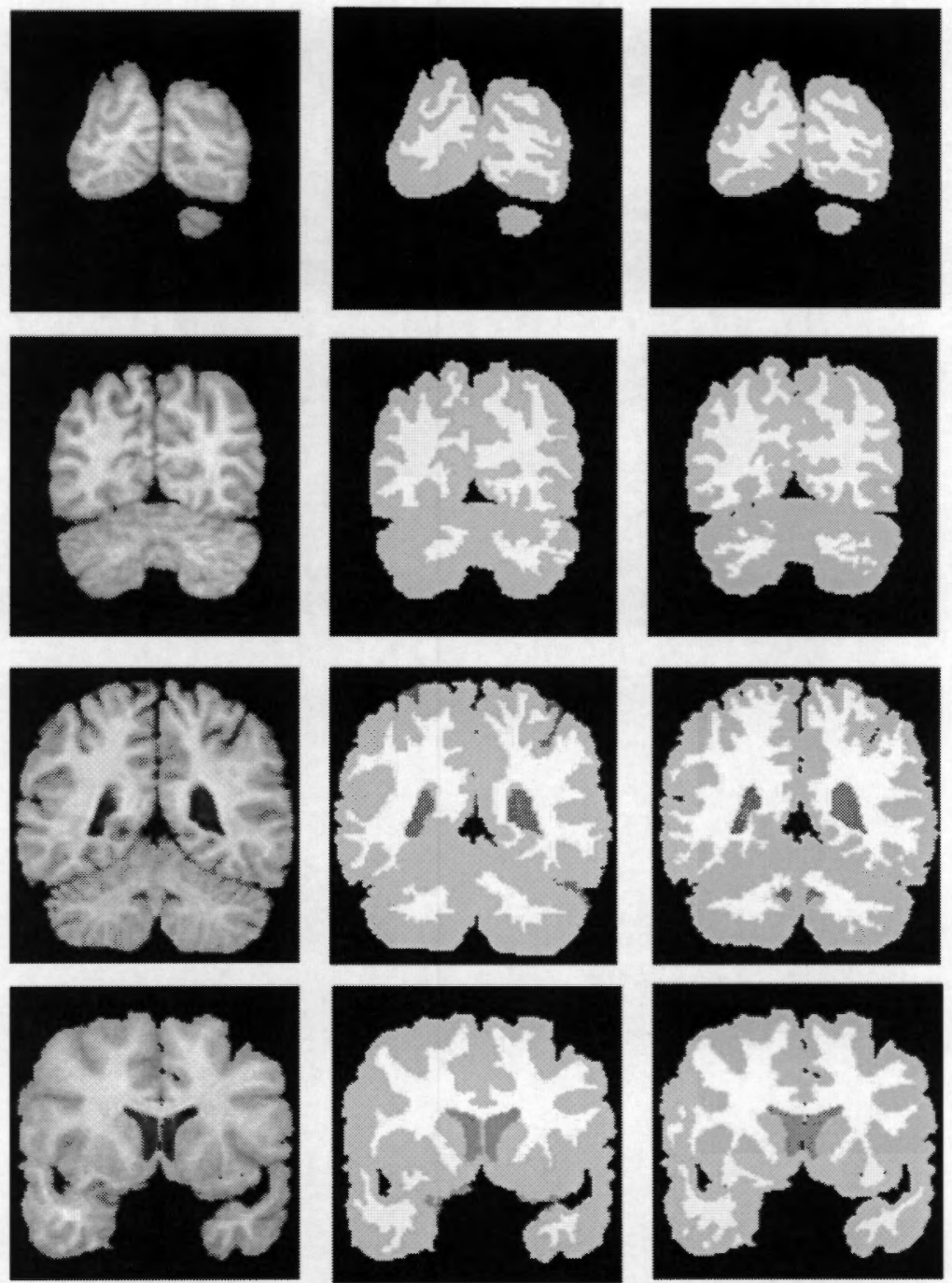

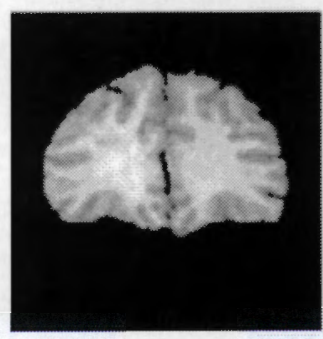

(a)

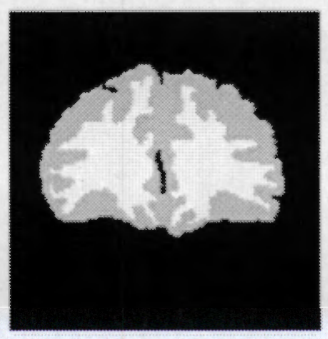

(b)

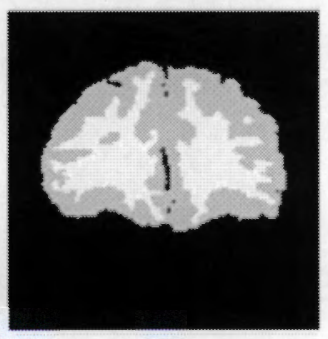

(c)

Figura 4.2: Ejemplos de segmentacion de imagenes reales. Rebanadas de diferentes volumenes mostrando en la columna (a) las imagenes originales, en (b) los resultados de la segmentacion por Corrimiento de media, y en (c) las clasificaciones manuales por el experto. [62] 


\subsection{Construcción de la matriz de campo realista}

\subsubsection{Problema Directo.}

En la estimación del potencial eléctrico registrado en la superficie de un cuerpo tridimensional conductor de forma arbitraria y con conductividad homogénea, generado por una distribución de fuentes dentro de dicho cuerpo, el tamaño y el comportamiento electromagnético del cuerpo, para nuestro caso el cerebro, nos permite utilizar una aproximación quasi-estática de las ecuaciones de Maxwell [54]. Se denotará a $\Omega_{G}$ como la región del espacio ocupada por el cuerpo y a $\partial \Omega_{G}$ la frontera de dicho cuerpo. ver Figura 4.3.

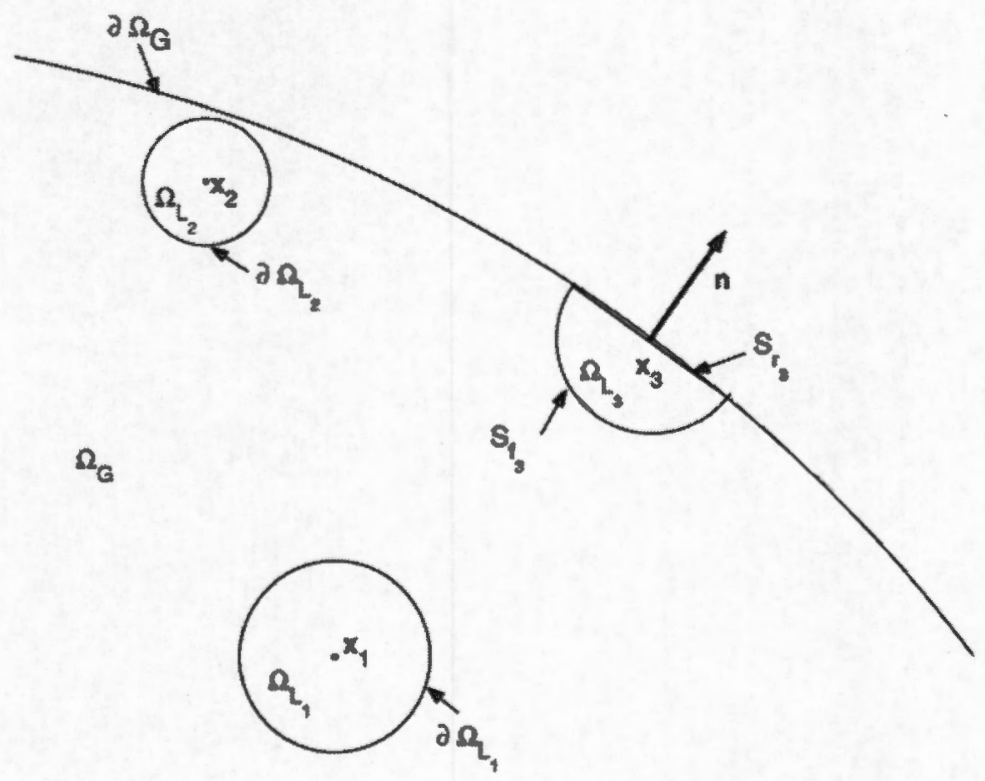

Figura 4.3: Esquema del problema electromagnético. [33]

Según Ellenrieder [32-34] el potencial eléctrico en una posición $\boldsymbol{r}$ puede plantearse como la superposición de dos términos $\Phi(\boldsymbol{r})=\Phi_{F}(\boldsymbol{r})+\Phi_{N}(\boldsymbol{r})$; el primero es el potencial debido a las fuentes de corriente primaria y el segundo debido a las fuentes de corriente secundarias o volumétricas. El problema directo del EEG tiene condi- 
ciones de frontera de Neumann, es decir, la componente del flujo normal a través de la superficie de la superficie del cuerpo que contiene una fuente de corriente, es cero. Planteando el problema de forma diferencial, resulta:

$$
\begin{aligned}
& \nabla^{2} \Phi_{F}(\boldsymbol{r})=\nabla^{2} \Phi(\boldsymbol{r})=\nabla \cdot(q \delta(\boldsymbol{r}-\boldsymbol{p})) \\
& \nabla^{2} \Phi_{N}(\boldsymbol{r})=0 \\
& \left.\nabla \Phi_{N}(\boldsymbol{r}) \cdot \boldsymbol{n}\right|_{\partial \Omega_{G}}=-\left.\nabla \Phi_{F}(\boldsymbol{r}) \cdot \boldsymbol{n}\right|_{\partial \Omega_{G}}
\end{aligned}
$$

donde, $q$ y $\boldsymbol{p}$ son la magnitud y la posición de la fuente encerrada en el cuerpo respectivamente; el término $\Phi_{F}(r)$ corresponde al potencial eléctrico en el punto $\boldsymbol{r}$ producido por dicha fuente, en un medio homogéneo infinito. Este término y su gradiente proyectado sobre la normal pueden ser calculados analíticamente, el término que debe ser calculado numéricamente es $\Phi_{N}(r)$, y corresponde a la ecuación de Laplace con condiciones de frontera de Neumann cuya solución es más suave que la solución original al problema.

En la utilización del método de integrales de frontera, se colocan nodos en los puntos $x_{i}$ tanto dentro, como en la superficie del cuerpo, asociando a cada nodo una ecuación que describa el potencial en dicho nodo. Por lo tanto, se tiene un sistema lineal de ecuaciones que representa el sistema a resolver, cuya solución es un vector de potenciales en todos los nodos. Estas ecuaciones relacionan el potencial $\Phi$ de cada nodo $i$ en una región, con los nodos cercanos al punto en interés, llamada región de influencia (ROI). Para simplificar los cálculos se eligen ROI esféricas, tal que cada una de ellas es subconjunto del volumen del cuerpo $\left(\Omega_{L_{i}} \subset \Omega_{G}\right)$, y la unión de todas es el volumen total del cuerpo $\left(U \Omega_{L_{i}}=\Omega_{G}\right)$.

El potencial eléctrico de un nodo debido a corrientes secundarias, se puede expresar a través de la primera identidad de Green, obteniendo la siguiente expresión: 


$$
\begin{aligned}
\Phi_{N}\left(\boldsymbol{r}_{i}\right)= & \int_{\partial \Omega_{L_{i}}} \psi\left(\boldsymbol{r}_{i}, \boldsymbol{r}^{\prime}\right) \nabla^{\prime} \Phi_{N}\left(\boldsymbol{r}^{\prime}\right) \cdot \boldsymbol{n} d S^{\prime}- \\
& \int_{\partial \Omega_{\Sigma_{i}}} \Phi_{N}\left(\boldsymbol{r}^{\prime}\right) \nabla^{\prime} \psi\left(\boldsymbol{r}_{i}, \boldsymbol{r}^{\prime}\right) \cdot \boldsymbol{n} d S^{\prime}- \\
& \int_{\Omega_{L_{i}}} \psi\left(\boldsymbol{r}_{i}, \boldsymbol{r}^{\prime}\right) \nabla^{2} \Phi_{N}\left(\boldsymbol{r}^{\prime}\right) d^{3} \boldsymbol{r}^{\prime}
\end{aligned}
$$

donde, $r^{\prime}$ es la posición de cada punto que rodea al nodo, $\boldsymbol{r}_{i}$ es la posición del nodo, $\boldsymbol{n}$ es el vector normal a la superficie y $\psi\left(\boldsymbol{r}_{i}, \boldsymbol{r}^{\prime}\right)$ denota la función fundamental para obtener la solución única a la ecuación de Poisson que describa el sistema. Dicha función fundamental está dada por:

$$
\psi\left(\boldsymbol{r}_{i}, \boldsymbol{r}^{\prime}\right)=\frac{1}{4 \pi\left|\boldsymbol{r}_{i}-\boldsymbol{r}^{\prime}\right|}-\frac{1}{4 \pi r_{0}}
$$

$r_{0}$ denota el radio de la esfera que rodea al nodo. La función fundamental debe cumplir las siguientes condiciones:

$$
\begin{gathered}
\nabla^{2} \psi\left(\boldsymbol{r}, r^{\prime}\right)=-\delta\left(\boldsymbol{r}-\boldsymbol{r}^{\prime}\right) \\
\left.\psi\right|_{\partial \Omega_{L}}=0
\end{gathered}
$$

Por lo tanto, para nodos internos, relacionando las Ecs. $4.1,4.2$ y 4.4, se tiene :

$$
4 \pi \Phi_{N}\left(\boldsymbol{r}_{i}\right)=\frac{1}{r_{0 i}^{2}} \int_{\partial \Omega_{L_{i}}} \Phi_{N}\left(\boldsymbol{r}^{\prime}\right) d S^{\prime}
$$

Para nodos en la superficie del cuerpo, la región $\Omega_{L_{i}}$ queda definida como la intersección entre la esfera y el dominio $\Omega_{G}$ (ver Figura 4.3); por lo tanto, la frontera de la región local para nodos de la superficie estará formada por $\partial \Omega_{L}=S_{f} \cup S_{r}$, donde $S_{f}$ es la superficie que corresponde a la media esfera dentro del volumen del cuerpo y $S_{r}$ es la circunferencia que pertenece a la frontera real $\partial \Omega_{G}$. Para este caso, 
si el radio de la esfera que define la región local es pequeño, $S_{r}$ se toma como un círculo del plano normal a $n$, vector normal de la superficie del cuerpo; por lo tanto, el vector $\boldsymbol{r}_{\boldsymbol{i}}-\boldsymbol{r}$ será normal a $\boldsymbol{S}_{\boldsymbol{r}}$. De esta forma la Ec. 4.2 para nodos en la superficie queda definida como:

$$
\begin{array}{r}
2 \pi \Phi_{N}\left(\boldsymbol{r}_{i}\right)=\frac{1}{r_{0_{i}}^{2}} \int_{S_{f_{i}}} \Phi_{N}\left(\boldsymbol{r}^{\prime}\right) d S^{\prime}+ \\
\int_{S_{r_{i}}}\left(\frac{1}{\left|\boldsymbol{r}_{i}-\boldsymbol{r}^{\prime}\right|}-\frac{1}{r_{0}}\right) \nabla \Phi_{N}\left(\boldsymbol{r}^{\prime}\right) \cdot \boldsymbol{n} d S^{\prime}
\end{array}
$$

El potencial eléctrico se toma como una aproximación localmente determinada por el vecindario, tal que, para cualquier punto $r \in \Omega_{G}$, se tiene la siguiente expresión que define el potencial eléctrico debido a corrientes primarias:

$$
\Phi_{N}(\boldsymbol{r}) \cong \hat{\Phi}_{N}(\boldsymbol{r})=\boldsymbol{p}^{T}(\boldsymbol{r}) \boldsymbol{a}
$$

donde $\boldsymbol{p}(\boldsymbol{r})$ es el vector de funciones bases de aproximación y $\boldsymbol{a}$ es el vector que contiene los coeficientes de la aproximación, por lo tanto, la multiplicación de estos dos vectores es la aproximación del potencial en cada nodo, resultante de la contribución de los nodos circundantes, y se denotará como $\hat{\boldsymbol{\Phi}}_{N}$.

Tomando para nuestro caso un vector de funciones de base monomial de orden 2 , definido por:

$$
\boldsymbol{p}\left(r_{x}, r_{y}, r_{z}\right)=\left[1, r_{x}, r_{y}, r_{z}, r_{x} r_{y}, r_{x} r_{z}, r_{y} r_{z}, r_{x}^{2}, r_{y}^{2}, r_{z}^{2}\right]
$$

Se debe de tener en cuenta el carácter local de la aproximación, por lo que el vector $\boldsymbol{a}$ varía en el espacio. Entonces el problema está en encontrar el vector de coeficientes de la aproximación. Para encontrar dichos coeficientes se plantea la minimización del siguiente jacobiano: 


$$
\begin{gathered}
B\left(\boldsymbol{r}_{i}\right)=\sum_{j=1}^{n} w_{j}\left(\boldsymbol{r}_{i}\right)\left(\tilde{\Phi}_{N}\left(\boldsymbol{r}_{i}\right)-\hat{\Phi}_{N}\left(\boldsymbol{r}_{i}\right)\right)^{2} \\
B\left(\boldsymbol{r}_{i}\right)=\sum_{j=1}^{n} w_{j}\left(\boldsymbol{r}_{i}\right)\left(\tilde{\Phi}_{N}\left(\boldsymbol{r}_{i}\right)-\boldsymbol{p}^{T}\left(\boldsymbol{r}_{j}\right) \boldsymbol{a}\right)^{2}
\end{gathered}
$$

Siendo $\tilde{\Phi}_{N}\left(\boldsymbol{r}_{i}\right)$ el potencial estimado en el nodo $i, n$ el número de nodos dentro de la ROI del nodo $i$, y $w_{j}\left(\boldsymbol{r}_{i}\right)$, funciones de peso del nodo $i$ debido al nodo circundante $j$, para nuestro caso estas funciones de peso son de tipo radial Gaussiana Ec. (4.10), las cuales ponderan la contribución de los nodos cercanos al punto $\boldsymbol{r}$ y disminuyen la de aquellos nodos lejanos a dicho punto. Es de hacer notar que el jacobiano se denota como la diferencia entre el potencial aproximado producto de las funciones de base y los coeficientes contra un potencial estimado en cada nodo.

Tomando en cuenta sólo aquellos nodos que están dentro de un radio establecido (en una geometría esférica), y haciendo cero la contribución de los demás nodos de la región $\Omega_{G}$, se tiene la definición de las funciones de peso gaussiana como:

$$
w_{j}(\boldsymbol{r})= \begin{cases}\frac{e^{-\left(\frac{\mid \boldsymbol{r}-\boldsymbol{r}_{j} j}{\lambda_{j}}\right)^{2}}-e^{-\left(\frac{R_{j}}{\lambda_{j}}\right)^{2}}}{1-e^{-\left(\frac{R_{j}}{\lambda_{j}}\right)^{2}}} & \left|\boldsymbol{r}-\boldsymbol{r}_{j}\right| \leq R_{j} \\ 0 & \left|\boldsymbol{r}-\boldsymbol{r}_{j}\right| \geq R_{j}\end{cases}
$$

donde $\lambda_{j}$ es una constante positiva y $R_{j}$ es el tamaño de la región de influencia del punto $r_{j}$.

Derivando la Ec. 4.9 con respecto al vector $\boldsymbol{a}$ e igualando a cero, se tiene la 
siguiente solución:

$$
\boldsymbol{a}(\boldsymbol{r})=\left(\boldsymbol{P}^{T} W(\boldsymbol{r}) \boldsymbol{P}\right)^{-1} \boldsymbol{P}^{T} W(\boldsymbol{r}) \tilde{\Phi}_{N}
$$

donde, se definen los siguientes vectores:

$$
\begin{gathered}
\boldsymbol{P}=\left[p\left(\boldsymbol{r}_{1}\right), \ldots, p\left(\boldsymbol{r}_{n}\right)\right]^{T} \\
\boldsymbol{W}(\boldsymbol{r})=\left[w_{1}(\boldsymbol{r}), \ldots, w_{n}(\boldsymbol{r})\right] \\
\tilde{\boldsymbol{\Phi}}=\left[\tilde{\Phi}_{1}, \ldots, \tilde{\Phi}_{n}\right]^{T}
\end{gathered}
$$

Para obtener una solución única al problema de mínimos cuadrados móviles, se debe de cumplir que el número de nodos en la región de influencia del punto $r$ tiene que ser mayor que $m$, que son los elementos del vector $\boldsymbol{p}(\boldsymbol{r})(m=10$ para una base monomial de orden 2). Si tomamos la siguiente función, denominada función de forma, como:

$$
\Psi^{T}(\boldsymbol{r})=\boldsymbol{p}^{T}(\boldsymbol{r})\left(\boldsymbol{P}^{T} \boldsymbol{W}(\boldsymbol{r}) \boldsymbol{P}\right)^{-1} \boldsymbol{P}^{T} \boldsymbol{W}(\boldsymbol{r})
$$

se tiene que la solución a la aproximación del potencial en el nodo, está dada por:

$$
\hat{\Phi}_{N}(\boldsymbol{r})=\Psi^{T}(\boldsymbol{r}) \tilde{\Phi}_{N}=\sum_{j=1}^{n} \boldsymbol{\Psi}_{j}(\boldsymbol{r}) \tilde{\Phi}_{N j}
$$

donde las funciones de formas $\Psi_{j}$ deben de cumplir la siguiente condición:

$$
\sum \Psi_{j}(\boldsymbol{r})=1 \quad \forall r \in \Omega_{G}
$$


Se hace notar que $\Psi_{j}\left(\boldsymbol{r}_{i}\right) \neq \delta_{i j}$ por lo tanto el método no interpola sobre los valores del potencial eléctrico de los nodos como lo realiza BEM o FEM.

Por lo tanto las Ecs. 4.5 y 4.6 quedan definidas, para el potencial de los nodos internos:

$$
4 \pi \sum_{j=1}^{n} \Psi_{j}\left(\boldsymbol{r}_{i}\right) \tilde{\Phi}_{N j}=\frac{1}{r_{0_{i}}^{2}} \int_{\partial \Omega_{L_{i}}} \sum_{j=1}^{n} \Psi_{j}\left(\boldsymbol{r}^{\prime}\right) \tilde{\Phi}_{N j} d S^{\prime}
$$

y para el potencial de los nodos de superficie:

$$
\begin{aligned}
& 2 \pi \sum_{j=1}^{n} \Psi_{j}\left(\boldsymbol{r}_{i}\right) \tilde{\Phi}_{N j}=\frac{1}{r_{0_{i}}^{2}} \int_{S_{f_{i}}} \sum_{j=1}^{n} \Psi_{j}\left(\boldsymbol{r}^{\prime}\right) \tilde{\Phi}_{N j} d S^{\prime} \\
& \quad+\int_{S_{r_{i}}}\left(\frac{1}{\left|r_{i}-r^{\prime}\right|}-\frac{1}{r_{0}}\right) \nabla \Phi_{N}\left(r^{\prime}\right) \cdot \boldsymbol{n d} d S^{\prime}
\end{aligned}
$$

Planteando una ecuación para cada nodo del volumen total, sabiendo que el laplaciano del potencial debido a fuentes secundarias es igual a cero y el flujo normal a la superficie puede ser determinado analíticamente, resulta el siguiente sistema lineal de ecuaciones:

$$
\Psi \tilde{\boldsymbol{\Phi}}_{N}=\boldsymbol{G} \tilde{\boldsymbol{\Phi}}_{N}+\boldsymbol{F}
$$

donde para nodos internos:

$$
\begin{gathered}
f_{i}=0 \\
G_{i j}=\frac{1}{4 \pi r_{0}^{2}} \int_{\partial \Omega_{L_{i}}} \Psi_{j}\left(r^{\prime}\right) d S^{\prime}
\end{gathered}
$$

y para nodos externos se tiene que: 


$$
\begin{gathered}
f_{i}=\frac{1}{2 \pi} \int_{S_{r_{i}}}\left(\frac{1}{\left|r_{i}-r^{\prime}\right|}-\frac{1}{r_{0}}\right) \nabla \Phi_{N}\left(r^{\prime}\right) \cdot n d S^{\prime} \\
G_{i j}=\frac{1}{4 \pi r_{0}^{2}} \int_{\partial \Omega_{L_{i}}} \Psi_{j}\left(r^{\prime}\right) d S^{\prime}
\end{gathered}
$$

Despejando la ecuación, los coeficientes están dados por la siguiente expresión:

$$
\tilde{\boldsymbol{\Phi}}_{N}=\boldsymbol{H}^{-1} \boldsymbol{F}
$$

donde la matriz $\boldsymbol{H}$ está dada por $\boldsymbol{\Psi}-\boldsymbol{G}$.

Por lo tanto, el potencial eléctrico debido a la carga superficial en cada nodo está dado por:

$$
\boldsymbol{\Phi}_{N}=\boldsymbol{\Psi} \tilde{\boldsymbol{\Phi}}_{N}
$$

\subsubsection{Problema Inverso.}

Si se plantea que el potencial en el cuero cabelludo es el resultado de la suma de dos factores, el primero $\left(\Phi_{F e}\right)$ debido a la suposición de que la fuente de corriente está inmersa en un medio homogéneo infinito y es a la altura del cuero cabelludo donde se mide dicho potencial, y el segundo término $\left(\boldsymbol{\Phi}_{\mathrm{Ne}}\right)$ es debido a la densidad de corriente en la superficie, entonces el potencial total en cada electrodo está dado por la siguiente expresión:

$$
\boldsymbol{\Phi}_{e}=\boldsymbol{\Phi}_{F e}+\boldsymbol{\Phi}_{N e}
$$

donde $\Phi_{e}=\left[\Phi\left(e_{1}\right), \Phi\left(e_{2}\right), \ldots, \Phi\left(e_{N}\right)\right]^{T}$, es el vector de potenciales registrados en el cuero cabelludo en $N$ electrodos localizados en $\boldsymbol{e}_{i}$ posiciones. La ecuación de Poisson que denota la relación entre las densidades de corriente dentro del volumen con respecto a los potenciales de los electrodos, está dada por: 


$$
\nabla \cdot\left(\sigma \nabla \Phi_{e}\right)=-\nabla \cdot \boldsymbol{J}
$$

donde $\boldsymbol{J}=\left[J_{1}, J_{2}, \ldots, J_{M}\right]^{T}$, es el vector de densidades de corriente en $M$ nodos dentro de la región $\Omega_{G}$.

El potencial medido en los electrodos $\boldsymbol{\Phi}_{e}$ debido a la densidad de corriente dentro del volumen, se puede caracterizar como el producto de la matriz de campo, denotada por $\boldsymbol{K}$, multiplicada por el vector de densidades de corriente, por lo tanto:

$$
\Phi_{e}=\boldsymbol{K} \boldsymbol{J}
$$

Entonces, sustituyendo la Ec. 4.25 en Ec. 4.23, resulta:

$$
\boldsymbol{K} \boldsymbol{J}=\boldsymbol{\Phi}_{F e}+\boldsymbol{\Phi}_{N e}
$$

La relación entre la fuente de corriente y el potencial $\Phi_{F e}\left(\boldsymbol{r}_{i}\right)$, se puede encontrar analíticamente y se definirá $\boldsymbol{K}_{\infty}$ como el kernel para una propagación en un medio homogéneo infinito, por lo tanto:

$$
\Phi_{F e}=\boldsymbol{K}_{\infty} \boldsymbol{J}
$$

donde $\boldsymbol{K}_{\infty}$ está definida como:

$$
k_{\infty}\left(\boldsymbol{r}_{e}, \boldsymbol{r}_{\beta}\right)=\frac{1}{4 \pi \sigma} \frac{\left(\boldsymbol{r}_{e}-\boldsymbol{r}_{\beta}\right)}{\left\|\boldsymbol{r}_{e}-\boldsymbol{r}_{\beta}\right\|^{3}}-\frac{1}{4 \pi \sigma} \frac{\left(\boldsymbol{r}_{R}-\boldsymbol{r}_{\beta}\right)}{\left\|\boldsymbol{r}_{R}-\boldsymbol{r}_{\beta}\right\|^{3}}
$$

$\boldsymbol{r}_{e}=$ coordenadas de los electrodos, donde $e=1 \ldots d$,

$\boldsymbol{r}_{\beta}=$ coordenadas de los voxeles, donde $\beta=1 \ldots m$,

$\boldsymbol{r}_{R}=$ coordenadas del electrodo de referencia

Sustituyendo Ec. 4.27 en Ec. 4.26, se tiene: 


$$
\boldsymbol{K} \boldsymbol{J}=\boldsymbol{K}_{\infty} \boldsymbol{J}+\boldsymbol{\Phi}_{N e}
$$

Sustituyendo Ec. 4.21 y Ec. 4.22 en Ec. 4.29 , resulta:

$$
\boldsymbol{K} \boldsymbol{J}=\boldsymbol{K}_{\infty} \boldsymbol{J}+\boldsymbol{\Psi} \boldsymbol{H}^{-1} \boldsymbol{F}
$$

donde el vector $\boldsymbol{F}$ está dado por el gradiente del potencial de los nodos de la superficie proyectado en la normal de dicha superficie del volumen (incluyendo electrodos). Tomando una región de influencia esférica de radio $r_{0}$, se denota como:

$$
\boldsymbol{F}=\left(\frac{r_{0}}{2}\right) m\left(\nabla \boldsymbol{\Phi}_{N e} \cdot \boldsymbol{n}\right)
$$

donde $m=1$ para nodos externos (ver Ec. 4.20) y $m=0$ para nodos internos (ver Ec. 4.19). Por las condiciones de frontera de Neumann, se tiene que el gradiente del potencial eléctrico debido a la carga superficial proyectado sobre la normal, es igual al potencial eléctrico debido a la carga volumétrica proyectado sobre la normal, es decir:

$$
\left.\nabla \Phi_{N e}\left(\boldsymbol{r}_{\boldsymbol{i}}\right) \cdot \boldsymbol{n}\right|_{\partial \Omega_{G}}=-\left.\nabla \Phi_{F e}\left(\boldsymbol{r}_{i}\right) \cdot \boldsymbol{n}\right|_{\partial \Omega_{G}}
$$

Sustituyendo Ec. 4.31 en Ec. 4.30, se tiene:

$$
\boldsymbol{K} \boldsymbol{J}=\boldsymbol{K}_{\infty} \boldsymbol{J}+\boldsymbol{\Psi} \boldsymbol{H}^{-1} \frac{r_{0}}{2}\left(-\nabla \Phi_{F e}\left(\boldsymbol{r}_{i}\right) \cdot \boldsymbol{n}\right)
$$

donde $\boldsymbol{K}$ representa la matriz de campo del modelo sin malla, por lo que se denotará como $\boldsymbol{K}_{M L}$, resultando:

$$
\boldsymbol{K}_{M L} \boldsymbol{J}=\boldsymbol{K}_{\infty} \boldsymbol{J}+\boldsymbol{\Psi} \boldsymbol{H}^{-1} k \frac{r_{0}}{2} \boldsymbol{K}_{\infty} \boldsymbol{J}
$$

Entonces, por lo tanto, el kernel para resolver el problema inverso, que caracteriza 
a un modelo de cabeza realista construido por el método sin malla, que toma en cuenta las densidades de corriente tanto superficial como volumétrica, está dado por:

$$
\boldsymbol{K}_{M L}=\boldsymbol{K}_{\infty}\left[\boldsymbol{I}+\boldsymbol{\Psi} \boldsymbol{H}^{-1} k \frac{r_{0}}{2}\right]
$$

\subsection{Solución de Problema Inverso.}

\subsubsection{Algoritmo de Tomografía Electromagnética de baja Res- olución Estandarizada (sLORETA).}

El problema de localización de fuentes distribuidas de corriente puede estar determinado por encontrar la solución de $\hat{\boldsymbol{J}}$ a través de la siguiente Ec. [94]:

$$
\hat{\boldsymbol{J}}=\min \left\{\left\|\boldsymbol{\Phi}-\boldsymbol{K}_{M L} \boldsymbol{J}\right\|^{2}+\alpha\|\boldsymbol{J}\|^{2}\right\}
$$

donde $\Phi$ es un vector de tamaño $N \times 1$ que contiene los potenciales eléctricos registrados por los electrodos en cuero cabelludo, $\boldsymbol{J}$ es un vector de $3 M \times 1$ que representa las fuentes de corriente localizadas en $M$ posiciones dentro del volumen del cerebro, $\boldsymbol{K}$ es la matriz de campo, y $\alpha$ es el parámetro de regularización de Tikhonov (ver apéndice A). La fuente estimada está dada por:

$$
\hat{\boldsymbol{J}}=\boldsymbol{T} \boldsymbol{K}_{M L} \boldsymbol{J}=\boldsymbol{K}_{M L}^{T}\left[\boldsymbol{K}_{M L} \boldsymbol{K}_{M L}^{T}+\alpha \boldsymbol{I}\right]^{+} \boldsymbol{K}_{M L} \boldsymbol{J}=\boldsymbol{R J}
$$

donde "+" denota la pseudo-inversa de Moore-Penrose y $\boldsymbol{R}$ es la matriz resolución, la cual describe la desviación de la fuente de actividad real con la fuente estimada; idealmente $\boldsymbol{R}$ debería de ser la matriz identidad. Normalmente, la matriz resolución 
no es la matriz identidad, debido a la naturaleza del mal condicionamiento del problema inverso. Es de hacer notar que el rango de la matriz resolución no puede exceder al rango de la matriz de campo $\boldsymbol{K}_{M L}$ que tiene la característica de ser mal condicionada, por lo tanto, $\boldsymbol{R}$ es no invertible. La idea básica de sLORETA es normalizar la estimación usando la inversa por bloques de la matriz resolución $\boldsymbol{R}$, como sigue:

$$
\hat{\boldsymbol{J}}_{l}^{T}\left(\boldsymbol{R}_{l l}\right)^{-1} \hat{\boldsymbol{J}}_{l}
$$

donde $\hat{\boldsymbol{J}}_{l}$ es un vector de tamaño $3 \times 1$ que contiene la estimación de la fuente en el $l$-ésimo voxel y $\boldsymbol{R}_{l l}$ es una matriz de tamaño $3 \times 3$ que contiene el $l$ - ésimo bloque diagonal de la matriz resolución. Aunque la imagen resultante de sLORETA es borrosa, el valor máximo está correctamente centrado en la localización de la fuente $[94,128]$.

\subsubsection{Algoritmo de Focal Underdetermined System Solver (FOCUSS) estandarizado, combinado con sLORETA.}

FOCUSS es un algoritmo de alta resolución, recursivo, que implementa el método de Norma Mínima Ponderada (WMN) y converge a una solución rala $[50,51,75,76]$. sLORETA mejora significativamente el error de localización que tiene el método de WMN a través del proceso de estandarización que utiliza. En cada paso de las iteraciones que realiza FOCUSS se tiene que calcular la inversa de WMN, por lo que es razonable pensar que también se puede aplicar en cada paso una estandarización del resultado. En FOCUSS, la solución a la Ec. 4.25 está dada por:

$$
\min _{\boldsymbol{J}}\|\boldsymbol{C J}\|^{2} \quad \text { sujeto a } \quad \boldsymbol{\Phi}=\boldsymbol{K}_{M L} \boldsymbol{J}
$$

donde $\boldsymbol{C}$ es la matriz de ponderación definida como: 


$$
C=\left(D^{-1}\right)^{T} D^{-1}
$$

$\boldsymbol{D}$ es una matriz diagonal de $3 M \times 3 M$, la cual es refinada recursivamente. La solución a la Ec. 4.39 a la $i$ - ésima iteración es:

$$
\begin{aligned}
\tilde{\boldsymbol{J}}_{i} & =\boldsymbol{C}_{i}^{-1} \boldsymbol{K}_{M L}^{T}\left[\boldsymbol{K}_{M L} \boldsymbol{C}_{i}^{-1} \boldsymbol{K}_{M L}^{T}\right]^{+} \boldsymbol{\Phi} \\
& =\boldsymbol{D}_{i} \boldsymbol{D}_{i}^{T} \boldsymbol{K}_{M L}^{T}\left(\boldsymbol{K}_{M L} \boldsymbol{D}_{i} \boldsymbol{D}_{i}^{T} \boldsymbol{K}_{M L}^{T}\right)^{+} \boldsymbol{\Phi}
\end{aligned}
$$

En cada iteración la matriz $\boldsymbol{D}$ es actualizada basada en la densidad de corriente estimada en la iteración previa, como sigue:

$$
\boldsymbol{D}_{i}=\boldsymbol{Q} \boldsymbol{D}_{i-1}\left[\operatorname{Diag}\left(\tilde{\boldsymbol{J}}_{i-1}(1), \tilde{\boldsymbol{J}}_{i-1}(2), \ldots, \tilde{\boldsymbol{J}}_{i-1}(3 M)\right)\right]
$$

donde $\tilde{J}_{i-1}(n)$ representa al $n$ - ésimo elemento del vector $\tilde{\boldsymbol{J}}$ de la iteración previa. $\boldsymbol{Q}$ es la matriz diagonal que compensa la profundidad de las fuentes.

$$
\boldsymbol{Q}=\operatorname{Diag}\left[\frac{1}{\left\|\boldsymbol{K}_{M L_{1}}\right\|}, \ldots, \frac{1}{\left\|\boldsymbol{K}_{M L_{3 M}}\right\|}\right]
$$

donde $\left\|\boldsymbol{K}_{M L_{i}}\right\|$ denota la $i$ - ésima columna de la matriz $\boldsymbol{K}_{M L}$. Si se incorpora estandarización dentro del algoritmo de FOCUSS, sustituyendo Ec. 4.25 en Ec. 4.41, se tiene:

$$
\tilde{\boldsymbol{J}}_{i}=\boldsymbol{D}_{i} \boldsymbol{D}_{i}^{T} \boldsymbol{K}_{M L}^{T}\left(\boldsymbol{K}_{M L} \boldsymbol{D}_{i} \boldsymbol{D}_{i}^{T} \boldsymbol{K}_{M L}^{T}\right)^{+} \boldsymbol{K}_{M L} \boldsymbol{J}=\boldsymbol{R}_{i} \boldsymbol{J}
$$

Tal que la matriz resolución en la $i$ - ésima iteración es:

$$
\boldsymbol{R}_{i}=\boldsymbol{D}_{i} \boldsymbol{D}_{i}^{T} \boldsymbol{K}_{M L}^{T}\left(\boldsymbol{K}_{M L} \boldsymbol{D}_{i} \boldsymbol{D}_{i}^{T} \boldsymbol{K}_{M L}^{T}\right)^{+} \boldsymbol{K}_{M L}
$$

La potencia de la fuente estimada en la $i$ - ésima iteración es normalizada a través 
de:

$$
\hat{\boldsymbol{J}}_{i}^{T}(l)\left[\boldsymbol{R}_{i}(l, l)\right]^{-1} \hat{\boldsymbol{J}}_{i}(l)
$$

donde el subíndice $i$ es el índice de la iteración, $\hat{\boldsymbol{J}}_{i}(l)$ es la estimación de la fuente en el $i$ - ésimo voxel dada por Ec. 4.41, y $\left[\boldsymbol{R}_{i}(l, l)\right]$ es una matriz de $3 \times 3$ que contiene el bloque de la $l$ - ésima diagonal de la matriz resolución.

\subsubsection{Algoritmo de Standarized Shrinking LORETA-FOCUSS (SSLOFO).}

El algoritmo nombrado como Standarized Shrinking LORETA-FOCUSS (SSLOFO), es el algoritmo de FOCUSS tomando como entrada la solución de sLORETA y recortando el espacio solución. El algoritmo puede ser resumido como:

1. Se estima la densidad de corriente $\hat{\boldsymbol{J}}_{0}$ utilizando sLORETA.

2. Se inicializa la matriz de ponderación de acuerdo a la Ec. 4.40, con:

$$
\boldsymbol{D}_{0}=\operatorname{Diag}\left(\hat{\boldsymbol{J}}_{0}(1), \hat{\boldsymbol{J}}_{0}(2), \ldots, \hat{\boldsymbol{J}}_{0}(3 M)\right)
$$

3. Se estima de la potencia de la fuente usando FOCUSS estandarizado de acuerdo a las Ecs. 4.44 y 4.46.

4. Se mantienen los nodos con valores mayores de potencia.

5. Se redefine el espacio solución que contenga solamente los nodos de mayor potencia, manteniendo la correspondencia entre elementos de $J$ y las columnas en $\boldsymbol{K}_{M L}$.

6. Se actualiza la matriz de ponderación de acuerdo a la Ec. 4.42 . 
7. Se repiten los pasos 3 al 6 hasta que: a) la solución no cambie en dos pasos consecutivos, o b) la solución en cualquier iteración sea menos rala que la solución estimada por la iteración previa, o c) la potencia de la fuente de cualquier nodo exceda un umbral establecido por el usuario.

\subsection{Simulación de registros de EEG.}

Las señales de EEG simuladas que se utilizaron para las pruebas fueron generadas en un modelo de medio homogéneo infinito (MHI) de cabeza de forma esférica a través del algoritmo presentado por [28]; las señales son generadas para un número de fuentes $S_{i}$ colocadas dentro de un volumen conductor homogéneo e isotrópico. Las fuentes irradian sus señales omnidireccionalmente. Los sensores (electrodos) son colocados en la superficie del volumen, en una conFigura ción estándar 10-20 de 64 electrodos. Las señales en los electrodos son mezclas lineales de la radiación desde todas las fuentes utilizadas. Cada fuente genera una señal $S_{i}(n)$ dada por:

$$
\begin{gathered}
S_{i}(n)=-f_{i}(n) a_{i}(n), \quad n=0, \ldots, N-1 \\
f_{i}(n)=\sin (2 \pi n \cdot 0,005 \cdot(2000-n) / 2000) \\
a_{i}(n)=\exp \left(\frac{-(n-\mu)^{2}}{2 \sigma}\right)
\end{gathered}
$$

donde $N$ es el número de muestras temporales de la señal generada por la fuente, $f_{i}(n)$ es una señal de frecuencia variable modulada por una campana Gaussiana $a_{i}(n)$. Este tipo de señal se escogí ya que presenta la ventaja de tener un sólo máximo en un tiempo determinado. El valor del potencial de los electrodos en este valor máximo de la señal es el que se utiliza para la solución del problema inverso. Un modelo de volumen conductor de radio unitario, homogéneo e isotrópico es utilizado en la experimentación.

La suma de las señales provenientes de las fuentes a los sensores es calculada a 
Capítulo 4. Metodología propuesta para la solución del problema inverso del EEG

través de:

$$
\Phi_{e}(n)=\sum_{i=1}^{L} S_{i}(n) \cdot d_{e_{i}}
$$

donde $\Phi_{e}$ es el potencial eléctrico en el sensor (electrodo), $L$ es el número de fuentes utilizadas. El coeficiente de la distancia $d_{e_{i}}$ para un par consistente en el sensor $\boldsymbol{r}_{e}$ y la fuente $\boldsymbol{r}_{i}$ está definido por:

$$
d_{e_{i}}=\left\{\begin{array}{cc}
1, & \left\|\boldsymbol{r}_{e}-\boldsymbol{r}_{i}\right\|=0 \\
\frac{1}{\left\|\boldsymbol{r}_{e}-\boldsymbol{r}_{i}\right\|}, & \left\|\boldsymbol{r}_{e}-\boldsymbol{r}_{i}\right\|>0
\end{array}\right.
$$




\section{Capítulo 5}

\section{Resultados y Discusión}

\subsection{Problema inverso}

Se presentan los resultados de localización de fuentes de actividad eléctrica obtenidos, para la solución del problema inverso, considerando un modelo de volumen conductor esférico y un modelo de volumen conductor realista de cabeza, a través del método sin malla.

\subsubsection{Error de localización.}

Para la evaluación de la precisión en los resultados obtenidos se utiliza un error de localización $(\varepsilon)$ que fue determinado a través de la distancia entre la posición de la fuente estimada $\boldsymbol{X}_{\text {est }}$ de la solución del problema inverso y la posición de la fuente utilizada $\boldsymbol{X}_{\text {sim }}$ en la generación de los EEG simulados. 


$$
\begin{gathered}
\varepsilon=\sqrt{\left\|\boldsymbol{X}_{e s t}-\boldsymbol{X}_{s i m}\right\|} \\
\boldsymbol{X}_{e s t}^{i}=\left[x_{e s t}^{i}, y_{e s t}^{i}, z_{e s t}^{i}\right] \\
\boldsymbol{X}_{s i m}^{i}=\left[x_{s i m}^{i}, y_{s i m}^{i}, z_{s i m}^{i}\right]
\end{gathered}
$$

\subsubsection{Modelo esférico de volumen conductor de cabeza.}

Se generaron diferentes registros de EEG utilizando las referencias espaciales mostradas en la Figura 5.1, donde se consideró que el eje X positivo pertenece al lóbulo temporal derecho, el eje $\mathrm{X}$ negativo pertenece al lóbulo temporal izquierdo, también se consideró que el eje Y positivo pertenece al lóbulo frontal y el eje $\mathrm{Y}$ negativo al lóbulo occipital, y por último, el eje $\mathrm{Z}$ va desde el lóbulo parietal ( $\mathrm{Z}$ positivo) a la parte inferior de la cabeza ( $\mathrm{Z}$ negativo), teniendo como intersección de los tres ejes el centro del espacio de Talairach.

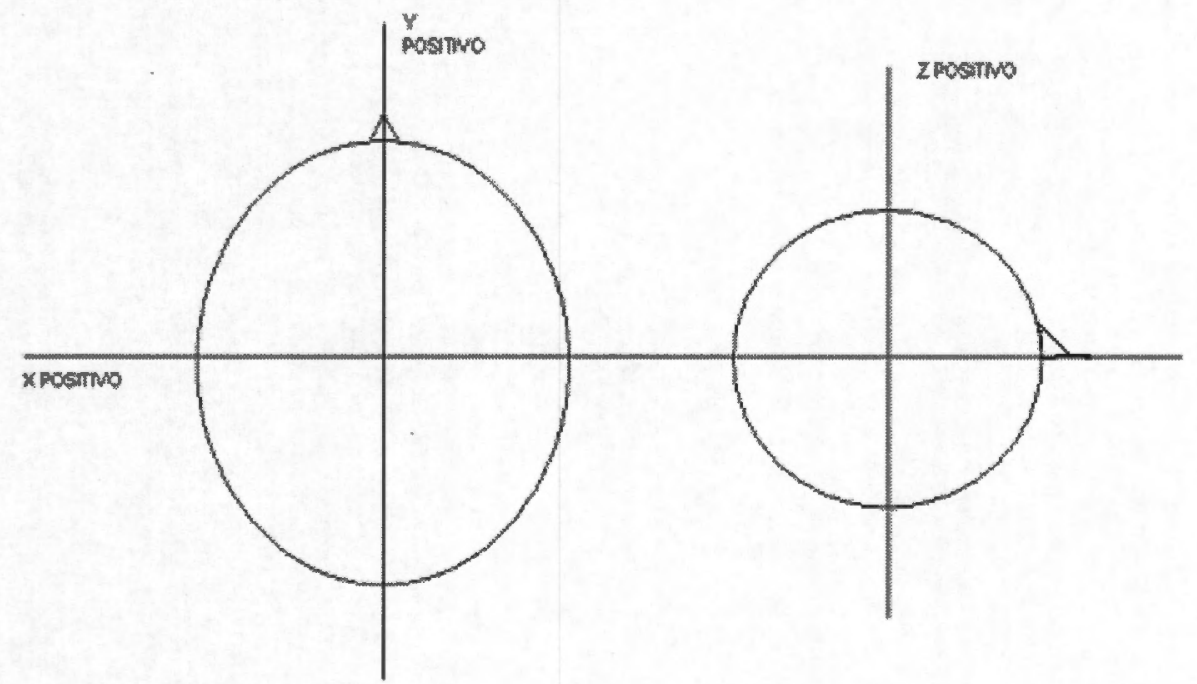

Figura 5.1: Referencias utilizadas en la generación de señales en una esfera unitaria.

Para analizar el comportamiento de los algoritmos de sLORETA y de Norma 
Mínima, en localización de fuentes, en un modelo esférico de radio unitario, se generaron 18 registros de EEG a través del algoritmo descrito en la Sección 4.4. La ubicación de las fuentes en la generación de EEG fue arbitraria, es decir, no se pretendía ver el comportamiento de los algoritmos en profundidad, ver Tabla 5.1, donde se muestra la posición $\mathrm{X}, \mathrm{Y}$ y $\mathrm{Z}$ de la fuente generadora y se muestra la profundidad con respecto a la superficie.

Tabla 5.1: Posición de 18 registros de EEG dentro de un modelo esférico de cabeza en unidades normalizadas a esfera unitaria (U.N.), teniendo en cuenta que el radio de la esfera es igual a $87 \mathrm{~mm}$.

\begin{tabular}{|c|c|c|c|c|}
\hline EEG & Posición X & Posición Y & Posición Z & Profundidad \\
\hline \hline & $U . N$. & $U . N$. & $U . N$. & $U . N$. \\
\hline \hline 1 & 0,000 & 1,000 & 0,000 & 0,000 \\
\hline 2 & 1,000 & 0,000 & 0,000 & 0,000 \\
\hline 3 & 0,000 & 0,000 & 1,000 & 0,000 \\
\hline 4 & 0,000 & $-1,000$ & 0,000 & 0,000 \\
\hline 5 & $-1,000$ & 0,000 & 0,000 & 0,000 \\
\hline 6 & 0,000 & 0,600 & 0,000 & 0,400 \\
\hline 7 & 0,600 & 0,000 & 0,000 & 0,400 \\
\hline 8 & 0,600 & 0,200 & 0,000 & 0,368 \\
\hline 9 & 0,600 & 0,200 & 0,200 & 0,337 \\
\hline 10 & $-0,600$ & $-0,200$ & 0,200 & 0,337 \\
\hline 11 & 0,400 & 0,400 & 0,200 & 0,400 \\
\hline 12 & $-0,400$ & $-0,400$ & 0,200 & 0,400 \\
\hline 13 & 0,600 & 0,400 & 0,500 & 0,123 \\
\hline 14 & 0,600 & $-0,400$ & 0,500 & 0,123 \\
\hline 15 & 0,800 & 0,000 & 0,600 & 0,000 \\
\hline 16 & 0,000 & 0,800 & 0,600 & 0,000 \\
\hline 17 & 0,000 & $-0,800$ & 0,600 & 0,000 \\
\hline 18 & 0,000 & 0,600 & 0,800 & 0,000 \\
\hline
\end{tabular}

En la Figura 5.2 se muestra los resultados del desempeño en la localización de fuentes de la Tabla 5.1 para sLORETA (en magenta) y para Norma Mínima (en azul). Se observa que el método de solución de problema inverso por sLORETA tiene menor error de localización $(\varepsilon)$ para fuentes en profundidad (registros del 6 
al 14) que el presentado por el método de Norma Mínima, lo cual es de esperarse, ya que el método de Norma Mínima encuentra la proyección sobre la superficie más cercana a la fuente [94]. Para fuentes superficiales los dos métodos presentan similar comportamiento.

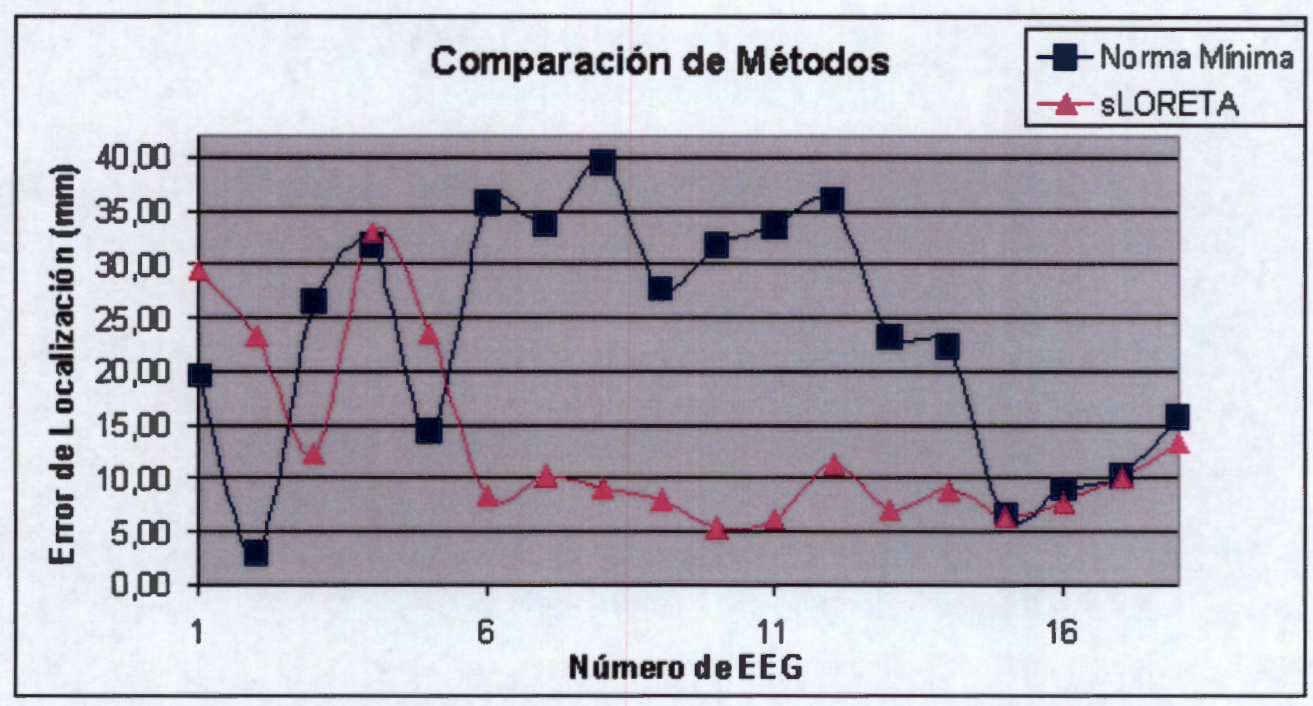

Figura 5.2: Gráfica de comparación de errores de localización $(\varepsilon)$ entre la utilización de Norma Mínima (en azul) y sLORETA (en magenta) en la solución del problema inverso para 18 registros de EEG simulados. Medida en milimetros teniendo en cuenta que el radio de la esfera es $87 \mathrm{~mm}$.

Luego se generaron 17 registros de EEG a diferentes profundidades, como se muestra en la Tabla 5.2. Las fuentes fueron ubicadas en posiciones de voxeles que pertenecen a materia gris normalizada y que también pertenecen a una esfera unitaria. El tamaño de los voxeles de materia gris normalizada es de $7 \times 7 \times 8 \mathrm{~mm}^{3}$, resultando en 2472 voxeles. Se utilizo sLORETA en la solución del problema inverso, por su desempeño en profundidad, tratando de encontrar la máxima profundidad de fuente posible con un error de localización aceptable. El comportamiento del error (columna "Error de localización" en Tabla 5.2) no tiene una tendencia clara con respecto a la profundidad de la fuente, llegando a obtener un error de localización 
igual a cero con profundidad cercana a 0.5 U.N. $(43,07 \mathrm{~mm})$, lo cual está reportado por [94] para un modelo esférico.

Tabla 5.2: Posiciones de las fuentes generadoras de 17 registros de EEG simulados y error de localización con sLORETA. Las fuentes fueron posicionadas en voxeles de materia gris normalizada pertenecientes también a una esfera unitaria y la actividad fue registrada con 64 electrodos. U.N. es unidad normalizada con respecto al radio de la esfera $(87 \mathrm{~mm})$ donde se localizan los electrodos.

\begin{tabular}{|c|c|c|c|c|c|c|}
\hline & $\mathrm{X}$ & $\mathrm{Y}$ & $\mathrm{Z}$ & Profundidad & Profundidad & Error de localización \\
\hline \hline EEG & U.N. & U.N. & U.N. & U.N. & $m m$ & $m m$ \\
\hline \hline 1 & $\mathbf{0 , 1 0 3}$ & 0,943 & 0,161 & 0,04 & 3,31 & $\mathbf{1 7 , 4 9}$ \\
\hline 2 & $-0,264$ & $-0,483$ & 0,713 & 0,10 & 8,70 & $\mathbf{4 , 2 6}$ \\
\hline 3 & $-0,609$ & 0,563 & 0,161 & 0,16 & 13,49 & $\mathbf{1 0 , 7 9}$ \\
\hline 4 & $-0,161$ & $-0,172$ & 0,805 & 0,16 & 14,09 & $\mathbf{0 , 0 0}$ \\
\hline 5 & $-0,149$ & $-0,080$ & 0,805 & 0,18 & 15,49 & $\mathbf{0 , 0 0}$ \\
\hline 6 & $-0,414$ & 0,471 & 0,529 & 0,18 & 15,66 & $\mathbf{0 , 0 0}$ \\
\hline 7 & $-0,345$ & 0,103 & 0,713 & 0,20 & 17,57 & $\mathbf{0 , 0 0}$ \\
\hline 8 & $-0,448$ & 0,517 & 0,345 & 0,23 & 20,36 & $\mathbf{0 , 0 0}$ \\
\hline 9 & $-0,310$ & 0,287 & 0,621 & 0,25 & 21,66 & $\mathbf{1 0 , 2 7}$ \\
\hline 10 & $-0,448$ & $-0,276$ & 0,529 & 0,25 & 22,10 & $\mathbf{1 1 , 3 1}$ \\
\hline 11 & $-0,632$ & 0,103 & 0,253 & 0,31 & 27,06 & $\mathbf{0 , 0 0}$ \\
\hline 12 & $\mathbf{0 , 4 7 1}$ & 0,345 & 0,345 & 0,32 & 28,01 & $\mathbf{1 1 , 7 5}$ \\
\hline 13 & $-0,264$ & 0,368 & 0,437 & 0,37 & 32,28 & $\mathbf{0 , 0 0}$ \\
\hline 14 & $-0,080$ & 0,046 & 0,621 & 0,37 & 32,36 & $\mathbf{0 , 0 0}$ \\
\hline 15 & $\mathbf{0 , 5 6 3}$ & 0,023 & 0,069 & 0,43 & 37,58 & $\mathbf{9 , 4 0}$ \\
\hline 16 & 0,287 & 0,138 & 0,437 & 0,46 & 39,93 & $\mathbf{0 , 0 0}$ \\
\hline 17 & 0,379 & 0,218 & 0,253 & 0,50 & 43,07 & $\mathbf{0 , 0 0}$ \\
\hline
\end{tabular}

Al no encontrar un patrón de error de localización asociado a la profundidad de la fuente, se buscó encontrar un parámetro de error de localización por zonas del cerebro, encontrando que el menor error de localización se presenta para los lóbulos temporales. En el siguiente experimento se buscó encontrar el comportamiento de sLORETA en los lóbulos de interés a este trabajo, es decir, lóbulo temporal derecho y lóbulo temporal izquierdo. En la Tabla 5.3 se muestran las posiciones de las fuentes de 8 registros de EEG simulados en voxeles de materia gris pertenecientes a los 
lóbulos temporales, donde los primeros cuatro registros son de fuentes localizadas en el lóbulo temporal derecho y los siguientes cuatro registros son de fuentes localizadas en el lóbulo temporal izquierdo. Las fuentes están ubicadas en diferentes radios para cada lóbulo, porque además se buscaba ver el comportamiento de sLORETA en la localización para fuentes ubicadas radialmente, este tipo de pruebas no han sido reportadas hasta el momento.

Tabla 5.3: Generación de 8 registros localizados radialmente en el lóbulo temporal derecho (1-4) y lóbulo temporal izquierdo (5-8).

\begin{tabular}{|c|c|c|c|c|c|c|c|c|}
\hline & $\mathrm{X}$ & $\mathrm{Y}$ & $\mathrm{Z}$ & Profundidad & $\mathrm{R}$ & $\theta$ & $\beta$ & Error \\
\hline \hline EEG & U.N. & U.N. & U.N. & $m m$ & U.N. & grados & grados & $m m$ \\
\hline \hline 1 & 0,770 & 0,011 & 0,069 & 19,75 & 0,773 & 0,855 & 5,117 & $\mathbf{4 , 4 4}$ \\
\hline 2 & 0,747 & $-0,034$ & 0,069 & 21,66 & 0,751 & $-2,643$ & 5,268 & $\mathbf{8 , 9 6}$ \\
\hline 3 & 0,563 & 0,023 & 0,069 & 37,58 & 0,568 & 2,337 & 6,975 & $\mathbf{9 , 4 0}$ \\
\hline 4 & 0,471 & $-0,034$ & 0,069 & 45,41 & 0,478 & $-4,185$ & 8,304 & $\mathbf{1 0 , 0 1}$ \\
\hline 5 & $-0,770$ & 0,011 & 0,069 & 19,75 & 0,773 & 179,145 & 5,117 & $\mathbf{4 , 9 6}$ \\
\hline 6 & $-0,724$ & 0,046 & 0,069 & 23,58 & 0,729 & 176,367 & 5,430 & $\mathbf{1 0 , 0 1}$ \\
\hline 7 & $-0,632$ & $-0,023$ & 0,069 & 31,67 & 0,636 & 182,083 & 6,222 & $\mathbf{8 , 2 7}$ \\
\hline 8 & $-0,448$ & $-0,011$ & 0,069 & 47,50 & 0,454 & 181,469 & 8,744 & $\mathbf{1 0 , 0 1}$ \\
\hline
\end{tabular}

En la Figura 5.3 se muestra la comparación de los errores de localización de la Tabla 5.3, donde vemos que el comportamiento del error de localización es similar para cualquiera de los lóbulos temporales, y no es mayor de $10 \mathrm{~mm}$, es decir, cercano al $12 \%$ de una esfera de radio de $87 \mathrm{~mm}$, que corresponde a la unidad. Este resultado coincide con lo reportado por Pascual-Marqui, de que el error de localización es cercano a una unidad de tamaño de voxel, recordando que para nuestro caso se trabajó con voxeles de $7 \times 7 \times 8 \mathrm{~mm}^{3}$. 


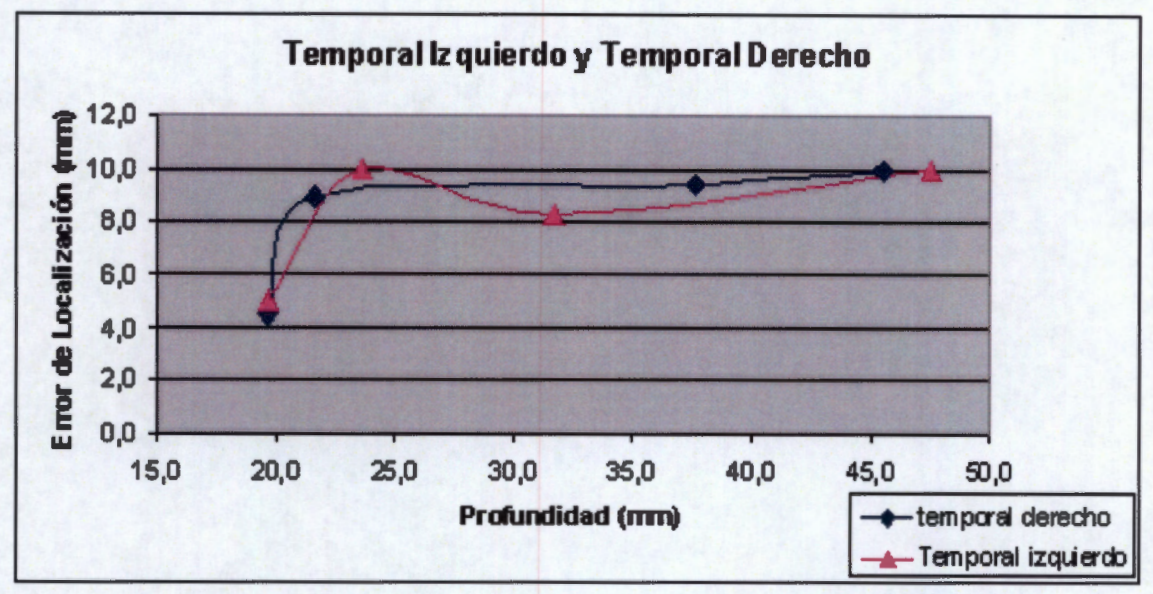

Figura 5.3: Comparación de errores de localización $(\varepsilon)$ entre lóbulo temporal izquierdo y lóbulo temporal derecho. Esfera unitaria corresponde a un radio de $87 \mathrm{~mm}$.

Para comprobar la influencia del tamaño del voxel en el espacio solución del problema inverso, se probó con una resolución de voxel de $6 \times 6 \times 6 \mathrm{~mm}^{3}$, en la detección de fuentes posicionadas radialmente, en la Tabla 5.4 se muestra la posición de la fuente utilizada para la generación de 8 registros de EEG.

Tabla 5.4: Posición de las fuentes utilizadas en la generación de 8 registros de EEG, para una resolución de voxel de $6 \times 6 \times 6 \mathrm{~mm}^{3}$ de materia gris ( 5426 voxeles en todo el volumen), lóbulo temporal derecho (1-4) y lóbulo temporal izquierdo (5-8). Esfera unitaria (corresponde a un radio de $87 \mathrm{~mm}$ )

\begin{tabular}{|c|c|c|c|c|c|c|c|c|}
\hline EEG & $\mathrm{X}$ & $\mathrm{Y}$ & $\mathrm{Z}$ & Profundidad & $\mathrm{R}$ & $\theta$ & $\beta$ & Error \\
\hline \hline & U.N. & U.N. & U.N. & $m m$ & U.N. & grados & grados & $m m$ \\
\hline \hline 1 & 0,747 & $-0,069$ & 0,023 & 21,66 & 0,751 & $-5,274$ & 1,755 & $\mathbf{6 , 0 0}$ \\
\hline 2 & 0,609 & $-0,034$ & 0,023 & 33,84 & 0,611 & $-3,240$ & 2,158 & $\mathbf{7 , 8 3}$ \\
\hline 3 & 0,471 & $-0,069$ & 0,023 & 45,50 & 0,477 & $-8,326$ & 2,763 & $\mathbf{8 , 0 0}$ \\
\hline 4 & 0,368 & $-0,080$ & 0,023 & 54,20 & 0,377 & $-12,339$ & 3,494 & $\mathbf{1 1 , 4 0}$ \\
\hline 5 & $-0,759$ & $-0,080$ & 0,023 & 20,62 & 0,763 & 186,054 & 1,726 & $\mathbf{5 , 3 9}$ \\
\hline 6 & $-0,632$ & $-0,057$ & 0,023 & 31,76 & 0,635 & 185,195 & 2,074 & $\mathbf{6 , 0 0}$ \\
\hline 7 & $-0,494$ & $-0,080$ & 0,023 & 43,41 & 0,501 & 189,246 & 2,629 & $\mathbf{6 , 0 0}$ \\
\hline 8 & $-0,425$ & $-0,023$ & 0,023 & 49,85 & 0,427 & 183,094 & 3,090 & $\mathbf{7 , 8 3}$ \\
\hline
\end{tabular}

En la Figura 5.4 se muestra la comparación de los errores de localización de la 
Tabla 5.4, donde vemos que el comportamiento del error de localización es similar para cualquiera de los lóbulos temporales, y no es mayor del $13 \%$ del radio unitario, que corresponde a $11.40 \mathrm{~mm}$. Como puede observarse, la resolución de voxel de $6 \times 6 \times 6 \mathrm{~mm}^{3}$ no mejora sustancialmente el error de localización, por lo cual, se puede inferir que una resolución de voxel de $7 \times 7 \times 8 \mathrm{~mm}^{3}$ presenta un buen comportamiento en la localización de fuentes, y el costo computacional es menor, por ello, será la resolución de voxel utilizada en la construcción de los modelos de volumen conductor realista.

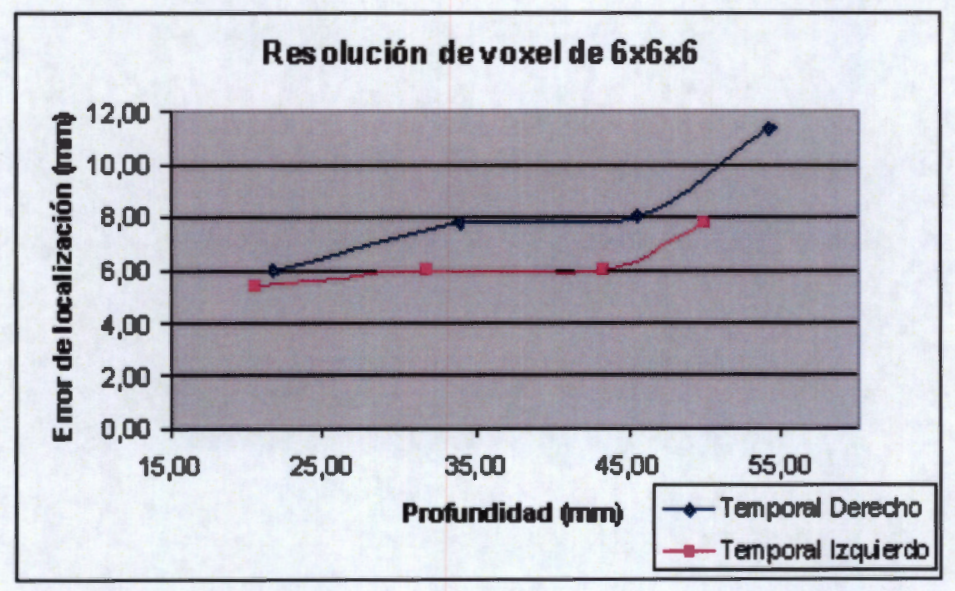

Figura 5.4: Comparación de errores de localización $(\varepsilon)$ entre lóbulo temporal izquierdo y lóbulo temporal derecho, para tamaño de voxel de $6 \times 6 \times 6 \mathrm{~mm}^{3}$. Esfera unitaria que corresponde a un radio de $87 \mathrm{~mm}$.

\subsubsection{Modelo de volumen conductor realista de cabeza.}

Se generaron 25 registros de EEG simulados a través del procedimiento descrito en la Sección 4.4 para diferentes localizaciones de fuente única, dentro de un modelo esférico unitario. La información anatómica del cerebro fue obtenida desde IBSR, correspondiente a un sujeto sin reportes patológicos, y registrados al espacio de Talairach. Para extraer el volumen de materia gris, estas imágenes de RM fueron segmentadas a través del algoritmo descrito en la sección 4.1; los voxeles de materia 
gris $\left(1 \times 1 \times 1 \mathrm{~mm}^{3}\right)$ fueron submuestreados para obtener una resolución de $(7 \times$ $7 \times 8 \mathrm{~mm}^{3}$ ); esto produjo 2472 voxeles de materia gris, con 854 pertenecientes a la superficie. Se asumió un medio homogéneo, isotrópico de conductividad $1,0 \mathrm{~S} / \mathrm{m}^{2}$ y el volumen fué normalizado, para obtener un radio máximo igual a la unidad (corresponde a un radio de $87 \mathrm{~mm}$ ), con lo que fueron simulados los registros. El centro del volumen conductor esférico usado para la simulación fue registrado al centro del espacio de Talairach del volumen de materia gris segmentada, como se puede ver en la Figura 5.5, donde los voxeles de materia gris están representados por puntos azules y los electrodos por puntos rojos inscritos en la esfera.

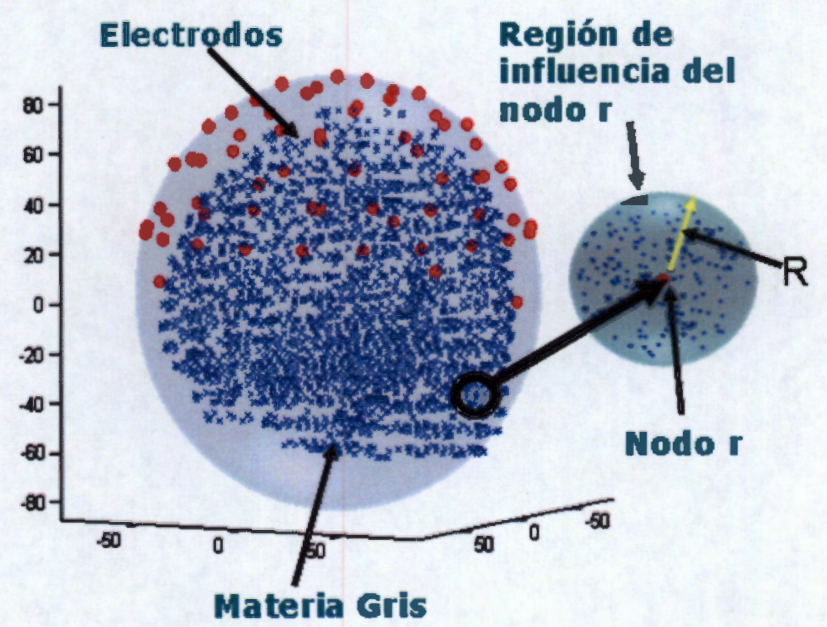

Figura 5.5: Volumen esférico conductor (usado en la simulación de EEG, problema directo) registrado con el centro del volumen conductor realista de materia gris (usado en la solución del problema inverso). Esfera unitaria (corresponde a un radio de $87 \mathrm{~mm}$ )

Para encontrar los mejores parámetros de la función de peso Gaussiana ( $R$ y ג) en la Ec. 4.10, los errores de localización fueron calculados para diferentes combinaciones de parámetros. Esto fue llevado a cabo para 10 registros simulados de EEG, con posiciones de fuentes indicadas en la Tabla 5.5. El radio de las regiones de influencia (R) normalizados a una esfera unitaria (corresponde a un radio de 87 
$m m$ ) y la atenuación del kernel Gaussiano $(\lambda)$ fueron variados de acuerdo a la Tabla 5.6, para obtener diferentes combinaciones del método sin malla.

Tabla 5.5: Posiciones de fuentes usadas en la simulación de 10 registros de EEG , las unidades son relativas a una esfera de radio unitario (corresponde a un radio de 87 $m m)$.

\begin{tabular}{|c|c|c|c|}
\hline EEG & Posición X & Posición Y & Posición Z \\
\hline \hline & U.N & U.N & $U . N$ \\
\hline \hline 1 & -0.080 & 0.851 & 0.253 \\
\hline 2 & -0.172 & -0.874 & 0.253 \\
\hline 3 & -0.161 & -0.172 & 0.805 \\
\hline 4 & -0.770 & -0.264 & 0.069 \\
\hline 5 & 0.793 & 0.103 & 0.069 \\
\hline 6 & 0.471 & 0.483 & 0.345 \\
\hline 7 & -0.713 & 0.287 & 0.253 \\
\hline 8 & 0.563 & -0.632 & 0.253 \\
\hline 9 & 0.655 & 0.425 & 0.253 \\
\hline 10 & -0.448 & -0.218 & 0.437 \\
\hline
\end{tabular}

Tabla 5.6: Parámetros $\mathrm{R}$ y $\lambda$ de las diferentes combinaciones del método sin malla, usados en las pruebas.

\begin{tabular}{|c|c|c|c|c|c|}
\hline & & Combinación 1 & Combinación 2 & Combinación 3 & Combinación 4 \\
\hline \hline & & MC1 & MC2 & MC3 & MC4 \\
\hline \hline $\mathrm{R}$ & U.N. & 0.305 & 0.305 & 0.3529 & 0.3529 \\
\hline$\lambda$ & $U . N$. & 0.1411 & 0.1176 & 0.1176 & 0.1411 \\
\hline $\mathrm{R} / \lambda$ & & 2.17 & 2.6 & 3.0 & 2.5 \\
\hline
\end{tabular}

La Figura 5.6 muestra el error para las diez señales simuladas, después de aplicar la prueba para las diferentes combinaciones de parámetros para las funciones de peso Gaussianas. Para apreciar la variación de los errores obtenidos para las diferentes localizaciones de fuentes, se muestra la tendencia lineal para cada combinación; se puede apreciar que para la combinación $\mathrm{MC} 1(\mathrm{R} / \lambda=2.17)$ el error permanece constante para todas las posiciones de fuentes probadas. Para todos los casos sLORETA fue aplicado, para encontrar la solución al problema inverso, con un parámetro de 
regularización de Tikhonov (ver Anexo A), $\alpha$ igual a cero.

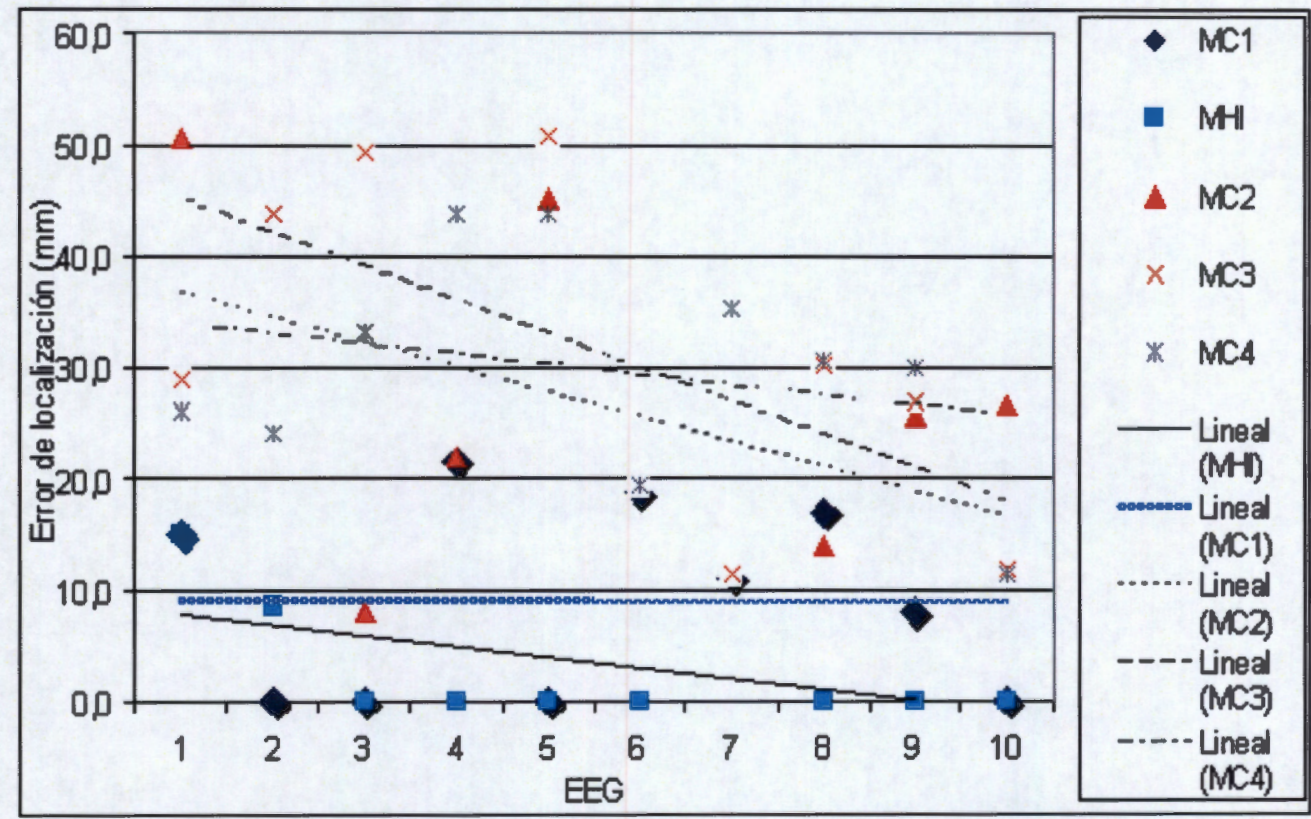

Figura 5.6: Error de localización $(\varepsilon)$ calculado para los 10 registros simulados, aplicando las cuatro diferentes combinaciones de parámetros. Las líneas representan la tendencia lineal del error para cada combinación de parámetros (ver Tabla 5.6) y para medio homogéneo infinito (MHI). Esfera unitaria (corresponde a un radio de $87 \mathrm{~mm})$.

Para probar el comportamiento del método contra la profundidad de la fuente, 15 registros fueron simulados, incrementando gradualmente la distancia entre la fuente y el cuero cabelludo, como se puede ver en la Tabla 5.7. 
Tabla 5.7: Posición de las fuentes usadas para la simulación de 15 registros de EEG, unidades relativas a una esfera de radio unitario (corresponde a un radio de $87 \mathrm{~mm}$ ).

\begin{tabular}{|c|c|c|}
\hline EEG & \multicolumn{2}{|c|}{ Distancia del centro a la fuente } \\
\hline \hline & U.N. & $m m$ \\
\hline \hline 1 & 0,347 & 30,19 \\
\hline 2 & 0,401 & 34,89 \\
\hline 3 & 0,447 & 38,89 \\
\hline 4 & 0,494 & 42,98 \\
\hline 5 & 0,505 & 43,94 \\
\hline 6 & 0,537 & 46,72 \\
\hline 7 & 0,567 & 49,33 \\
\hline 8 & 0,600 & 52,20 \\
\hline 9 & 0,663 & 57,68 \\
\hline 10 & 0,758 & 65,95 \\
\hline 11 & 0,821 & 71,43 \\
\hline 12 & 0,838 & 72,91 \\
\hline 13 & 0,884 & 76,91 \\
\hline 14 & 0,926 & 80,56 \\
\hline 15 & 1,000 & 87,00 \\
\hline
\end{tabular}

En la Figura 5.7 se muestra el error de localización obtenido para estas fuentes, contra la distancia desde el centro de la esfera o el centro del espacio de Talairach para el caso de la materia gris a la posición de la fuente. La tendencia lineal también se incluye, pero sólo como una indicación del comportamiento de la función de error contra la profundidad de la fuente. Es de apreciar un decremento del error, cuando las fuentes están cercanas a la superficie, esto es para la combinación de $R / \lambda=2.17$, mientras que para las otras combinaciones el error presenta un comportamiento diferente. También se muestra que para la combinación $\mathrm{MC1}$, el error permanece por debajo del $30 \%(26.1 \mathrm{~mm})$ para distancias normalizadas arriba o iguales a 0.4 $(34.8 \mathrm{~mm})$. 


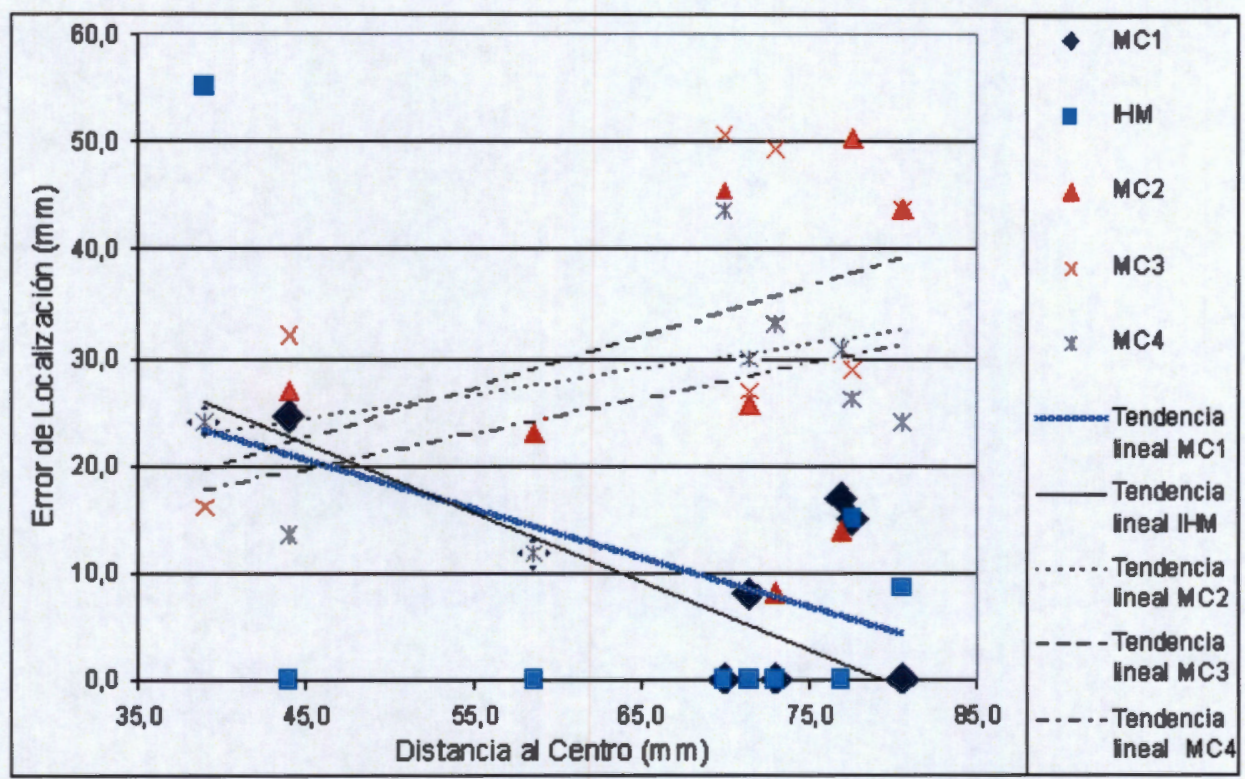

Figura 5.7: Error de localización $(\varepsilon)$ contra profundidad de la fuente para cuatro diferentes combinaciones de parámetros del método sin malla (ver Tabla 5.6) y medio homogéneo infinito (MHI). Esfera unitaria (corresponde a un radio de 87 $m m$ )

Dados los resultados que se muestran en la Figura 5.6 y Figura 5.7, se realizó otra prueba, donde se compara solamente la combinación $\mathrm{MC1}$ contra el comportamiento de localización de fuentes usando medio homogéneo infinito para otros 15 registros simulados de EEG. La Figura 5.8 muestra que el error de localización de la combinación MC1, en todos los casos, no es mayor del $30 \%$. 


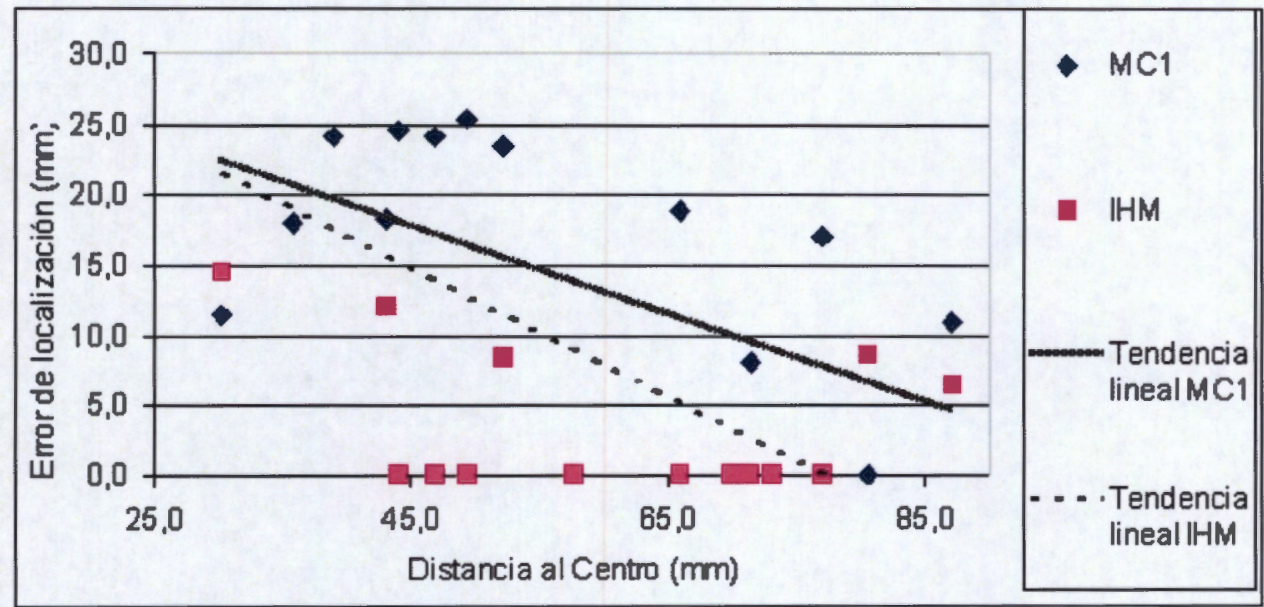

Figura 5.8: Error de localización contra profundidad de fuente: comparación de la combinación $\mathrm{MC1}$ y la solución con medio homogéneo infinito (MHI).

Para la solución del problema inverso, se probaron diferentes variantes de LORETA, tales.como sLORETA, SLOFO y SSLOFO, descritos en las Secciones 4.3.1, 4.3.2 y 4.3.3 para medio homogéneo infinito y para un modelo realista de volumen conductor construido por el método sin malla con los parámetros óptimos $R / \lambda=2.17$, según las pruebas anteriormente descritas. Podemos apreciar en la Figura 5.9, donde solamente presentamos la comparación de los métodos SLOFO y sLORETA y profundidades entre $0.37(32.19 \mathrm{~mm})$ y $0.12(10.44 \mathrm{~mm})$ con respecto a la superficie de la materia gris, que SLOFO tiene un mejor comportamiento que sLORETA para medio homogéneo infinito, con un error por debajo del $10 \%(8.7 \mathrm{~mm})$ y con una tendencia lineal casi constante. Pero, para un modelo realista sin malla, el mejor comportamiento lo presenta sLORETA con un error máximo cercano a 16\% (13.92 $\mathrm{mm})$ para fuentes más profundas. Por lo tanto, se puede apreciar que el método de solución de problema inverso que mejores resultados otorga para nuestra metodología, es SLORETA. 


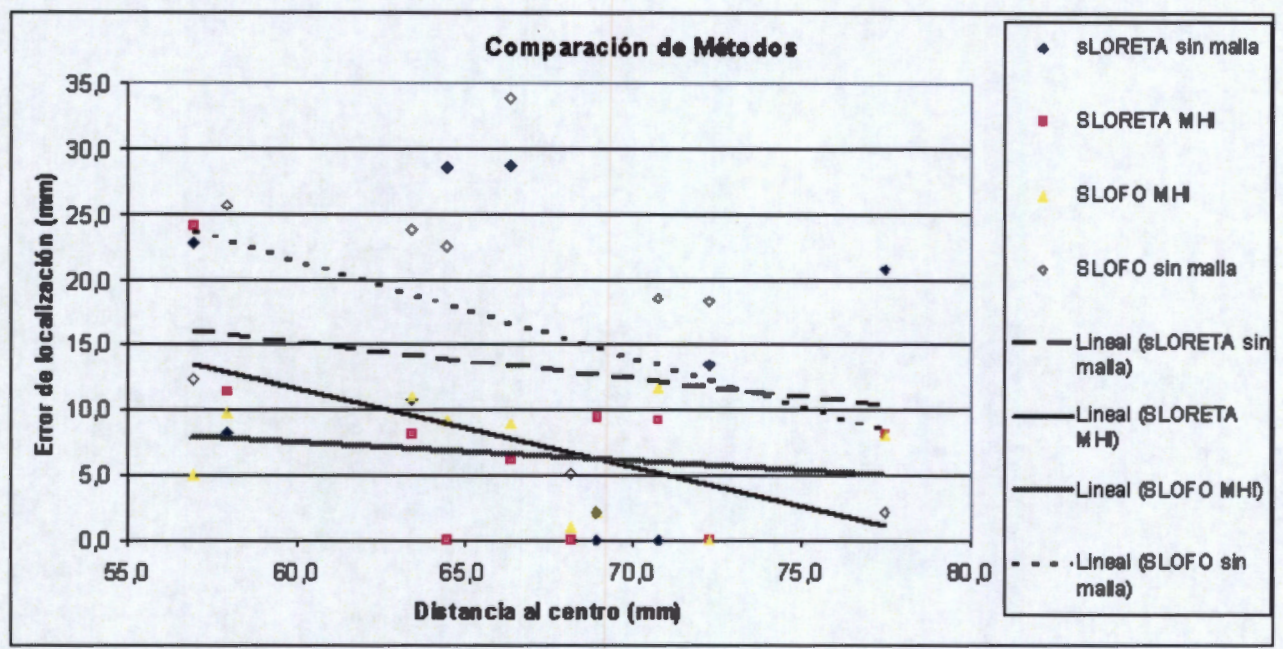

Figura 5.9: Comparación de los métodos de solución de problema inverso (sLORETA y SLOFO) para la combinación de parámetros $\mathrm{MC1}$ y medio homogéneo infinito (MHI), para detección de fuentes en una profundidad para distancias normalizadas al centro entre 0,63 y 0,88 . Esfera unitaria (corresponde a un radio de $87 \mathrm{~mm}$ )

Hemos asumido que el problema directo del EEG sea modelado como un sistema lineal, $\boldsymbol{\Phi}=\boldsymbol{K}_{M L} \boldsymbol{J}$, conscientes que es un sistema lineal mal condicionado, es decir, para pequeños cambios en las densidades de corriente dentro del cerebro $J$ (entrada del sistema), podemos tener grandes cambios en el potencial medido en el cuero cabelludo $\Phi$ (salida del sistema), esto se refleja en la deficiencia en rango de la matriz de campo $\boldsymbol{K}_{M L}$ (ver Apéndice A).

El método sin malla que se ha sido descrito en las Secciones 4.2.1 y 4.2.2 para encontrar la matriz de campo realista que caracteriza a un medio conductor electromagnético (la cabeza, en el caso de EEG) ha sido usado para encontrar la solución de problema inverso. El método propuesto tiene la ventaja de no necesitar la construcción de una malla que interconecte los nodos que forman el volumen conductor; para calcular el potencial en cada nodo, sólo se requiere la cantidad y la posición de cada uno de los nodos vecinos (Ec. 4.7). La precisión de la localización de la fuente no se ve afectada y la complejidad que implica la construcción de una malla en los 
métodos de FEM o BEM no es necesaria, reduciendo así las operaciones computacionales. Una gran ventaja de la metodología propuesta es que se garantiza que el espacio solución sean los voxeles que pertenecen a materia gris, ya que el procedimiento de segmentación usado, incorpora la correlación de las imágenes filtradas por corrimiento de media con un Atlas anatómico probabilístico para la clasificación de las estructuras cerebrales. Se ha reportado y hemos corroborado que los parámetros más relevantes que afectan al desempeño de la utilización del método sin malla son: 1. la región de influencia del nodo, medida por el radio de la esfera centrada en el nodo $(R)$ y 2 . la atenuación de la contribución de los nodos circundantes $(\lambda)$, dentro de la región de influencia. Lo cual, nos hizo probar diferentes combinaciones de estos dos parámetros (Tabla 5.6) para la construcción de la matriz de campo necesaria para la solución del problema inverso; las pruebas para encontrar cuál era la mejor combinación de parámetros, fueron hechas generando 10 registros de EEG simulados sin ruido, con posición de fuentes controlada y aleatoria (Tabla 5.5) y el error fue calculado a través de la Ec. 5.1. La Figura 5.6 muestra la tendencia lineal de estos errores para los 10 registros simulados, donde es posible ver que el mejor desempeño lo tiene la $\mathrm{MC} 1\left(\frac{R}{\lambda}=2,17\right)$, cuyo error promedio es del $10 \%$ (8 $\mathrm{mm})$, en contraste con las otras combinaciones, donde el error llega hasta el $40 \%$ para algunos registros. Estos errores coinciden con lo reportado por [33] en la solución del problema directo utilizando el método sin malla y por [100] utilizando un modelo de volumen conductor construido con BEM y como solución de problema inverso, Norma Mínima para fuentes en profundidad. Está claro que el método sin malla necesita un cantidad considerable de nodos dentro de la región de influencia de un nodo para alcanzar una buena precisión; además es obvio que con una mayor región de influencia, se obtiene mayor exactitud de la aproximación del potencial. En este sentido, fueron realizadas pruebas con señales simuladas de EEG para fuentes de corriente profundas (ver Figura 5.7), y el comportamiento del méto- 
do sin malla para radios grandes es mejor para la localización de fuentes profundas; sin embargo, la precisión se pierde cuando las fuentes están localizadas cerca de la superficie. Esto es verificado cuando se comparan las combinaciones 1 y 3 , donde $R_{M C 3}>R_{M C 1}$. Por otro lado, si se comparan las combinaciones MC1 y $\mathrm{MC2}$, las cuales tienen el mismo radio pero diferentes atenuaciones $\left(\lambda_{M C 2}>\lambda_{M C 1}\right)$, el error de localización incrementa cuando la atenuación es menor, para posición de la fuente cercana a la superficie. La Figura 5.8 muestra la comparación del comportamiento en localización de fuentes profundas para la combinación de parámetros $\mathrm{MC1}$ contra el modelo de medio homogéneo infinito (MHI) y es fácil notar que la tendencia lineal de los dos es bastante similar. La combinación de parámetros $\mathrm{MC1}$ presenta un error de localización menor del $10 \%(8.7 \mathrm{~mm})$, para fuentes cercanas a la superficie, pero para fuentes profundas la tendencia lineal de $\mathrm{MC1}$ va cercana a la tendencia lineal que presenta el caso de MHI. La utilización del modelo de medio homogéneo infinito para construir la matriz de campo tiene un mejor desempeño en la localización de fuentes, comparados a la solución utilizando un modelo de volumen conductor construido con el método sin malla; esto es lo que esperábamos ya que los registros de EEG fueron generados asumiendo un medio conductor homogéneo infinito, así solo el mal condicionamiento del proceso de inversión es el causante de error. Por lo tanto, ésta es nuestra referencia para poder comparar el desempeño del método sin malla y los errores que introduce éste con la aproximación local de los potenciales en los nodos.

Para sustentar estadísticamente nuestra metodología se realizaron 200 simulaciones de EEG, con fuentes localizadas aleatoriamente en los lóbulos temporales y 100 registros simulados de EEG, con fuentes localizadas radialmente en los lóbulos temporales, con una profundidad promedio de $39.97+/-14.019 \mathrm{~mm}$, con respecto a la superficie de la materia gris. Con las mismas condiciones de los experimentos anteriormente realizados, que fueron: Registros de EEG simulados de fuente única 
en una conFigura ción 10-20 de 64 electrodos, modelo de volumen conductor construido a través del modelo sin malla, a partir de IRM, con un tamaño de voxel de $7.0 \times 7.0 \times 8.0 \mathrm{~mm}$, con un total de 2472 voxeles de materia gris, y utilizando el método de solución de problema inverso de sLORETA. A continuación se presentan los resultados obtenidos:

Tabla 5.8: Error promedio de localización en 200 registros de EEG simulados, con fuentes únicas localizadas aleatoriamente en los lóbulos temporales.

\begin{tabular}{|c|c|c|}
\hline & Meshless $\mathrm{R}=26, \lambda=12$ & Medio Homogéneo Infinito \\
\hline \hline Error en $\mathrm{X}(\mathrm{mm})$ & $4.955+/-3.477$ & $3.91+/-3.228$ \\
\hline Error en $\mathrm{Y}(\mathrm{mm})$ & $10.775+/-4.934$ & $10.515+/-4.805$ \\
\hline Error en $\mathrm{Z}(\mathrm{mm})$ & $5.0+/-4.351$ & $4.72+/-4.479$ \\
\hline Error $(\mathrm{mm})$ & $13.959+/-5.102$ & $13.272+/-5.041$ \\
\hline
\end{tabular}

Tabla 5.9: Error de localización en 100 registros de EEG simulados, con fuentes únicas localizadas radialmente en los lóbulos temporales.

\begin{tabular}{|c|c|c|}
\hline & Meshless $\mathrm{R}=26, \lambda=12$ & Medio Homogéneo Infinito \\
\hline \hline Error X $(\mathrm{mm})$ & $4.98+/-4.269$ & $5.12+/-3.978$ \\
\hline Error $\mathrm{Y}(\mathrm{mm})$ & $10.32+/-6.72$ & $10.16+/-5.98$ \\
\hline Error Z $(\mathrm{mm})$ & $5.2+/-4.459$ & $5.52+/-4.759$ \\
\hline Error $(\mathrm{mm})$ & $13.968+/-6.8$ & $14.058+/-6.03$ \\
\hline
\end{tabular}

En la Figura 5.10 se muestra gráficamente la posición de la fuentes radiales utilizadas para realizar la Tabla 5.9.

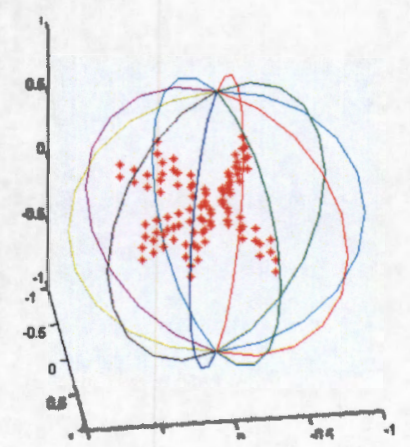

Figura 5.10: Posición 3D de fuentes radiales localizadas en los lóbulos temporales utilizadas en la generación de 100 registros de EEG simulados. 
Para poder comparar el desempeño de nuestra metodología, a continuación se presentan los casos que utilizan métodos de solución de problema inverso para fuentes distribuidas.

1. Pascual-Marqui en [92] trabaja con datos de EGG simulados con una conFigura ción 10-20 de 64 electrodos y utiliza un modelo de volumen conductor realista construido a través de BEM, con imágenes de RM obtenidas de McGill University, con una resolución de voxel de $7 \mathrm{~mm}$. Ellos obtuvieron un error de localización de fuentes únicas de $11.45 \mathrm{~mm}$ utilizando LORETA y lo comparan con el error de localización obtenido por Norma Mínima que fué de $18.61 \mathrm{~mm}$.

2. Liu y colaboradores presentan en [75] el método de Shrinking LORETAFOCUSS, cuyo desempeño con registros de EEG simulados en una conFigura ción 10-20 de 127 electrodos, un modelo de volumen conductor esférico de 3 capas y una resolución de voxel de $7 \mathrm{~mm}$, con un total de 2394 nodos, consiguieron obtener un error de localización de fuente única menor de $7 \mathrm{~mm}$, específicamente un error promedio de $2.44 \mathrm{~mm}$, con un error máximo de 38.34 $m m$.

3. Schimpf y colaboradores presentan en [109] el método de Adaptive Standarized LORETA-FOCUSS y su desempeño ante registros de EEG simulados en una conFigura ción 10-20 de 81 electrodos, utilizando un modelo de volumen conductor realista construido a través de FEM a partir de imágenes de RM, y un tamaño de voxel de $2.0 \times 2.0 \times 3.2 \mathrm{~mm}^{3}$; con lo cual obtuvieron un error promedio de localización de fuente única de $7 \mathrm{~mm}$ para señales con $\mathrm{SNR}=5$ $\mathrm{dB}$ y de $3.0 \mathrm{~mm}$ para señales con $\mathrm{SNR}=10 \mathrm{~dB}$.

4. Liu y colaboradores presenta en [76] el método de SSLOFO y su desempeño de localización de fuentes ante registros de EEG simulados, las pruebas se realizaron para dos casos: el primero para un modelo de volumen conductor 
esférico de tres capas con una resolución de voxel de $7 \mathrm{~mm}, 2394$ nodos y una conFigura ción de 127 electrodos; obteniendo un error de localización de fuentes en conFigura ción de 128 dipolos de $0 \mathrm{~mm}$ y una desviación estándar de $0 \mathrm{~mm}$. El segundo caso es un modelo realista de volumen conductor construido a través de FEM, con información de imágenes de RM, un tamaño de voxel de $4.0 \times 4.0 \times 3.2 \mathrm{~mm}^{3}, 3035$ nodos, y una conFigura ción de 145 electrodos para los registros simulados; obteniendo un error de localización de tres fuentes únicas colocadas a una distancia promedio de $30 \mathrm{~mm}$. Con la localización estimada por SSLOFO, resuelven el problema directo obteniendo la señal resultante en los electrodos, correlacionan dicha señal con la señal original y obtienen un coeficiente de correlación promedio de $\mathbf{0 . 9}$.

Al comparar nuestros resultados presentados en la Tabla 5.8 y la Tabla 5.9, con los cuatro casos anteriormente descritos, podemos hacer notar que nuestra metodología entrega una localización precisa de fuentes, en tanto que el error obtenido está cercano a la distancia entre vértices lejanos de un voxel $(12.73 \mathrm{~mm})$ que concuerda con el caso No. 1 de Pascual-Marqui presentado anteriormente, utilizando BEM para la construcción del modelo de volumen conductor y LORETA como método de solución de problema inverso y con 64 electrodos al igual que nosotros, con la diferencia de utilizar voxeles de menor tamaño. Si comparamos nuestros resultados con el caso No. 2, los resultados obtenidos por nuestra metodología, se tiene que el error promedio de sus pruebas es menor, pero el error máximo obtenido es muy superior al nuestro, a pesar de utilizar una conFigura ción de 127 electrodos, pero utilizan un modelo de volumen conductor esférico, lo que demuestra que la utilización de un modelo realista de volumen conductor, entrega mejores resultados. Para el caso No. 3, que utilizó FEM y SLORETA-FOCUSS, nuestros errores son mayores, pero utiliza tamaño de voxeles mucho menores y una conFigura ción de 81 electrodos. Nos es imposible comparar nuestros resultados con los resultados obtenidos en el caso 
No. 4, ya que estos obtienen un error cero, para un modelo de volumen conductor esférico de tres capas, pero estimando localizaciones de fuentes en conFigura ción de 128 dipolos y no para fuentes únicas.

Los errores que se presentan en los ejes $\mathrm{X}$ y $\mathrm{Z}$, son menores que una arista del voxel utilizado y tienen un menor error de localización comparado con el eje $\mathrm{Y}$; lo cual era de esperarse ya que los electrodos están posicionados en una esfera, y ésta no se ajusta adecuadamente a la curvatura que presenta la zona temporal del cerebro, a diferencia del eje $\mathrm{X}$ y el eje $\mathrm{Z}$.

El mal condicionamiento de la matriz de campo puede medirse en base al cociente del máximo valor singular entre el mínimo valor singular de $\boldsymbol{K}_{M L}$, es decir, se mide la deficiencia en rango de la matriz, entre mayor sea este cociente, mayor será el mal condicionamiento del sistema. En la Figura 5.11, se presentan los valores singulares de una matriz de campo construida con el método sin malla $(R=26, \lambda=12)$ y los valores singulares de la matriz de medio homogéneo infinito $\left(\boldsymbol{K}_{\infty}\right)$; se puede apreciar que, para el primer caso, los valores singulares decaen más lentamente que para el segundo caso y tiene más valores singulares diferentes de cero. Entonces, podemos decir, en base a esto, que la construcción de la matriz de campo por el método sin malla, actúa como un método de regularización del mal condicionamiento del sistema lineal del EEG. 


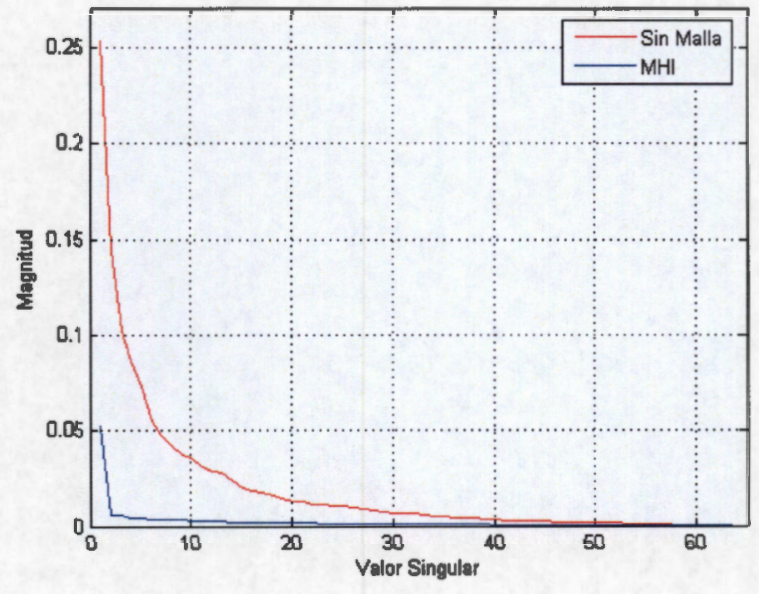

Figura 5.11: Gráfica de valores singulares para las matrices de campo de la combinación de parámetros $\mathrm{MC1}$ (en rojo) y para medio homogéneo infinito (en azul).

\subsection{Visualización de información anatómica y fun- cional fusionada.}

Los algoritmos de solución del problema inverso fueron programados en Matlab y la fusión de la información anatómica y funcional se construyó, por lo tanto, en Matlab, para esto se empleo la interfaz diseñada en nuestro trabajo y que aparece detallada en el Anexo B.

Se puede apreciar en la Figura 5.12 la fusión de la información anatómica correspondiente a materia gris y la información funcional de dos fuentes de actividad eléctrica, una en el lóbulo temporal derecho y la otra en el lóbulo occipital, mostrando las intensidades de las densidades de corriente codificadas en colores, siendo la intensidad máxima la de color rojo y la intensidad mínima la azul. 


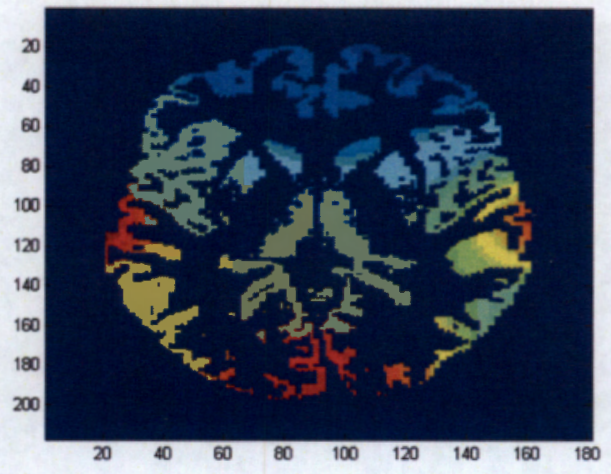

Figura 5.12: Información anatómica y funcional fusionada en Matlab

El sistema desarrollado presenta un nuevo horizonte en el sistema hospitalario, para la planeación de cirugías estereotáxicas de epilepsia de lóbulo temporal, por medio de la visualización 3D de información funcional e información anatómica fusionada. En esta fusión de información no se ha sacrificado la precisión en la localización de fuentes, como se puede apreciar anteriormente, en la comparación de métodos tradicionales de construcción del modelo de volumen conductor realista (FEM y BEM) contra la presición obtenida por nuestra metodología. Con el método sin malla se evita la construcción de un mallaje y las consecuentes complicaciones que esto implica.

El sistema fue pensado para que pueda ser usado con facilidad por los usuarios (Figura B.7), y provee al médico de una visualización adecuada para una correcta planeación de la cirugía, ya que cuenta con toda la información necesaria (Figura B.8). El paradigma de la Cirugía Asistida por Computadora [55,65,112], requiere la integración de la mayor cantidad de información sobre el paciente, por lo tanto, nuestro sistema cumple este requisito. Otra ventaja, del sistema, es que utiliza un método no invasivo (EEG y no electrocorticografía) para la obtención de la información funcional, y es posible utilizarla en cirugías de alto riesgo [60]. 


\section{Capítulo 6}

\section{Conclusiones}

La contribución de este trabajo ha sido establecer una metodología precisa para resolver el problema inverso del EEG, ampliamente estudiado como un problema mal condicionado. Lo que se buscó, con esta metodología, fue mejorar la resolución espacial en la detección de fuentes eléctricas estimadas, que son generadoras de los potenciales registrados en el cuero cabelludo.

En esta metodología, se incorpora la información anatómica (IRM) y funcional (EEG) específica del paciente, los puntos fundamentales que podemos decir que mejoran la resolución espacial, son tres:

1. Un método robusto de segmentación, como es el procedimiento no paramétrico basado en el cálculo del corrimiento de media, que además es clasificado con un atlas probabilístico de materia gris, materia blanca y líquido cefalorraquídeo, y garantiza que el espacio solución sea materia gris. En algunas metodologías se incorpora dicho atlas para mejorar la resolución espacial de la solución del problema inverso del EEG.

2. La construcción de la matriz de campo del volumen conductor realista de cabeza, a partir del método sin malla, lo cual es el aporte fundamental de nuestro trabajo. Se decidió incidir en la construcción de una matriz de campo 
realista que incorpora la información anatómica del paciente para mejorar la localización de fuentes. Una de las ventajas por la que se decidió utilizar el método sin malla, es que los métodos que relacionan los voxeles de la información anatómica a través de una malla, tales como, BEM y FEM, requieren la discretización de las superficies de las estructuras cerebrales a través de elementos de malla contínua no traslapadas, y se sabe que el enmallado es difícil de aplicar a superficies irregulares e introduce artefactos debidos a la malla; este problema se presenta cuando las mallas no están bien construidas, especialmente si hablamos de problemas inversos mal condicionados [125], como el del EEG. Estas dificultades nos dieron la pauta para aplicar el método sin malla en la solución de la ecuación de Laplace aplicado a la cabeza. Aunque el método sin malla utiliza una matriz de campo rala, a diferencia de la matriz completa que entrega la construcción del volumen conductor a partir de una suposición de medio homogéneo infinito, el comportamiento es bastante bueno para localizar fuentes en profundidad, con el beneficio de que nuestra metodología toma en cuenta la información anatómica del paciente. La construcción de la matriz de campo por medio del método sin malla, presenta una alternativa para la construcción de modelos de volumen conductor realista para ser utilizado como el espacio solución del problema inverso del EEG; y podría llegar a tener una mejor precisión en la localización de fuentes eléctricas para sistemas mal condicionados. Además presenta la ventaja de llegar a ser utilizado como un factor de regularización de los sistemas mal condicionados (ver Figura 5.11).

3. La utilización de sLORETA, para resolver el problema inverso del EEG, que garantiza una localización precisa de las fuentes generadoras de potencial en profundidad. Aunque se probaron diferentes variantes de LORETA, tales como sLORETA, SLOFO y SSLOFO unidos a los pasos anteriores (segmentación por 
corrimiento de media y método sin malla) concluimos que sLORETA, presenta el mejor comportamiento para nuestra metodología. (ver Figura 5.9).

Nuestra metodología se convierte en una herramienta útil para realizar una buena planeación de cirugía de epilepsia de lóbulo temporal, ya que, el error promedio es del $10 \%(8.7 \mathrm{~mm})$, que corresponde a un voxel de $7.0 \times 7.0 \times 8.0 \mathrm{~mm}^{3}$, en la detección de fuentes generadoras de potencial, y se considera como muy bueno en la solución de sistemas mal condicionados, que utilizan el modelo de fuentes de corriente distribuidas [94]. Por lo tanto, se garantiza que el modelo propuesto de volumen conductor realista sin malla, se comporta dentro los rangos de error de localización obtenidos hasta el momento por diversos métodos y podría ser utilizado en el ambiente clínico para guiar al médico en la planeación de la cirugía.

Con el objetivo de mejorar la resolución espacial en la solución de este tipo de problema, la metodología propuesta en este trabajo, será una base de partida para añadir más métodos, tales como el Laplaciano de los potenciales en el cuero cabelludo, esperando obtener cada vez menores errores, sin aumentar considerablemente el costo computacional.

El presente trabajo abre el horizonte a nuevas investigaciones orientadas en dos sentidos: la primera, mejorar la presición en la localización de fuentes a través de la solución del problema inverso del EEG, aumentando el número de electrodos utilizados para el registro de la señal electroencefalográfica o disminuyendo la resolución del voxel a $1.0 \times 1.0 \times 1.0 \mathrm{~mm}^{3}$. Segundo, incorporación de información de imágenes de Tomografia Computada para poder realizar un modelo de volumen conductor realista con mayor número de capas y no solamente materia gris.

También los trabajos posteriores a este trabajo, pueden estar orientados en incorporar mayor información en la interfaz gráfica realizada, para orientar de una mejor forma al médico en el momento de elaborar la planeación de la neurocirugía.

El método sin malla, que no necesita la construcción de un mallaje, abre el camino 
a la simulación de las deformaciones inherentes en el momento de una craneotomía, de una forma más sencilla y rápida, que la utilizada por FEM o BEM.

En nuestro trabajo se utilizaron registros de EEG simulados ya que sólo se pretendía demostrar las ventajas del método presentado en la localización de fuentes; pero una perspectiva sería probar nuestra metodología ante registros reales de EEG. 


\section{Apéndice A}

\section{Método de Regularización de}

\section{Tikhonov}

El tratamiento numérico de sistemas de ecuaciones lineales $\boldsymbol{A x}=\boldsymbol{b}$, con un coeficiente matricial mal condicionado, depende del tipo de mal condicionamiento de la matriz de campo $\boldsymbol{A}$. Entonces, tenemos dos clases importante de problemas a considerar [1]:

1. Problemas de deficiencia de rango (rank) que son caracterizados por que la matriz $\boldsymbol{A}$ tiene un grupo de pequeños valores singulares, y se tiene una diferencia bien definida entre el mayor y el menor valor singular de la matriz. Esto implica que una o más filas y columnas de $\boldsymbol{A}$ son una combinación lineal de algunas filas o columnas restantes.

2. Problemas discretos mal condicionados. Aquí, todos los valores singulares de la matriz $\boldsymbol{A}$ gradualmente decaen a cero, además el cociente entre el mayor y el menor valor singular no cero es grande, y no tenemos una noción numérica del rango de la matriz. La mayor dificultad de estos problemas discretos mal condicionados es que son esencialmente indeterminados debido al grupo de 
pequeños valores singulares de la matriz $\boldsymbol{A}$. Es donde nos encontramos con la necesidad de incorporar información adicional sobre la solución deseada en orden de estabilizar el problema y obtener una solución única. Este es el propósito de la regularización.

Una forma de obtener una solución adecuada para problemas lineales mal condicionados o con deficiencia de rango, es por medio de la regularización. La principal idea de la regularización es encontrar un nuevo problema o método que suavice el efecto del ruido en los datos de entrada y encuentre una solución del sistema lineal mal condicionado $\boldsymbol{A x}=\boldsymbol{b}$ más "regular" o suave. Para la solución de problemas mal condicionados los métodos más comunes entregan una solución no aceptable, por lo tanto, los métodos de regularización son necesarios. La discusión del mal condicionamiento de la matriz $\boldsymbol{A}$ requiere del conocimiento de sus valores singulares (SVD, por sus siglas en inglés) y del manejo de éstos a través de métodos de regularización, como por ejemplo, el método de regularización de Tikhonov.

La regularización por Tikhonov es el método más utilizado en problemas mal condicionados lineales. El método de regularización de Tikhonov se encarga de obtener la solución exacta o de mínimos cuadrados de sistemas lineales, minimizando el siguiente jacobiano:

$$
J(x)=\|A x-b\|_{2}^{2}
$$

sujeto a $\|L x\| \leq \beta$, donde $L$ es un operador diferencial.

Se agrega a la Ec. A.1 un término que acote los componentes grandes, por ende, los reduce y de esta forma se estabiliza el cálculo.

$$
J_{\alpha}(x)=\|\boldsymbol{A x}-\boldsymbol{b}\|_{2}^{2}+\alpha\|\boldsymbol{L} \boldsymbol{x}\|_{2}^{2}
$$


donde $\alpha>0$ es llamado el parámetro de regularización de Tikhonov. Si se considera el caso cuando $\boldsymbol{L}=\boldsymbol{I}$, es decir, es el operador identidad, se tiene:

$$
J_{\alpha}(x)=\|\boldsymbol{A x}-\boldsymbol{b}\|_{2}^{2}+\alpha\|\boldsymbol{x}\|_{2}^{2}
$$

La Ec. A.3 puede escribirse como:

$$
\begin{aligned}
J_{\alpha}(\boldsymbol{x}) & =(\boldsymbol{A x}-\boldsymbol{b})^{T}(\boldsymbol{A x}-\boldsymbol{b})+\alpha \boldsymbol{x}^{T} \boldsymbol{x} \\
= & (\boldsymbol{A} \boldsymbol{x})^{T}(\boldsymbol{A} \boldsymbol{x})-2 \boldsymbol{x}^{T} \boldsymbol{A}^{T} \boldsymbol{b}+\alpha \boldsymbol{x}^{T} \boldsymbol{x}+\boldsymbol{b}^{T} \boldsymbol{b}
\end{aligned}
$$

El mínimo se encuentra a través de $\left.\frac{\partial}{\partial x} J_{\alpha}(x)\right|_{x=x_{\alpha}}=0$ :

$$
\left.\frac{\partial}{\partial x} J_{\alpha}(x)\right|_{x=x_{\alpha}}=2 A^{T} A x_{\alpha}-2 A^{T} b+2 \alpha x_{\alpha}=0
$$

Se tiene:

$$
\boldsymbol{x}_{\alpha}=\left(\boldsymbol{A}^{T} \boldsymbol{A}+\alpha \boldsymbol{I}\right)^{-1} \boldsymbol{A}^{T} \boldsymbol{b}
$$

Utilizando la descomposición en valores singulares (SVD) de la matriz $\boldsymbol{A}$ en la Ec. A.6, se tiene:

$$
\boldsymbol{x}_{\alpha}=\sum_{i=1}^{n}\left[\left(\boldsymbol{v}_{i} \sigma_{i}^{T} \boldsymbol{u}_{i}^{T}\right)\left(\boldsymbol{u}_{i} \sigma_{i} \boldsymbol{v}_{i}^{T}\right)+\alpha \boldsymbol{I}\right]^{-1}\left(\boldsymbol{v}_{i} \sigma_{i}^{T} \boldsymbol{u}_{i}^{T}\right) \boldsymbol{b}
$$

donde $n$ es el número de valores singulares de la matriz $\boldsymbol{A}$, entonces:

$$
\boldsymbol{x}_{\alpha}=\sum_{i=1}^{n}\left[\sigma_{i}^{2}+\alpha\right]^{-1}\left(\boldsymbol{v}_{i} \sigma_{i} \boldsymbol{u}_{i}^{T}\right) \boldsymbol{b}
$$


Reordenando la Ec. A.8, se tiene:

$$
\boldsymbol{x}_{\alpha}=\sum_{i=1}^{n} \frac{\sigma_{i}}{\sigma_{i}^{2}+\alpha}\left(\boldsymbol{u}_{i}^{T}\right) \boldsymbol{b} v_{i}
$$

El efecto de la regularización es minimizar la contribución de los términos involucrados en la solución, por los valores singulares pequeños, y de esta forma se logra estabilizar la solución. 


\section{Apéndice B}

\section{Herramienta para Construcción del}

\section{Modelo Anatómico por Interfaz}

\section{Gráfica con usuario.}

Uno de los objetivos de nuestro trabajo es entregar al médico una herramienta para planeación de cirugías de epilepsia de lóbulo temporal; por lo tanto, la etapa de visualización que reúne toda la metodología es de importancia para nuestro trabajo. Para poder presentar al médico los datos de la información anatómica y funcional fusionados, y éste pueda realizar la planeación de cirugía. Se analizaron diversas herramientas de visualización, y se optó por utilizar las librerías de Visualization Toolkit (VTK) [121]; porque ha probado ser una herramienta robusta de visualización de imágenes médicas utilizada en sistemas CAS [42].

\section{B.1. Visualization Toolkit.}

En un primer momento se realizaron pruebas de visualización de volúmenes reconstruidos a partir de imágenes 2D por RM en una serie de $181 \times 217 \times 181$ de la base 
de datos de [17], primero como superficies de las diferentes estructuras anatómicas codificadas en tonos de grises a través de una segmentación por umbralización de las imágenes 2D con resolución de voxel de $1 \mathrm{~mm}^{3}$. (Figura B.1).

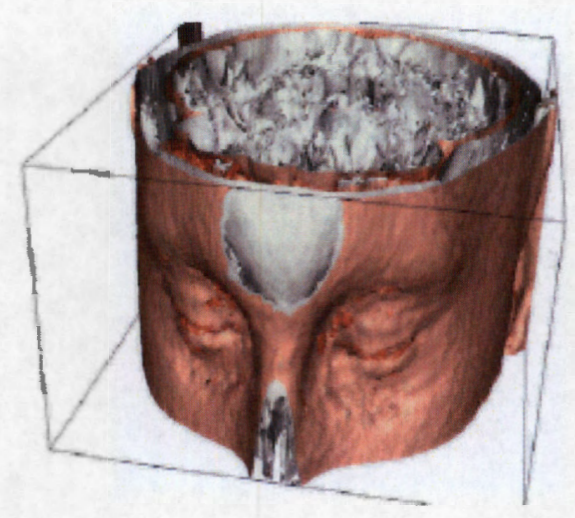

Figura B.1: Reconstrucción 3D de superficie de imágenes por resonancia magnética . Imágenes de 181x217, estudio de 181 imágenes, resolución de voxel de $1 \mathrm{~mm}^{3}$.

Luego se utilizó el procedimiento de segmentación por corrimiento de media ponderado por mapas de confianza presentado por [63] y descrito en la Sección 4.1 para luego reconstruir los volúmenes de cerebro, y así poder visualizar las diferentes estructuras que componen el cerebro, en este caso, materia gris, materia blanca y líquido cefalorraquídeo. Variando la opacidad de las capas exteriores se logra visualizar el interior del cerebro, como se puede ver en la Figura B.2a, donde se trasluce la capa que pertenece a la materia blanca y materia gris, lo cual permite observar los ventrículos. En la Figura B.2b se presenta la reconstrucción 3D de los ventrículos. 
ya están registradas al espacio de Talairach. La interfaz permite la visualización 3D del volumen, donde también es posible seleccionar la capa (tejido o clase) que se desea visualizar, además se puede escoger el color y la opacidad de cada estructura, como se muestra en la Figura B.4.

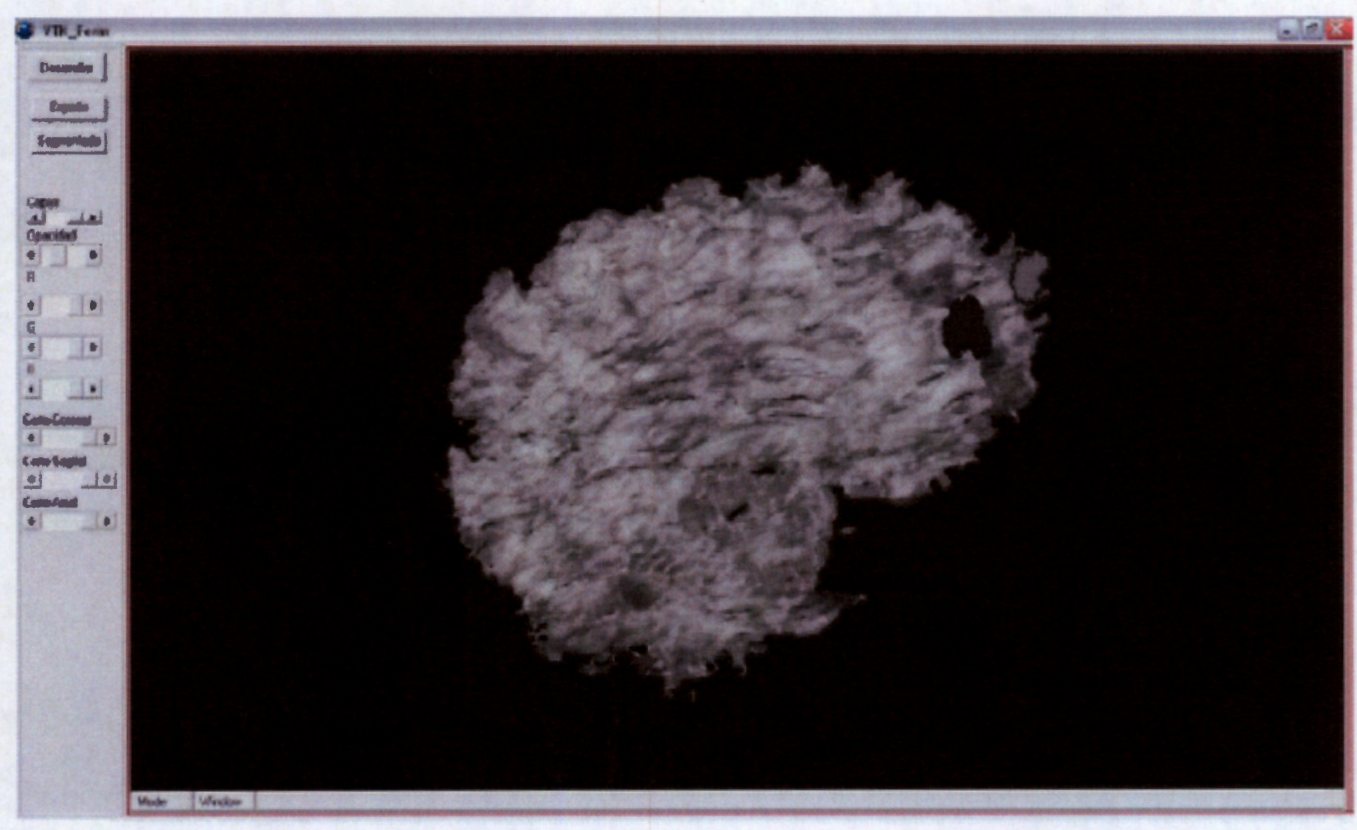

Figura B.4: Interfaz gráfica de usuario programada en Borland $\mathrm{C}++$, se pueden apreciar a la izquierda los controles de capa a reconstruir, opacidad de capa, barras de color (RGB).

También se pueden realizar cortes, axiales, sagitales y coronales, superponiendo imágenes 2D en estos cortes (Figura B.5). Los cortes pueden ser uno, dos o tres como se desee, permitiendo la visualización de una región de interés (ROI) como se puede ver en la Figura B.6. 
Capítulo B. Herramienta para Construcción del Modelo Anatómico por Interfaz Gráfica con usuario.

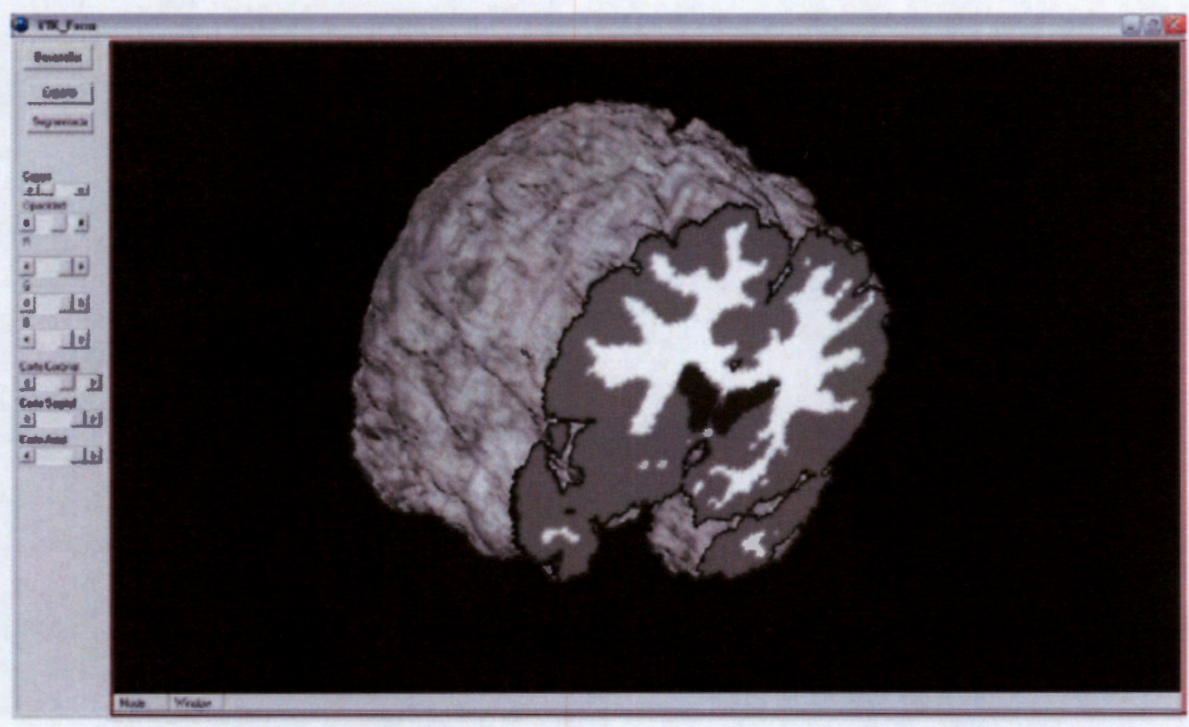

Figura B.5: Reconstrucción 3D con corte sagital superpuesto.

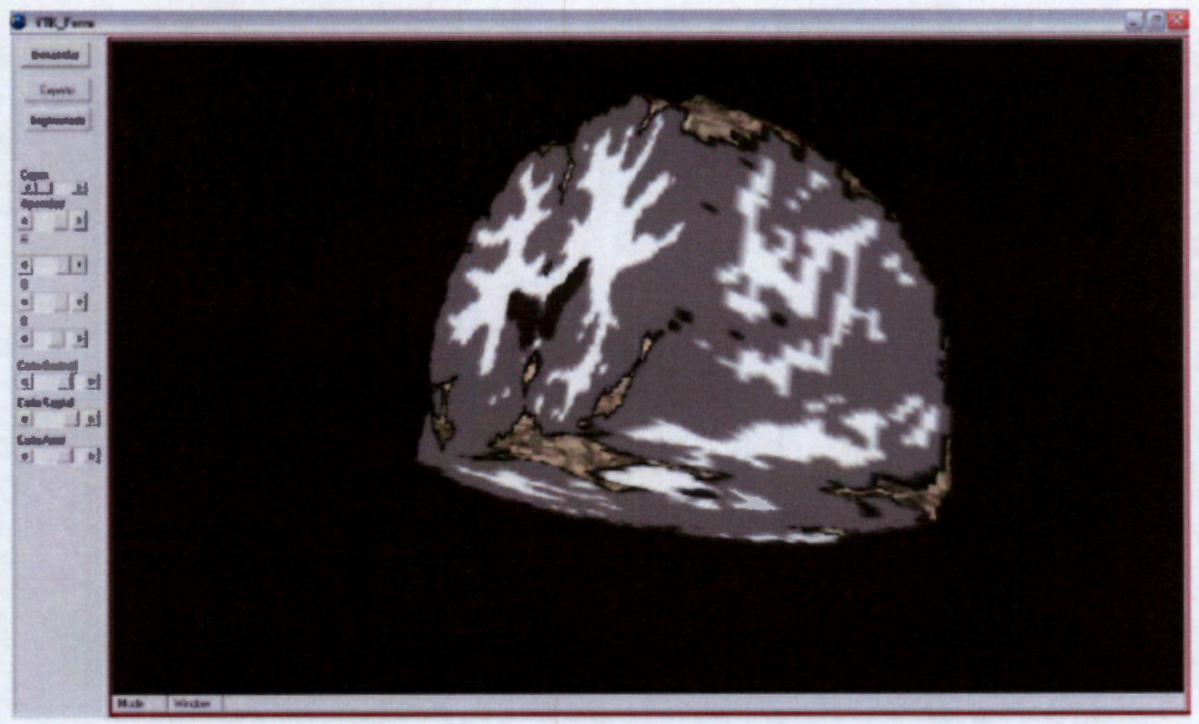

Figura B.6: Reconstrucción 3D con corte sagital, coronal y axial superpuesto. 


\section{B.3. Interfaz con QT 3.0 y VTK.}

Luego, se desarrolló una interfaz gráfica para la visualización de imágenes por resonancia magnética en $2 \mathrm{D}$ y $3 \mathrm{D}$, una vez segmentadas, programada con la herramienta de desarrollo QT 3.0, integrando las librerías de VTK, para incrementar las posibilidades en el menú de opciones para el usuario.

\section{B.3.1. Entrada de datos}

El sistema toma como entrada una serie de imágenes 2D, a través de una ventana de lectura de datos, lo que lo hace más flexible que el realizado en Borland $\mathrm{C}++$, en la Figura B.7 se puede apreciar la primera ventana que aparece al usuario.

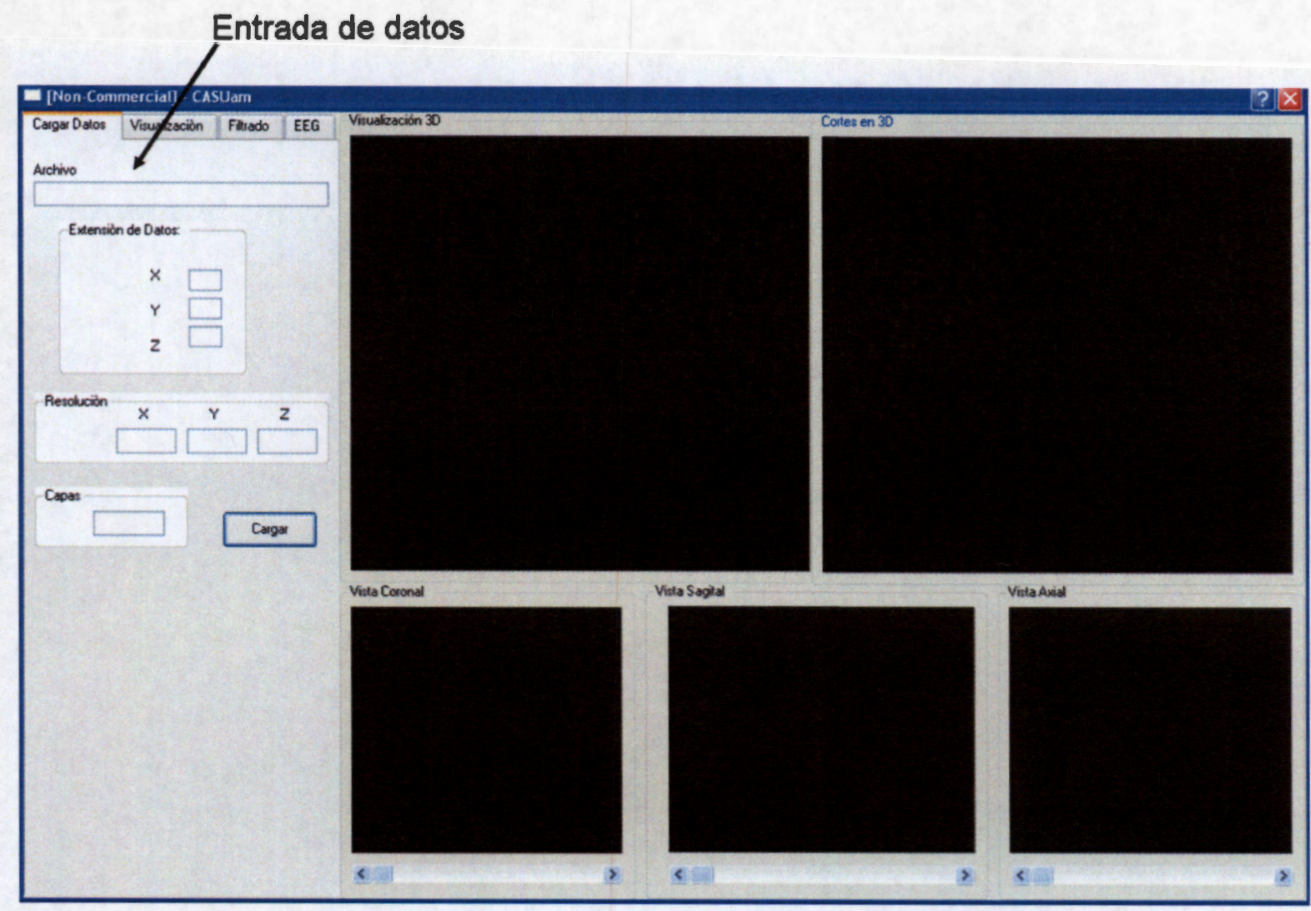

Figura B.7: Ventana de entrada de datos de imágenes 2D, donde solicita el nombre y la localización de la primera imagen de la serie, así como las dimensiones de las imágenes y el número de imágenes de toda la serie, también el número de capa a visualizar, para nuestro caso, 1 pertenece a materia gris, 2 , a materia blanca y 3 , a líquido cefalorraquídeo. 


\section{B.3.2. Visualización de información anatómica.}

Las imágenes han sido previamente registradas al espacio de Talairach, para mantener la correspondencia en cada cálculo con respecto al centro de este espacio. Además la interfaz permite la selección de diferentes cortes axiales, sagitales y coronales de todo el volumen, superponiendo imágenes 2D en la ventana de "visualización 3D". También se presenta los cortes en ventanas separadas ("Vista coronal", "Vista axial" y "Vista sagital") y en una ventana de proyección de planos ortogonales ("Cortes en 3D"). Al igual que en la interfaz creada con Borland C++, se puede seleccionar el color de las diferentes capas que se proyectan en dicha interfaz, asimismo, además se puede navegar en las diferentes vistas, a través de botones deslizantes. VTK provee una interacción con el despliegue de las imágenes y volúmenes, permitiendo un acercamiento y rotación de éstas.

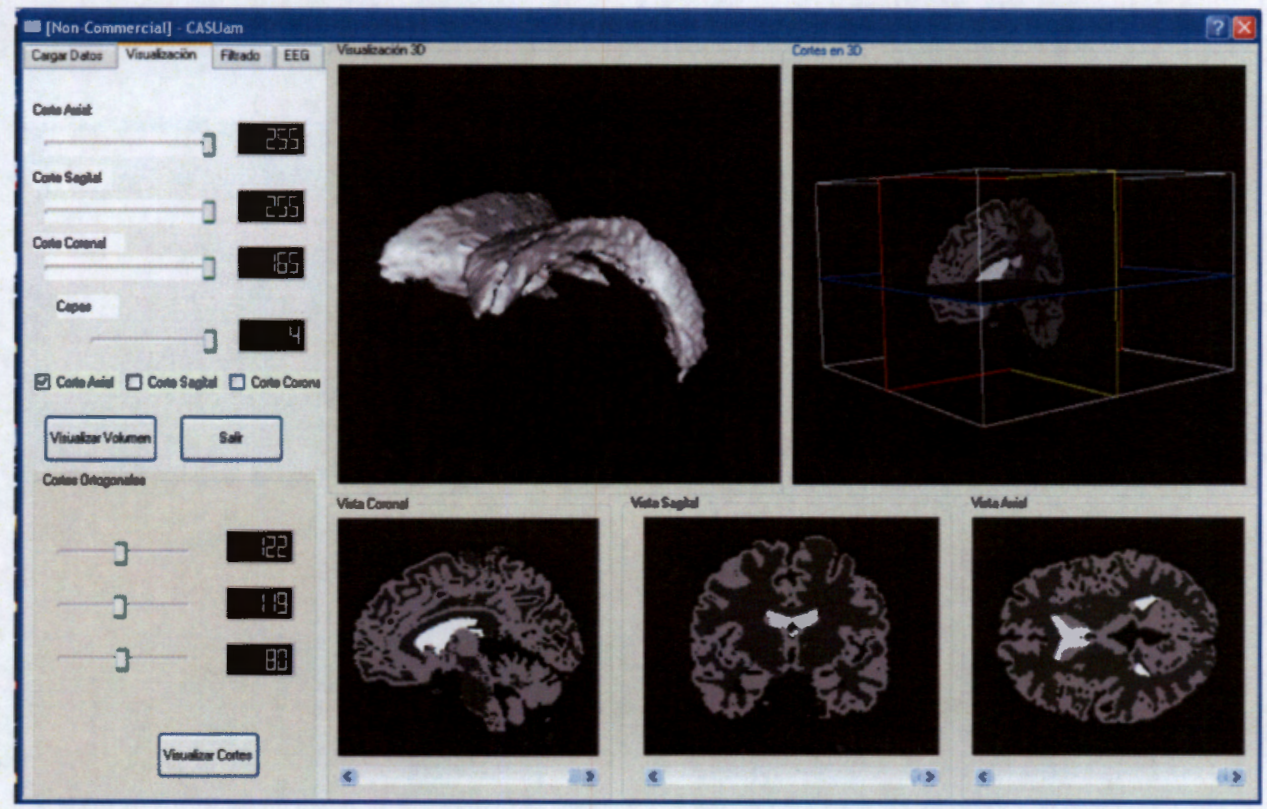

Figura B.8: Interfaz gráfica desarrollada con QT y VTK

La interfaz está prevista para la visualización de la conFigura ción de electrodos que se utilizará para la detección de fuentes de actividad eléctrica, así como 
Capítulo B. Herramienta para Construcción del Modelo Anatómico por Interfaz Gráfica con usuario.

referencias de marcadores fiduciales.

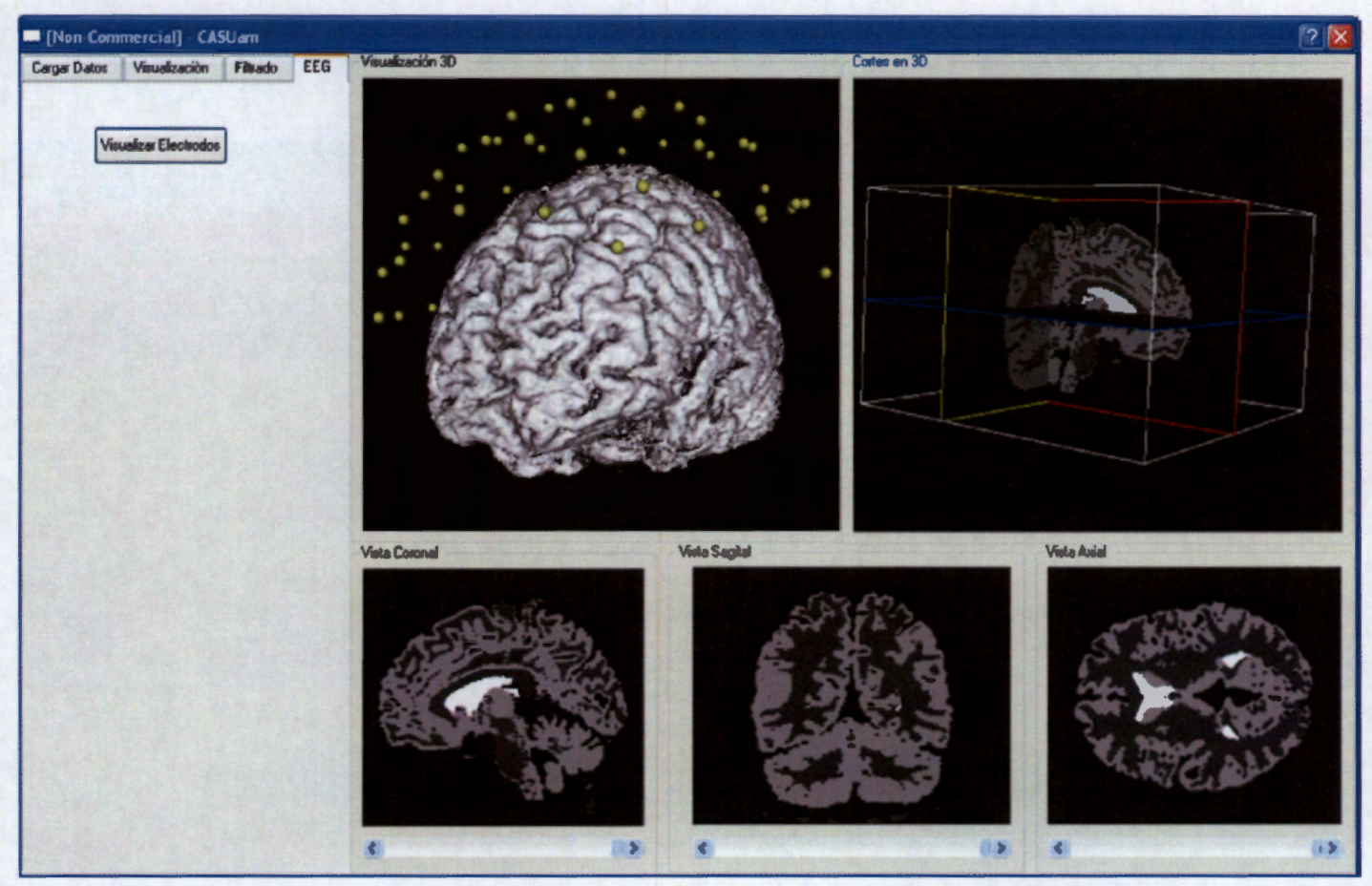

Figura B.9: Visualización de conFigura ción de electrodos, dentro de la interfaz con el usuario.

La interfaz también permite la entrada de datos de imágenes por TC, posibilitando en el futuro la fusión de las diversas modalidades de información anatómica (IRM y TC). 
Capítulo B. Herramienta para Construcción del Modelo Anatómico por Interfaz Gráfica con usuario.

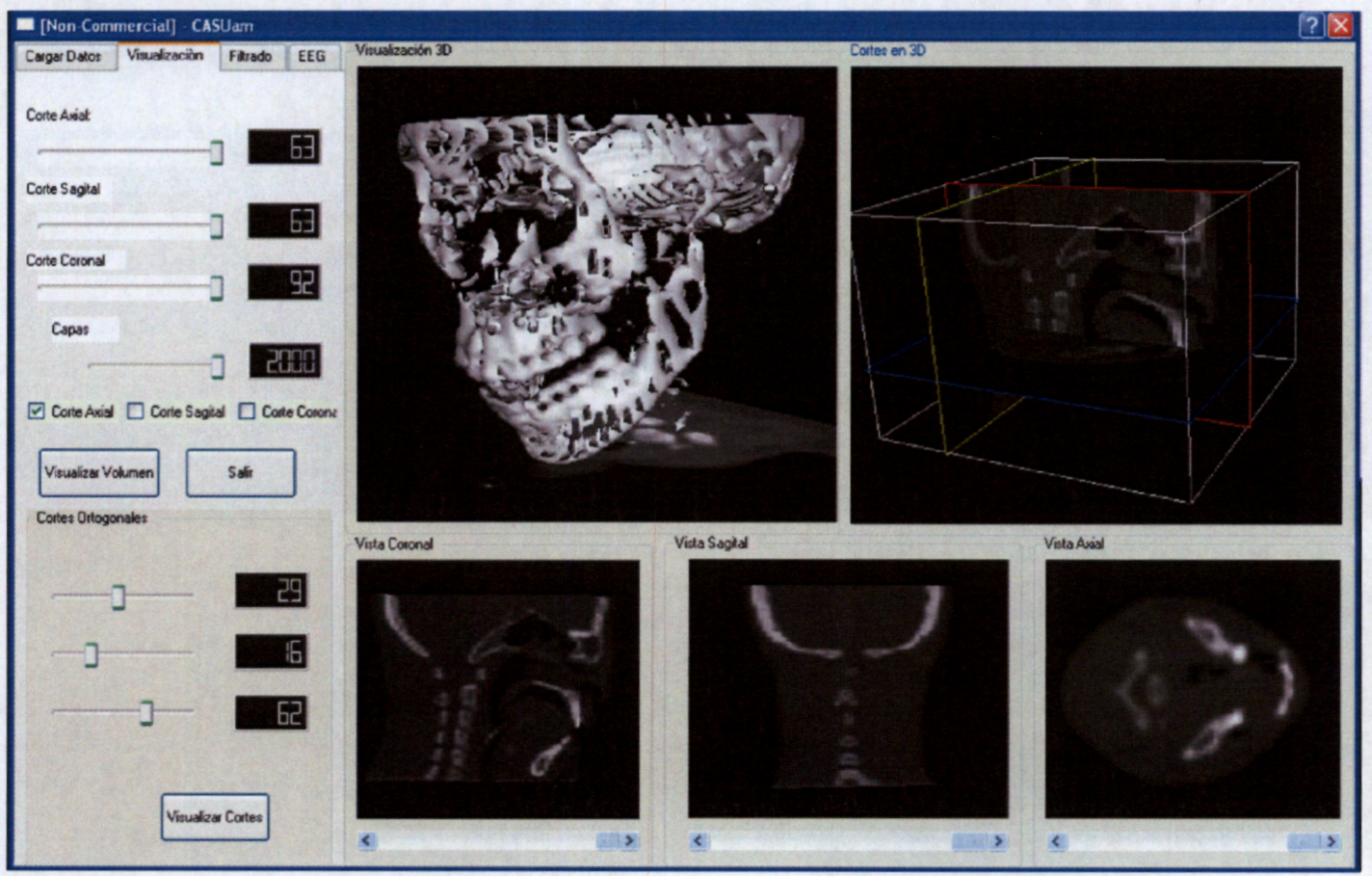

Figura B.10: Visualización de estudio de Tomografía Computada en interfaz gráfica QT-VTK. 
a)

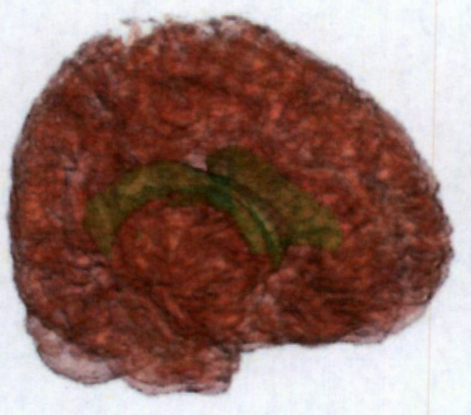

b)

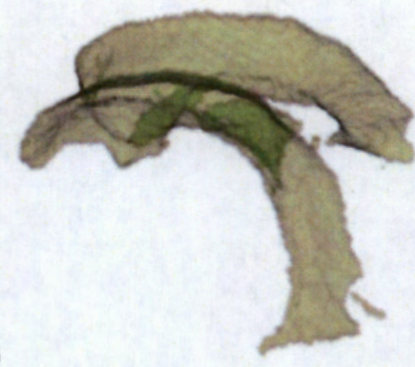

Figura B.2: Reconstrucción 3D de IRM. a) visualización de los ventrículos a través de opacar la superficie de materia blanca y gris. b) ventrículos

Se realizaron pruebas de superposición de imágenes $2 \mathrm{D}$ no segmentadas sobre cortes, axiales, sagitales y coronales en estos volúmenes, para poder otorgar al médico mayor información de la localización 3D de cualquier punto dentro del volumen (Figura B.3).
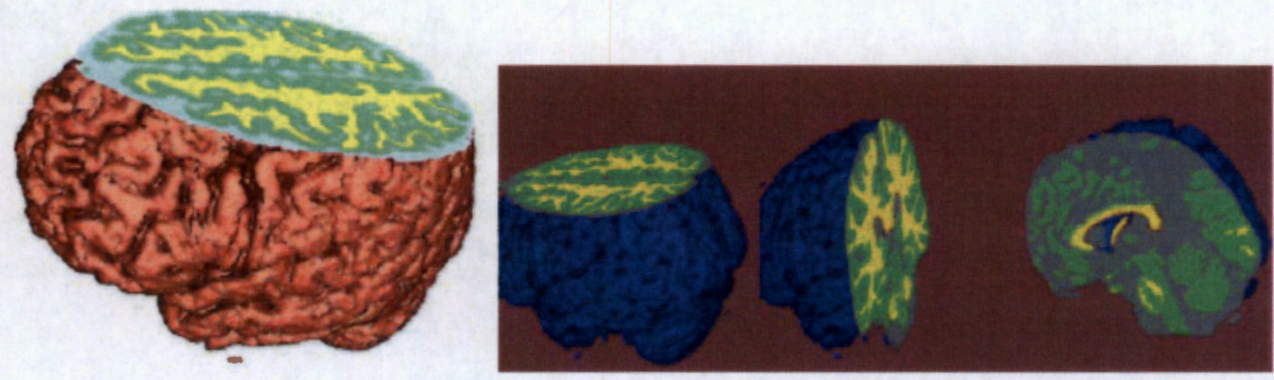

Figura B.3: Imágenes 2D superpuestas al volumen 3D de IRM, cortes axial, coronal y sagital.

\section{B.2. Interfaz con Borland $\mathrm{C}++\mathrm{y}$ VTK.}

Además se desarrolló una interfaz gráfica para la visualización de dichas imágenes por resonancia magnética, la cual fue programada en Borland $\mathrm{C}++6.0$, utilizando las librerías de VTK. A partir de una serie de imágenes 2D, se reconstruye la visualización 3D, tanto en superficie como en volumen. Las imágenes que se han utilizado, 


\section{Apéndice $\mathrm{C}$}

\section{Metodología de Segmentación por}

\section{Corrimiento de Media ponderado por}

Mapas de Confianza y Clasificación por Atlas probabilístico.

La segmentación por espacio característico manual puede producir resultados incorrectos, debido a la delineación manual y la asociación con tipos de tejido hechas por el usuario. También, la clasificación puede variar de experto a experto y aún puede haber diferencias por fatiga, en imágenes clasificadas por el mismo experto. Para evitar este tipo de errores, la segmentación debe ser manejada por la aplicación, es decir, soportada por información con un alto nivel de independencia. Para esto se requiere de una representación bastante confiable de los datos de entrada. Lo anterior se puede lograr por el análisis de imágenes basado en el espacio característico, pero sin la intervención del usuario. 
Capítulo C. Metodología de Segmentación por Corrimiento de Media ponderado por Mapas de Confianza y Clasificación por Atlas

probabilístico.

Un espacio característico es un mapeo de la entrada obtenido por el procesamiento de los datos en subconjuntos pequeños a la vez. Para cada subconjunto se obtiene una representación paramétrica de la característica de interés, y el resultado está mapeado hacia un punto en el espacio multidimensional del parámetro. Después de procesar la entrada, las características significativas corresponden a las regiones más densas en el espacio característico, es decir, a grupos (clusters). El objetivo del análisis de la imagen es la delineación de estos grupos.

En el enfoque de agrupamiento no paramétrico basado en la estimación de densidad, el espacio característico de una imagen se puede considerar como la función de densidad de probabilidad $(f d p)$ empírica de parámetro representado. Las regiones densas en el espacio característico corresponden al máximo local de la $f d p$, esto es, a las modas de una función desconocida. Una vez que se determina la ubicación de una moda, el grupo asociado con ella se delinea basándose en la estructura local del espacio característico.

En muchos problemas de reconocimiento de patrones, se dispone de muy poca información acerca de la $f d p$ verdadera y de su forma. Debido a esta falta de conocimiento se debe confiar en técnicas no paramétricas para obtener las estimaciones del gradiente de la densidad. Fukunaga y Hostetler [44], en su planteamiento para la detección de la moda y agrupamiento basado en el procedimiento de corrimiento de media, derivan un kernel general de estimación del gradiente multivariado usando las estimaciones de kernel de Parzen.

Una vez estimado el gradiente de densidad de probabilidad como el gradiente de la estimación de densidad, basándose en una función de kernel diferenciable, se aplica una función de kernel para entender el proceso involucrado en la estimación del gradiente, llegando a la interpretación intuitiva de que la estimación del gradiente de densidad es esencialmente una medida ponderada del corrimiento de la media de las observaciones alrededor del punto de análisis. La interpretación intuitiva se 
demuestra sustituyendo el kernel de Epanechnikov [35] en la expresión de la estimación del gradiente de densidad, derivando la expresión de lo que se llama el corrimiento de media muestral [44,62], que, como se definirá más adelante, será: $M_{h}(X)=\frac{1}{k} \sum_{X_{i} \in S_{h}(X)}\left(X_{i}-X\right)$, de las observaciones en una región o hiperesfera $S_{h}(X)$ alrededor de un punto $X$. El tamaño de la región $S_{h}(X)$ está dado en función del radio de una ventana $h, \mathrm{y} k$ que es el número de observaciones $X_{i}$ que caen dentro de $S_{h}(X)$. Si el gradiente en $X$ o la pendiente es cero, correspondiendo a una densidad uniforme sobre la región $S_{h}(X)$, el promedio del corrimiento de media será cero debido a la simetría de las observaciones cercanas a $X$. Sin embargo, con un gradiente de densidad diferente de cero apuntando en la dirección de mas rápido incremento de la $f d p$ en el promedio, más observaciones deben caer a lo largo de su dirección que en cualquier otra dentro de $S_{h}(X)$. Así, el corrimiento de media promedio debe apuntar en esa dirección y tener una longitud proporcional a la magnitud del gradiente.

\section{C.1. Corrimiento de Media}

El método de segmentación que se utiliza en este proyecto es no paramétrico y está basado en la estimación de una función de densidad de probabilidad.

La estimación de densidad es la construcción de un estimado de la función de densidad de los datos. La estimación paramétrica supone que los datos son extraídos de una familia de distribuciones paramétricas conocida, por ejemplo la distribución normal con media $\mu$ y varianza $\sigma^{2}$. La densidad se puede estimar encontrando estimaciones de $\mu$ y $\sigma^{2}$ de los datos y substituyendo sus estimaciones en la fórmula de la densidad normal. La desventaja de la aproximación paramétrica es que algunas veces puede ser muy rígida. Para evitar dicha rigidez, se hace lo que se conoce como una aproximación no paramétrica, en la cual los mismos datos guiarán a la estimación 


\section{Capítulo C. Metodología de Segmentación por Corrimiento de Media ponderado por Mapas de Confianza y Clasificación por Atlas probabilístico.}

que mejor los ajusta, a diferencia de lo que pudiera ser cuando esta restringida a una familia paramétrica dada.

En el caso de datos univariados, un estimador de densidad muy usado es el histograma, sin embargo para el caso multivariado, este método presenta dificultades. Entre otros métodos para la estimación de densidad de probabilidad se encuentran por ejemplo el estimador ingenuo (naive), que puede ser visto como una sumatoria de "cajas" centradas en las observaciones, por lo que presenta algunos brincos (debidos a que utiliza una función $w$ de pesos fijos) poco convenientes. Otro es el estimador por kernel, que es una generalización del estimador ingenuo, el cual reemplaza la función de pesos $w$ por una función kernel $K$, la cual debe cumplir con ser continua y diferenciable. Este estimador de kernel es la suma de "lóbulos" (protuberancias) colocadas en las observaciones. La forma de los lóbulos depende del estimador $K$ y el parámetro del ancho de ventana está dado por $h$, que también es llamado el parámetro de suavizado o ancho de banda y determina el ancho de cada lóbulo.

En materia de imágenes, se sugiere estimación no paramétrica, debido a que los espacios característicos de una imagen muchas veces están determinados por grupos de datos muy irregulares, cuyo número y formas no están disponibles. En el enfoque de agrupamiento no paramétrico basado en la estimación de densidad, el espacio característico de una imagen se puede considerar como la función de densidad de probabilidad ( $f d p)$ empírica del parámetro representado. En la estimación no paramétrica debe proporcionarse una detección confiable del máximo local de la densidad fundamental, i.e., las modas, porque son los centros de las regiones 0 "clusters", debido a que las regiones densas en el espacio característico corresponden al máximo local de la $f d p$, esto es, a las modas de la función desconocida. Una vez que se determina la ubicación de una moda, el grupo asociado con ella se delinea basándose en la estructura local del espacio característico. Para cierta dispersión en los datos (que es el caso de las IRM), la estimación por kernel es bastante adecua- 


\section{Capítulo C. Metodología de Segmentación por Corrimiento de Media} ponderado por Mapas de Confianza y Clasificación por Atlas

probabilistico.

da, es sencilla y para kernels que obedecen condiciones suaves, el promedio de las estimaciones se aproxima a la función desconocida.

El estimador de densidad de kernel multivariado, $\hat{f}(x)$ con kernel $K$ y ancho de ventana $h$ se define por [63]

$$
\hat{f}(\boldsymbol{x})=\frac{1}{n h^{d}} \sum_{i=1}^{n} K\left\{\frac{1}{h}\left(\boldsymbol{x}-\boldsymbol{X}_{i}\right)\right\}
$$

donde la función kernel $K(\boldsymbol{x})$ es una función definida para $\boldsymbol{x} d$-dimensional.

El kernel optimo, es decir, el que minimiza el Error Cuadrático Integrado Medio (ECIM) es el Epanechnikov, que para el caso multivariado está dado por:

$$
K_{e}(x)=\left\{\begin{array}{cc}
\frac{1}{2} c_{d}^{-1}(d+2)\left(1-x^{\mathrm{T}} x\right) & \text { si } \boldsymbol{x}^{\mathrm{T}} \boldsymbol{x}<1 \\
0 & \text { de otra manera }
\end{array}\right.
$$

donde $c_{d}$ es el volumen de la esfera unitaria en el espacio euclidiano $\boldsymbol{R}^{d} d$-dimensional. El uso de un kernel diferenciable permite definir la estimación del gradiente de densidad como el gradiente del estimador de densidad de kernel multivariado; así de la expresión:

$$
\hat{\nabla} f(x) \equiv \nabla \hat{f}(\boldsymbol{x})=\frac{1}{n h^{d}} \sum^{n} \nabla K\left\{\frac{1}{h}\left(\boldsymbol{x}-\boldsymbol{X}_{i}\right)\right\}
$$

Sustituyendo C.2 en C.3 y denotando con subíndice $E$ para enfatizar que se utiliza el kernel de Epanechnikov:

$$
\hat{\nabla} f_{E}(\boldsymbol{x})=\frac{1}{n\left(h^{d} c_{d}\right)} \frac{d+2}{h^{2}} \sum_{\boldsymbol{X}_{i} \in S_{h}(\boldsymbol{x})}\left[\boldsymbol{X}_{i}-\boldsymbol{x}\right]=\frac{n_{x}}{n\left(h^{d} c_{d}\right)} \frac{d+2}{h^{2}}\left(\frac{1}{n_{x}} \sum_{\boldsymbol{X}_{i} \in S_{h}(\boldsymbol{x})}\left[\boldsymbol{X}_{i}-\boldsymbol{x}\right]\right)
$$

donde la región $S_{h}(X)$ es una hiperesfera de radio $h$ teniendo el volumen $h^{d} c_{d}$, 
Capítulo C. Metodología de Segmentación por Corrimiento de Media ponderado por Mapas de Confianza y Clasificación por Atlas probabilistico.

centrada en $x, y$ conteniendo $n_{x}$ puntos de datos. El último término de C.4:

$$
M_{h}(\boldsymbol{x}) \equiv \frac{1}{n_{x}} \sum_{\boldsymbol{X}_{i} \in S_{h}(\boldsymbol{x})}\left[\boldsymbol{X}_{i}-\boldsymbol{x}\right]=\frac{1}{n_{x}} \sum_{\boldsymbol{X}_{i} \in S_{h}(\boldsymbol{x})} \boldsymbol{X}_{i}-\boldsymbol{x}
$$

es lo que se conoce como corrimiento de media muestral.

La cantidad $\frac{n_{x}}{n\left(h^{d} c_{d}\right)}$ es la estimación $\hat{f}(x)$ de la densidad del kernel calculada en la hiperesfera $S_{h}(X)$ (el kernel uniforme), y así se puede escribir C.4 como:

$$
\hat{\nabla} f_{E}(x)=\hat{f}(x) \frac{d+2}{h^{2}} M_{h}(x)
$$

donde $M_{h}(\boldsymbol{x})$ :

$$
M_{h}(x)=\frac{h^{2}}{d+2} \frac{\hat{\nabla} f(x)}{\hat{f}(x)}
$$

De esta última expresión se puede decir que el procedimiento del corrimiento de media es una técnica de optimización ascendente con el mejor paso, con un tamaño de paso variable que es proporcional a la magnitud del gradiente, que calcula el vector de corrimiento de media (Ec. C.7) para cada uno de los datos, corre o traslada el kernel por esta cantidad, y repite los cálculos hasta que se alcanza una moda. Así, los datos se dividen en grupos basándose solamente en sus trayectorias del corrimiento de media, y cuando dos puntos de datos convergen a la misma posición final, se considera que pertenecen al mismo grupo. El resultado o propósito del agrupamiento por corrimiento de media es usar un máximo local como una caracterización de los datos. La característica es la intensidad de los datos.

La segmentación y filtrado de una imagen conservando los bordes de alta calidad se pueden obtener aplicando el corrimiento de media en el domino combinado espacialrango.

El método está basado en la misma idea de correr iterativamente una ventana de tamaño fijo hacia el promedio de los datos dentro de ella. Los detalles de la imagen 
Capítulo C. Metodología de Segmentación por Corrimiento de Media ponderado por Mapas de Confianza y Clasificación por Atlas

probabilístico.

se conservan debido al carácter no paramétrico del análisis, que no supone a priori alguna estructura particular de los datos. La segmentación basada en agrupamiento (clustering) supone estructuras constantes por tramos; sin embargo, se generan problemas con regiones difíciles de reasignar o recuperar cuando se presentan cambios lentos de intensidad o cuando hay regiones de alta densidad. Estos problemas se resuelven tomando en cuenta la información espacial, i.e., procesando en el dominio espacial-rango. Esto se refiere a utilizar la información espacial $(x, y)$ de los pixeles de la imagen, pero además incluir otra característica, por ejemplo el nivel de gris, el color o la información espectral. En este proyecto se utiliza el nivel de gris en el dominio del rango. Al aplicar el algoritmo de corrimiento de media en el dominio conjunto espacial-rango, cada dato se asocia a un punto de convergencia que representa la moda local de la densidad en el espacio $d$-dimensional. En el proceso se definen el ancho de ventana espacial $\left(h_{e}\right)$, y el ancho de ventana de intensidad $\left(h_{i}\right)$ correspondiendo al rango, tomando en cuenta simultáneamente tanto la información espacial y de rango. La salida del filtro de corrimiento de media para un pixel de la imagen está definida como al información de rango alcanzada por el punto de convergencia. Este proceso logra un filtrado espacial de alta calidad que preserva discontinuidades.

Para realizar la tarea de segmentación, los puntos de convergencia suficientemente cercanos en el dominio conjunto son considerados como los centros de clase, y todos aquellos puntos que fueron llevados por el corrimiento de media al mismo punto, i.e., a una moda de la densidad, se fusionan para obtener las regiones homogéneas de la imagen.

El procedimiento para la segmentación por corrimiento de media en el dominio espacial-rango tiene el mismo diseño del filtrado (es un suavizado con preservación de bordes), es decir, se hace el reemplazo de pixeles tomando información de una ventana dinámica de la imagen que se mueve en la dirección del máximo incremento 
Capítulo C. Metodología de Segmentación por Corrimiento de Media ponderado por Mapas de Confianza y Clasificación por Atlas probabilístico.

del gradiente. Cada dato se asocia a un punto de convergencia que representa la moda local de la densidad en el espacio $d$-dimensional. Por lo tanto, el filtrado por corrimiento de media se adapta mejor a la estructura local de los datos.

El mapa de confianza ayuda a mejorar la estimación por corrimiento de media (CM), ya que se pondera cada pixel dentro de una región por una función de confianza de borde, tal que los pixeles que están situados cerca del borde (confianza cercana a uno) influyan menos en la determinación del nuevo centro del agrupamiento. La ecuación del CM modificada, que incluye la ponderación de la confianza del borde se deriva de la Ecuación C.5 de la siguiente manera:

$$
M_{h}(x)=\frac{1}{\sum\left(1-\varphi_{i}\right)} \sum_{\boldsymbol{X}_{i} \in S_{h}(\boldsymbol{x})}\left(1-\varphi_{i}\right) \boldsymbol{X}_{i}-\boldsymbol{x}
$$

donde $\boldsymbol{\varphi}_{\boldsymbol{i}}$ (de la Ecuación C.8) es la confianza del borde asociado a $\boldsymbol{X}_{\boldsymbol{i}}$.

Este nuevo vector de corrimiento de media (Ecuación C.8) se usará en la etapa de filtrado para obtener regiones homogéneas en intensidad de las imágenes procesadas.

\section{C.2. Fusión de Regiones}

Cuando ya se ha filtrado la imagen es necesario agrupar con criterios de proximidad en los dominios de espacio (en 2D) y rango, esto quiere decir que todos los pixeles que convergieron al mismo punto son fusionados y etiquetados, para obtener regiones homogéneas.

Después, se refina esta selección incorporando una matriz de adyacencia de regiones para luego reducir el número de regiones con el algoritmo de encontrar y unir (uniónfind).

En la Matriz de Adyacencia de Regiones (MAR) se almacena un valor booleano para establecer si hay un borde (arista) entre dos regiones (vértices). Para construirla se toma la imagen filtrada y se etiqueta, considerando cada etiqueta como una región y poniendo un valor de 1 entre regiones adyacentes y 0 de otra forma. De esta manera 
Capítulo C. Metodología de Segmentación por Corrimiento de Media ponderado por Mapas de Confianza y Clasificación por Atlas probabilístico.

se identifica el vecindario de cada región resultante.

La operación de fusión une las regiones que tienen modas asociadas que están localizadas dentro de una distancia de separación de $h_{i} / 2$, y satisface la condición de fuerza de borde débil. La fuerza del borde se calcula promediando los valores de los pixeles del mapa de confianza a la largo de la frontera que separa las regiones adyacentes. De esta manera, se fusionan las regiones adyacentes cuyas modas asociadas, en el dominio del rango, están localizadas dentro de una distancia predefinida unas de otras. La fusión de las regiones se realiza siempre y cuando se cumpla la condición de que la distancia, medida en modas entre dos regiones adyacentes, no sea mayor a 0.5. La distancia entre modas, i.e., la diferencia entre modas se normaliza con respecto al radio del rango $h_{i}$, por lo que la condición de fusión se traduce a que la distancia entre modas no sea mayor de $h_{i} / 2$. Si se cumple la condición anterior y la fuerza del borde entre regiones es menor que un umbral, $\xi$, esto es, tienen un borde débil entre ellas, indicando que realmente no hay una frontera entre las regiones, entonces las regiones se fusionan en una sola. El proceso de fusión es iterativo con la condición de paro de que el número de regiones a la salida del proceso sea igual al número de regiones a la entrada del proceso; es decir, que ya no haya una fusión posible con los criterios utilizados.

Podado Una vez que se ha obtenido el resultado final de la fusión de regiones de la imagen, se aplica un proceso de podado para remover las regiones cuya área (en número de pixeles), sea inferior al umbral, $\mu$, definido por el usuario. El podado se hace recorriendo la MAR para unir, a la región candidata respectiva, las regiones que sean muy pequeñas. La región candidata es la que cumple con ser adyacente a la que se está podando, también que la distancia, medida como diferencia de modas, es de un mínimo, o es la única región adyacente que tiene un área mayor que el umbral. Después se toman las modas calculadas resultantes de cada región final, se asignan etiquetas a las nuevas regiones, y el proceso de podado se repite iterativamente hasta 
Capítulo C. Metodología de Segmentación por Corrimiento de Media ponderado por Mapas de Confianza y Clasificación por Atlas probabilístico.

que el número de regiones no cambie o se alcance un número dado de iteraciones. Al terminar el podado se obtiene la imagen con el número de regiones al que se ha podido llegar con los criterios utilizados, es decir tenemos la imagen segmentada. La metodología para la segmentación por corrimiento de media ponderado con mapas de confianza, planteada para IRM por Jiménez-Alaniz [62,63] se resume en 4 pasos fundamentales que son: el cálculo del mapa de confianza de la imagen, este cálculo es la combinación lineal entre la función de distribución acumulativa empírica de la magnitud del gradiente de la imagen y la medida de confianza, que es el resultado de la correlación de ventanas de la imagen, con plantillas de borde ideal, definidas por la orientación del gradiente. Con la información del mapa de confianza se calcula el corrimiento de media, es decir se hace un filtrado de la imagen preservando bordes. El corrimiento de media estima las modas locales de la función de densidad de probabilidad para definir los centros de clase en el espacio característico, dando como resultado una imagen filtrada con preservación de bordes, conteniendo regiones de intensidad homogénea. Después del filtrado de la imagen, se construye un grafo de adyacencias que se analiza para fusionar las regiones adyacentes que están separadas por un borde de magnitud pequeña, calculada a partir del mapa de confianza, y su diferencia en modas de intensidad es menor de un valor predeterminado. Posteriormente, la imagen fusionada se somete a un proceso de podado, con el propósito de unir las regiones que tienen pocos pixeles, con la región adyacente que tiene un numero suficiente de pixeles y una diferencia mínima en intensidad.

\section{C.3. Clasificación de regiones con información a pri-} ori.

Después de la fusión y el podado obtenemos regiones homogéneas en intensidad, se ha reduciodo tanto como es posible el número de clases que conforman las 
Capítulo C. Metodología de Segmentación por Corrimiento de Media ponderado por Mapas de Confianza y Clasificación por Atlas probabilístico.

diferentes estructuras neuro-anatómicas del cerebro, no obstante, el número de ellas puede ser elevado, si se tiene en cuenta que las estructuras que se desean identicar son: Materia Gris (MG), Materia Blanca (MB) y Líquido Cefalorraquídeo (LCR). Para obtener el número de regiones deseado de la imagen segmentada, se propone el uso de conocimiento a priori, contenido en mapas de probabilidad para cada una de las clases de interés. Antes de utilizar los mapas de probabilidad, los datos de la imagen y la información a priori deben estar en el mismo espacio, esto requiere de una etapa de registro previo entre ellos al espacio de Talairach, para posteriormente aplicar una regla de clasicación y lograr la segmentación de la imagen en el número de clases deseado. 


\section{Bibliografía}

[1] S. Mohammed E. Abueldahab. Regularization of Il-Conditioned Linear Systems. $\mathrm{PhD}$ thesis, African Institute for Mathematical Sciences (AIMS), University of the Western Cape, 2007.

[2] V. E. Agapov. Numerical solution of the forward problem in electroencephalography. $\mathrm{PhD}$ thesis, Department of Mathematical Sciences, University of Alberta - Edmonton, 2001.

[3] Z. Akalm-Acar and N. Gencer. An advanced boundary element method (BEM) implementation for the forward problem of electromagnetic source imaging. Physics in Medicine and Biology, 2004.

[4] N. Archip, O. Clatz, S. Whalen, D. Kacher, A. Fedorov, A. Kot, N. Chrisochoides, F. Jolesz, A. Golby, P. M. Black, and S. K. Warfield. Non-rigid alignment of pre-operative MRI, fMRI, and DT-MRI with intra-operative MRI for enhanced visualization and navigation in image-guided neurosurgery. Neuroimage, 35:609-624, 2007.

[5] A. A. Armoundas, A.B. Feldman, D.A. Sherman, and R.J. Cohen. Applicability of the single equivalent point dipole model to represent a spatially distributed bio-electrical source. Medical and Biological Engineering and Computing, 39:562-570, 2001. 
[6] F. Babiloni, C. Babiloni, F. Carducci, L. Angelone, C. DelGratta, G. L. Romani, P. M. Rossini, and F. Cincotti. Linear inverse estimation of cortical sources by using high resolution EEG and fMRI priors. Internacional Journal of Bioelectromagnetism, 3.

[7] F. Babiloni, C. Babiloni, L. Locche, F. Cincotti, P. M. Rossini, and F. Carducci. High-resolution electro-encephalogram: source estimates of laplaciantransformed somatosensory-evoked potentials using a realistic subject head model constructed from magnetic resonance images. Medical and Biological Engineering and Computing, 38:512-519, 2000.

[8] F. Babiloni, F. Carducci, C. DelGratta, G.M. Roberti, F. Cincotti, O. Bagni, G. L. Romani, P. M. Rossini, and C. Babiloni. Multimodal integration of high resolution EEG, MEG and functional magnetic resonance data. Internacional Journal of Bioelectromagnetism, 1(1):62-74, 1999.

[9] F. Banovac and et al. Liver tumor biopsy in a respiring phantom with the assistance of a novel electromagnetic navigation device. Medical Image Computing and Computer-Assisted Intervention, pages 200-2007, 2002.

[10] P.L. Bazin, D.L. Pham, and et al. Free software tools for atlas-based volumetric neuroimage analysis.

[11] G. Bednarz and et al. Evaluation of the spatial accuracy of magnetic resonance imaging-based stereotactic target localization for gamma knife radiosurgery of functional disorders. Neurosurgery, 5(5):1156, 1999.

[12] T. Belytshko, P. Krysl, and Y. Krongauz. A three-dimensional explicit element-free galerkin method. International Journal Numerical Methods of Fluids, 24:1253-1270, 1997. 
[13] B.P. Benjani, D. Dormont, and et al. Bilateral subthalamic stimulation for parkinson disease by using three-dimensional stereotactic resonance imaging and electrophsiological guidance. Journal of Neurosurgery, 92:615-625, 2000.

[14] J. Bijhold. Three-dimensional verification of patient placement during radiother- apy using portal images. Medical Physiology, 20(2):347-356, 1993.

[15] W. Birkfellner. Calibration of tracking systems in a surgical environ- ment. IEEE Transactions on Medical Imaging, 17(5):737-742, 1998.

[16] M. Blackwell, D. Simon, and et al. Design and evaluation of 3-d pre-operative planning software: application to acetabular implant alignment.

[17] McConnell Brain Imaging Centre. Bic. http://www.bic.mni.mcgill.ca/brainweb/.

[18] M. Chabanas, V. Luboz, and Y. Payan. Patient specific finite element model of the face soft tissues for computer-assisted maxillofacial surgery. Medical Image Analysis, 7(2):131-151, 2003.

[19] A. Chabrerie, F. Ozlen, S. Nakajima, M. Leventon, H. Atsumi, E. Grimson, E. Keeve, S. Helmers, J. Riviello, G. Holmes, F. Duffy, F. Jolesz, R. Kikinis, and P. Black. Three-dimensional reconstruction and surgical navigation in pediatric epilepsy surgery. Lecture Notes in Computer Science, 1496, 1998.

[20] National Research Council Committee to Assess Health Risks from Exposure to Low Levels of Ionizing Radiation. Health Risks From Exposure To Low Levels Of Ionizing Radiation. The National Academies Press, 2005.

[21] N. Cuffin. Eccentric shperes models of the head. IEEE Transactions on Biomedical Engineering, 38(9):871-878, 1991. 
[22] N. Cuffin. EEG localization accuracy improvements using realistically shaped head models. IEEE Transactions on Biomedical Engineering, 43(3):299-303, 1996.

[23] F. Darvas, D. Pantazis, and et al. Mapping human brain function with MEG and EEG: methods and validation. Neuroimage, 23:S289-S299, 2004.

[24] P. Dawson. Patient dose in multislice CT: why is it increasing and does it matter? The British Journal of Radiology, 77:S10-13, 2004.

[25] J. de Munck and M. Peters. A fast method to compute the potential in the multisphere model. IEEE Transactions on Biomedical Engineering, 40(11):1166$1174,1993$.

[26] A. DiGiola, B. Jaramaz, F. Picard, and L. Nolte. Computer and robotic assisted hip and knee surgery. Oxford university press, 2004.

[27] L. Din, Y. Lai, and B. He. Low resolution brain electromagnetic tomography in a realistic geometry head model: a simulation study. Physics in Medicine and Biology, 50:45-56, 2005.

[28] M. Drozd, P. Husar, A. Nowakowski, and G. Henning. Detecting evoked potentials with SVD- and ICA-based statistical models. IEEE Engineering in Medicine and Biology Magazine, 2005.

[29] J. S. Ebersole. Functional neuroimaging with EEG source models to localize epileptogenic foci noninvasively. www.uchospitals.edu.

[30] J. S. Ebersole. Defining epileptogenic foci: past, present, and future. Journal of Clinical Neurophysiology, 14:470-483, Nov. 1997.

[31] J. S. Ebersole. Noninvasive localization of epileptogenic foci by EEG source modeling. Epilepsia, 41:S24-S33, 2000. 
[32] N. Ellenrieder, C. Muravchik, and A. Nehorai. MEG forward problem formulation using equivalent surface current densities. IEEE Transactions on Biomedical Engineering, 52(7):1210-1217, 2005.

[33] N. Ellenrieder, C. Muravchik, and A. Nehorai. A meshless method for solving the EEG forward problem. IEEE Transactions on Biomedical Engineering, 52(2):249-257, 2005.

[34] N. Ellenrieder, C. Muravchik, and A. Nehorai. Effects of geometric head model perturbations on the EEG forward and inverse problems. IEEE Transactions on Biomedical Engineering, 53(3):421-429, 2006.

[35] V. A. Epanechnikov. Nonparametric estimation of a multivariate probability density. Theory of Probability and Its Applications, 14:153-158, (URSS) 1969.

[36] J. J. Ermer, J. C. Mosher, S. Baillet, and R. M. Leahy. Rapidly re-computable EEG forward models for realistic head shapes.

[37] H. Eskola. Utilization of mri information in EEG studies. Internacional Journal of Bioelectromagnetism, 1(1):54-61, 1999.

[38] O. Faugeras, F. Clément, R. Deriche, R. Keriven, T. Papadopoulo, J. Roberts, T. Viéville, F. Devernay, J. Gomes, G. Hermosillo, P. Kornprobst, and D. Lingrand. The inverse EEG and MEG problems: The adjoint state approach. i: The continuous case. Technical report, Institut National de Recherche dn Informatique et en Automatique, 1999.

[39] G. Fichtinger, D. Stoainovici, and R. Taylor. The surgical CAD/CAM paradigm anda $\mathrm{n}$ implementation for robotically-assisted percutaneous local therapy. 
[40] G. López Flores, E. Guerra Figueredo, and et al. Resección microquirúrgica estereotáxica de tumores intracraneales guiada por imagen y asistida por computadora. Revista Cubana de Cirugía, 39(3), 2000.

[41] Center for Morphometric Analysis of Massachusetts General Hospital. IBSR. internet brain segementation repository. http://www.cma.mgh.harvard.edu/ibsr.

[42] M. Freiman. Preoperative planning and intaroperative registration for robotbased keyhole neurosurgery. Master's thesis, The Selim and Rachel Benin School of Computer Science and Engineering The Hebrew University of Jerusalem, 2005.

[43] M. Fuchs, R. Drenckhahn, H. A. Wischmann, and M. Wagner. An improved boundary element method for realistic volume-conductor modeling. IEEE Transactions on Biomedical Engineering, 45(8):980-997, 1998.

[44] K. Fukunaga and L. D. Hostetler. The estimation of the gradient of a density function, with applications in pattern recognition. IEEE Transactions on Information Theory, 21(1):32-40, January 1975.

[45] R. L. Galloway. The process and development of image-guided procedures. Annual Review of Biomedical Engineering, 3:83-108, 2001.

[46] O. Ganslandt, S. Behari, and et al. Neuronavigation: concept, techniques and applications. Neurology India, 50:244-255, 2002.

[47] A. H. Gee, R. W. Prager, G. M. Treece, and L. H. Berman. Engineering a freehand 3d ultrasound system. Pattern Recognition Letters, 24(4-5):757-777, 2003. 
[48] I. M. Germano. The neurostation system for image-guided, frameless stereotaxy. Neurosurgery, 37(2):348-350, 1995.

[49] I. M. Germano, H. Villalobos, and et al. Clinical use of the optical digitizer for intracraneal neuronavigation. Neurosurgery, 45(2):261-270, 1999.

[50] I. F. Gorodnitsky, J. S. George, and B. D. Rao. Neuromagnetic source imaging with FOCUSS: A recursive weighted minimum norm algorithm. Electroencephalography and Clinical Neurophysiology, 95:231-251, 1995.

[51] I. F. Gorodnitsky and B. D. Rao. Sparse signal reconstruction from limited data using FOCUSS: a re-weighted minimum norm algorithm. IEEE Transactions on Signal Process, 45(3):600-616, 1997.

[52] M. Grass, R. Koppe, E. Klotz, R. Proksa, M. H. Kuhn, H. Aerts, J. Op de Beek, and R. Kemkers. Three-dimensional reconstruction of high contrast objects using C-arm image intensifier projection data. Computerized Medical Imaging and Graphics, 23(6):311-321, 1999.

[53] W.E.L. Grimson and et al. An automatic registration method for frameless stereotaxy, image guided surgery and enhanced reality visualization. IEEE Transactions on Medical Imaging, 15(2):129-140, 1996.

[54] M. Hämäläinen and J. Sarvas. Realistic conductivity geometry model of the human head for interpretation of neuromagnetic data. IEEE Transactions on Biomedical Engineering, 36(2):165-171, 1989.

[55] E. Hazan and L. Joskowicz. Computer-assisted image-guided intramedullary nailing of femoral shaft fractures. Techniques in Orthopaedics, 18(2):1-9, 2003.

[56] B. He, X. Zhang, J. Lian, H. Sasaki, D. Wu, and V. L. Towle. Boundary element method-based cortical potential imaging of somatosensory evoked po- 
tentials using subjects magnetic resonance images. Neuroimage, 16:564-576, 2002.

[57] M. Heřmana, P. Dvořákb, and M. Houdek. CT-guided stereotaxy: first 10-year experience. Biomedical Papers, 147(2):221-226, 2003.

[58] C. L. Hoad, A. L. Martel, R. Kerslake, and M. Grevitt. A 3D MRI sequence for computer assisted surgery of the lumbar spine. Physics in Medicine and Biology, 46:N213-N220, 2001.

[59] M. Hund, A. Rezai, E. Kronberg, and et al. Magnetoencephalographic mapping: basis of new functional risk profile in the selection of patients with cortical brain lesions. Neurosurgery, 40(5):936-943, 1997.

[60] H. Huppertz, E. Hof, and et al. Localization of interictal delta and epileptiform EEG activity associated with focal epiletogenic brain lesions. Neuroimage, 13:15-28, 2001.

[61] J.R. Jiménez, V. Medina, and O. Yáñez. Nonparametric mri segmentation using mean shift and edge confidence maps. Proceedings of SPIE, 5032:1433$1441,2003$.

[62] J. R. Jiménez-Alaniz. Segmentación No paramétrica de Imágenes Cerebrales de Resonancia Magnética. $\mathrm{PhD}$ thesis, Universidad Autónoma Metropolitana -Iztapalapa, 2006.

[63] J. R. Jiménez-Alaniz, V. Medina-Bañuelos, and O. Yáñez-Suárez. Data-driven brain MRI segmentation supported on edge confidence and a priori tissue information. IEEE Transactions on Medical Imaging, 25(1):74-83, January 2006. 
[64] A. P. Jones. Diagnostic imaging as a measuring device for stereotactic neurosurgery. Physiological Measurement, 14:91-112, 1993.

[65] L. Joskowicz and R. H. Taylor. Computers in imaging and guided surgery. Computers in Science and Engineering, 3(5):65-72, 2001.

[66] M. K. Kalra and et al. Strategies for CT radiation dose optimization. Radiology, 230(3):619-628, 2004.

[67] K. Kansy, P. Wisskirchen, U. Behrens, Th. Berlage, G. Grunst, M. Jahnke, R. Ratering, H. J. Schwarzmaier, and F. Ulrich. LOCALITE - a frameless neuronavigation system for interventional magnetic resonance imaging systems.

[68] R.E. Kelley, J. DellaBadia, and et al. Neuroimaging of the complications of epilepsy surgery. Journal of Neuroimaging, 14:33-41, 2004.

[69] R. Kikinis and et al. Computer assisted interactive three-dimensional planning for neurosurgical procedures. Neurosurgery, 38(4):640-651, 1996.

[70] P.E. Kim and M. Singh. Functional magnetic resonance imaging for brain mapping in neurosurgery. Neurosurgery Focus, 15(1):1-7, 2003.

[71] T. S. Kim, Y. Zhou, S. Kim, and M. Singh. EEG distributed source imaging with a realistic finite-element head model. IEEE Transactions on Nuclear Science, 49(3):745-752, 2002.

[72] W. Kucharczyk and M. Bernstein. Do the benefits of image guidance in neurosurgery justify the costs? from stereotaxy to intraoperative mr. American Journal of Neuroradiology, 18:1855-1859, 1997.

[73] K. K. Kwong, J. W. Belliveay, and et al. Dynamic magnetic resonance imaging of human brain activity during primary sensory stimulation. Proceedings of the 
National Academy of Sciences of the United States of America, 89:5675-5679, 1992.

[74] L. Lemieux, Dale L. Bailey, and David Bell. Correcting for scanner errors in CT, MRI, SPECT, and $3 D$ ultrasound. Medical Image Registration. CRC Press, 2001.

[75] H. Liu, X. Gao, P. H. Schimpf, F. Yang, and S. Gao. A recursive algorithm for the three-dimensional imaging of brain electric activity: Shrinking LORETAFOCUSS. IEEE Transactions on Biomedical Engineering, 51(10):1794-1802, 2004.

[76] H. Liu, P. H. Schimpf, G. Dong, X. Gao, F. Yang, and S. Gao. Standardized shrinking LORETA-FOCUSS (SSLOFO): A new algorithm for spatiotemporal EEG source reconstruction. IEEE Transactions on Biomedical Engineering, 52(10):1681-1691, 2005.

[77] R. J. Maciunas. Computer-assisted Neurosurgery, volume 53, chapter 29, pages 267-271. Lippincott Williams and Wilkins, 2006.

[78] S. Manbir and W. Sungkarat. A novel approach neural activity directly by MRI. Proceedings of SPIE, 5746:109-117, 2005.

[79] C. R. Maurer and M. Fitzpatrick et al. Registration of head volume images using implantable fiducial markers. IEEE Transactions on Medical Imaging, 16(4):447-461, 1997.

[80] M. McGirt, K. Bulsara, and T. Cummings et al. Prognostic value of magnetic resonance imaging-guided stereotactic biopsy in the evaluation of recurrent malignant astrocytoma compared with a lesion due to radiation effect. Journal of Neurosurgery, 98:14-20, 2003. 
[81] P. Meer and B. Georgescu. Edge detection with embedded confidence. IEEE Transactions on Pattern Analysis and Machine Intelligence, 23(12):1351-1365, December 2001.

[82] P. Meer and I. Weiss. Smoothed differentiation filters for images. Journal of Visual Communication and Image Representation, 3:58-72, 1992.

[83] J. E. Moran, S. M. Bowyer, and N. Tepley. Multi-resolution FOCUSS: A source imaging technique applied to MEG data. Brain Topography, 18(1):1-17, 2005.

[84] J. Mosher, R. Leahy, and P. Lewis. EEG and MEG: forward solutions for inverse methods. IEEE Transactions on Biomedical Engineering, 40(3):245$259,1999$.

[85] T. Nara and S. Ando. A projective method for an inverse source problem of the poisson equation. Inverse Problems, 19:355-369, 2003.

[86] L. Neilson, M. Kovalyov, and Z. Koles. A computationally efficient method for accurately solving the EEG forward problem in a finely discretized head model. Clinical Neurophysiology, 116:2302-2314, 2005.

[87] C. Nimsky and O. Ganslandt et al. Intraoperative magnetic resonance imaging combined with neuronavigation: A new concept. Neurosurgery, 48(5):10821091, 2001.

[88] L. Nolte and R. Ganz. Computer assisted orthopaedic surgery (CAOS). Hogrefe and Huber, 1999.

[89] W.L. Nowinski and D. Belov. The cerefy neuroradiology atlas: a talairachtournoux atlas-based tool for analysis of neuroimages available over the internet. Neuroimage, 20:50-57, 2003. 
[90] W.L. Nowinski and A. Thirunavuukarasuu. A locus-driven mechanism for rapid and automated atlas assisted analysis of functional images by using the brain atlas for functional imaging. Neurosurgery Focus, 15(1):1-7, 2003.

[91] Department of Neurosurgery of Singapure General Hospital. Minimally invasive neurosurgery. http: //www.sgh.com.sg/MedicalSpcialtiesnServices/ClinicalSpecialties/Surgical/Neurosurgery/.

[92] R. Pascual-Marqui. Reply to comments made by r. grave de peralta menendez and s.l. gonzalez andino. Internacional Journal of Bioelectromagnetism, 1(2), 1999.

[93] R. Pascual-Marqui. Review of methods for solving the EEG inverse problem. Internacional Journal of Bioelectromagnetism, 1(1):75-86, 1999.

[94] R. Pascual-Marqui. Standardized low resolution brain electromagnetic tomography (sLORETA): technical details. Methods and Findings in Experimental and Clinical Pharmacology, 24:5-12, 2002.

[95] R. Pascual-Marqui, M. Esslen, and et al. Functional imaging with low resolution brain electromagnetic tomography (LORETA): review, new comparisons, and new validation. Japanese Journal of Clinical Neurophysiology, 20:81-94, 2002.

[96] R. Pascual-Marqui, R. Esslen, and et al. Functional imaging with low resolution brain electromagnetic tomography (LORETA): a review. Methods and Findings in Experimental and Clinical Pharmacology, (24):91-95, 2002.

[97] R. Pascual-Marqui, C. Michel, and et al. Low resolution electromagnetic tomography: A new method for localizing electrical activity in the brain. International Journal of Psychophysiology, 18:49-65, 1994. 
[98] T. M. Peters. Image-guided surgery., chapter 3. Number 2. SPIE Press, 2000.

[99] T. M. Peters. Image-guided surgery: From x-rays to virtual reality. Methods in Biomechanics and Biomedical Engineering, 4(1):27-57, 2000.

[100] B. Pinto and Q. Silva. A simple method for calculating the depth of EEG sources using minimum norm estimates (MNE). Medical and Biological Engineering and Computing, 45:643-652, 2007.

[101] Ch. Plummer, A. S. Harvey, and M. Cook. EEG source localization in focal epilepsy: Where are we now? Epilepsia, 49(2):201-218, 2008.

[102] L. Quinghang, L. Zamorano, and et al. The affecting factor on the application accuracy of image surgical localization systems. http://www.neurosurg.wayne.edu/cas/pub/accuracy.html .

[103] L. Rao, R. He, Y. Li, S. Liu, and W. Yan. Computations of electroencephalography and magnetoencephalography for real head model. IEEE Transactions on Magnetics, 36(4):1812-1816, 2000.

[104] S. L. Rauch, H. Kim, and et al. Volume reduction in the caudate nucleus following stereotactic placement of lesions in the anterior cingulote cortex in humans: a morphometric magnetic resonance imaging study. Journal of Neurosurgery, 93:1019-1025, 2000.

[105] M.M. Rehani and M. Berry. Radiation doses in computed tomography. the increasing doses of radiation need to be controlled. British Medical Journal, 320:593-594, 2000.

[106] B. J. Roth, M. Balish, A. Gorbach, and S. Sato. How well does a three-sphere model predict positions of dipoles in a realistically shaped head? Electroencephalography and Clinical Neurophysiology, 87:175-184, Oct. 1993. 
[107] E. Le Rumeur, M. Allard, and et al. Role of the mode of sensory stimulation in presurgical brain mapping in wich functional magnetic resonance imaging is used. Journal of Neurosurgery, 93:427-431, 2000.

[108] G.J. Rutten, N. Ramsey, and et al. Toward functional neuronavigation: implementation of functional magnetic resonance imaging data in a surgical quidance system for intraoperative identification of motor and language cortices. Neurosurgery Focus, 15(1):1-6, 2003.

[109] P. H. Schimpf, H. Liu, C. Ramon, and J. Haueisen. Efficient electromagnetic source imaging with adaptive standardized LORETA/FOCUSS. IEEE Transactions on Biomedical Engineering, 52(5):901-908, Mayo 2005.

[110] P. H. Schimpf, C. Ramon, and J. Haueisen. Dipole models for the EEG and MEG. IEEE Transactions on Biomedical Engineering, 49:409-418, Mayo 2002.

[111] S. Sgouros, S. Seri, and K. Natarajan. The clinical value of electroencephalogram/ magnetic resonance imaging co-registration and three-dimensional reconstruction in the surgical treatment of epileptogenic lesions the clinical value of electroencephalogram/ magnetic resonance imaging co-registration and three-dimensional reconstruction in the surgical treatment of epileptogenic lesions. Child's Nervous System, 17:139-144, 2001.

[112] M. Shoham, I. H. Lieberman, E. C. Benzel, D. Togawa, E. Zehavi, B. Zilberstein, M. Roffman, A. Bruskin, A. Fridlander, L. Joskowicz, S. Brink-Danan, and N. Knoller. Robotic assisted spinal surgery - from concept to clinical practice. Computer Aided Surgery, 12(2):105-115, 2007.

[113] R. K. Smith, K. J. Frank, and R. D. Bucholz. The neurostationTM - a highly accurate, minimally invasive solution to frameless stereotactic neurosurgery. Computerized Medical Imaging and Graphics, 18(4):247-256, 1994. 
[114] R. Srinivasan. Methods to improve the spatial resolution of EEG. Internacional Journal of Bioelectromagnetism, 1(1):102-111, 1999.

[115] T. S. Sumanaweera, J. R. Adler, S. Napel, and G. H. Glover. Characterization of spatial distortion in magnetic resonance imaging and its im- plications for stereotactic surgery. Neurosurgery, 35(4):696-704, 1994.

[116] S. Tissari and J. Rahola. Error analysis of a galerkin method to solve the forward problem in MEG using the boundary element method. Computer Methods and Programs in Biomedicine, 00:1-14, 2003.

[117] A. W. Toga and P. M. Thompson. Maps of the brain. The anatomical record, 256(37-53), 2001.

[118] H. Treuer, S. Hinsche, and et al. The influence of head frame distortions on stereotactic localization and targeting. Physics in Medicine and Biology, 49:3877-3887, 2004.

[119] B. Vanrumste, G. Van Hoey, R. Van de Walle, P. Van Hese, M. D'Havé, P. Boon, and I. Lemahieu. The realistic versus the spherical head model in EEG dipole source analysis in the presence of noise. Proceedings - 23rd Annual International Conference - IEEE/EMBS, 2001.

[120] F. Vinas, L. Zamorano, and et al. Application accuracy study of a semipermanent fiducial system for frameless stereotaxis. Computer Aided Surgery, 2:257-263, 1997.

[121] VTK. Visualization toolkit. http://www.vtk.org/.

[122] M. Wagner, M. Fuchs, and J. Kastner. Evaluation of sLORETA in the presence of noise and multiple sources. Brain Topography, 16(4):277-280, 2004. 
[123] A. Waites, M. Shaw, and et al. How reliable are fMRI-EEG studies of epilepsy? a nonparametric approach to analysis validation and optimization. Neuroimage, 24:192-199, 2005.

[124] D. Wang, W. Strugnell, G. Cowin, D. M. Doddrell, and R. Slaughter. Geometric distortion in clinical MRI systems part i: evaluation using a 3D phantom. Magnetic Resonance Imaging, 22(9):1211-1221, 2004.

[125] Y. Wang and Y. Rudy. Meshless methods in potential inverse electrocardiography. Proceedings - 28th Annual International Conference-IEEE EMBS, New York City, USA, pages 2558-2559, 2006.

[126] A. Westermark, S. Zachow, and B. L. Eppley. Three-dimensional os- teotomy planning in maxillofacial surgery including soft tissue prediction. Journal of Craniofacial Surgery, 16(1):100-104, 2005.

[127] S. Wirth and et al. C-arm based computed tomography - a comparative study. Computer Assisted Radiology and Surgery, pages 408-413, 2001.

[128] G. A. Worrell, T. D. Lagerlund, F. W. Sharbrough, B. H. Brinkmann, N.E. Busacker, K. M. Cicora, and T. J. O'Brien. Localization of the epileptic focus by low-resolution electromagnetic tomography in patients with a lesion demonstrated by MRI. Brain Topography, 12(4):273-282, 2000.

[129] D. Yao and B. He. A self-coherence enhancement algorithm and its application to enhancing three-dimensional source estimation from EEGs. Annals of Biomedical Engineering, 29:1019-1027, 2001.

[130] J. Yao and P. Dewald. Evaluation of different cortical source localization methods using simulated and experimental EEG data. Neuroimage, 25:369$382,2005$. 
[131] L. Zamorano, R. Pérez de la Torre, and Q. Hang. Stereotactic volumetric resection of malignant gliomas. Neurosurgical Operative Atlas, 9, 2000.

[132] L. Zamorano and Z. Jiang. Computer-assisted laser volumetric resection of intracraneal lesions. Proceedings of SPIE, 2132, 1994.

[133] L. Zamorano, L. Nolte, Ch. Jiang, and M. Kadi. Image guided neurosurgery: Frame-based and frameless approaches. Neurosurgical Operative Atlas, 3, 1993.

[134] L. Zamorano, L. Nolte, M. Kadi, and Z. Jiang. Interactive intraoperative localization using an infrared-based system. Neurological Research, 15:290$298,1993$.

[135] L. Zamorano, C. Vinas, Z. Jiang, and F.G. Diaz. Use of surgical wands in neurosurgery. Advances and Technical Standards in Neurosurgery, 24:78-128, 1998.

[136] X. Zhang, W. van Drongelen, and et al. High-resolution EEG: Cortical potencial imaging of interictal spikes. Clinical Neurophysiology, 114:1963-1973, 2003.

[137] Y. Zhang, K. Shao, D. Xie, and J. Lavers. Meshless method bases on orthogonal basis for computational electromagnetics. IEEE Transactions on Magnetics, 41(5):1432-1435, 2005.

[138] Z.Yaniv and K. Cleary. Computer aided interventions and medical robotics image-guided procedures: A review. Technical report, Imaging Science and Information Systems Center, Georgetown University, 2006. 